\title{
The impact of type II diabetes on behavioral and cellular aspects of neuroplasticity
}

\author{
A Thesis submitted to the Department of Psychology and Faculty of Graduate Studies \\ and Research of Carleton University in partial fulfillment of the requirements of the \\ degree of \\ Master of Science \\ Psychology \\ Specialization in Neuroscience
}

CTania Georgescu

Department of Psychology and Institute of Neuroscience

Carleton University (2007) 


$\begin{array}{ll}\begin{array}{l}\text { Library and } \\ \text { Archives Canada }\end{array} & \begin{array}{l}\text { Bibliothèque et } \\ \text { Archives Canada }\end{array} \\ \begin{array}{l}\text { Published Heritage } \\ \text { Branch }\end{array} & \begin{array}{l}\text { Direction du } \\ \text { Patrimoine de l'édition }\end{array} \\ \begin{array}{l}\text { 395 Wellington Street } \\ \text { Ottawa ON K1A ON4 } \\ \text { Canada }\end{array} & \begin{array}{l}\text { 395, rue Wellington } \\ \text { Ottawa ON K1A ON4 } \\ \text { Canada }\end{array}\end{array}$

Your file Votre référence ISBN: 978-0-494-27020-2 Our file Notre référence ISBN: 978-0-494-27020-2

NOTICE:

The author has granted a nonexclusive license allowing Library and Archives Canada to reproduce, publish, archive, preserve, conserve, communicate to the public by telecommunication or on the Internet, loan, distribute and sell theses worldwide, for commercial or noncommercial purposes, in microform, paper, electronic and/or any other formats.

The author retains copyright ownership and moral rights in this thesis. Neither the thesis nor substantial extracts from it may be printed or otherwise reproduced without the author's permission.
AVIS:

L'auteur a accordé une licence non exclusive permettant à la Bibliothèque et Archives Canada de reproduire, publier, archiver, sauvegarder, conserver, transmettre au public par télécommunication ou par l'Internet, prêter, distribuer et vendre des thèses partout dans le monde, à des fins commerciales ou autres, sur support microforme, papier, électronique et/ou autres formats.

L'auteur conserve la propriété du droit d'auteur et des droits moraux qui protège cette thèse. $\mathrm{Ni}$ la thèse ni des extraits substantiels de celle-ci ne doivent être imprimés ou autrement reproduits sans son autorisation.
In compliance with the Canadian

Privacy Act some supporting forms may have been removed from this thesis.

While these forms may be included in the document page count, their removal does not represent any loss of content from the thesis.
Conformément à la loi canadienne sur la protection de la vie privée, quelques formulaires secondaires ont été enlevés de cette thèse.

Bien que ces formulaires aient inclus dans la pagination, il n'y aura aucun contenu manquant. 


\section{Abstract}

Type II (T2D) diabetes is associated with alterations in learning, memory and increased prevalence of dementia, Alzheimer's disease, stroke and stress-related disorders, such as depression. We hypothesized that these associations may be due in part to central changes in neuroplasticity. Central cytokine dysregulations may be one mechanism underlying changes in plasticity, and may be further exacerbated by repeated stressful events. Accordingly, a mouse model of T2D was used to investigate changes in behavior, plasticity as measured by neurogenesis and central cytokine levels induced by stress and/or diabetes. We found that diabetes-prone C57 mice gain significantly more weight when fed a high fat diet as compared to their low-fat counterparts or to diabetes-resistant A/J mice, despite similar food intake. High-fat diet had no effect on memory and anxiety, however it increased depressive-like behavior in both strains. Diet had no effect on neurogenesis, nevertheless, again there were marked differences between the strains with the diabetes prone mice showing higher proliferation. Diet had no effect on cytokine levels in the hippocampus, but it is interesting to note that C57 mice showed decreased hippocampal levels of interleukin-10 (IL-10) when subjected to a chronic mild stressor, while $\mathrm{A} / \mathrm{J}$ mice showed the opposite pattern. Our results do not exclude the possibility that stress and central neuroinflammatory changes act synergistically in the development of cognitive deficits associated with diabetes, however, they do suggest that the initial phase of T2D is not accompanied by marked neuroinflammatory changes. 


\section{Acknowledgements}

During the past two years I have learned a great deal both academically and practically, in terms of new techniques, and I owe it all to the people who have taught, supported and encouraged me along the way. I would first like to thank my supervisors Dr. Shawn Hayley and Dr. John Stead for their invaluable expertise, patience and support. Thanks to John for patiently reading all my first drafts, no matter how littered with mistakes they were and to Shawn for answering my countless questions every day. Thanks to Kerry Rennie for teaching me everything I know about histology and for being a wonderful friend. I am also grateful to Natalie Lukenbill and Marzena Sieczkos for training me at the beginning of my two years of study and to the Anisman lab for sharing with me their knowledge and their behavior testing equipment. Thanks go to the vivarium staff for taking care of my mice and for their excellent recommendations and to Theresa Fortin for her histology suggestions and for always asking if the slides are turning black. A word of gratitude goes to Dr. Hymie Anisman for his invaluable statistical advice and Dr. Alfonso Abizaid for his insight and guidance. I would also like to thank all my friends throughout the department for their constant support and for always lending an ear to my problems. Last, but not least, I would like to thank my family for their continued faith in me, to my mom for her technical advice and to my dad for asking for constant updates on my research. 


\section{Table of contents}

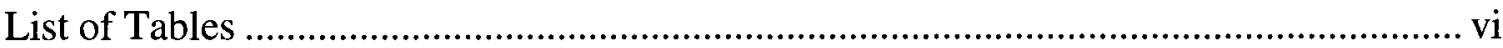

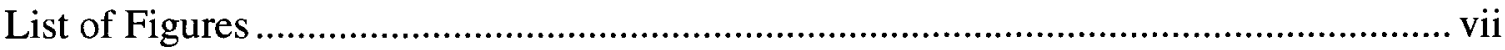

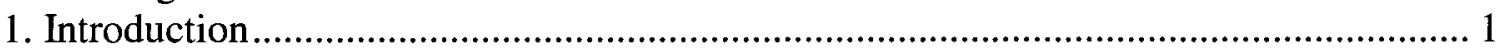

2. Cognitive impairments in diabetes................................................................. 4

2.1 Comorbidity of diabetes with neurodegenerative disorders ................................. 4

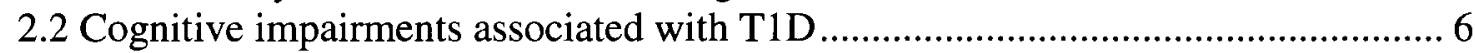

2.3 Cognitive impairments associated with T2D ................................................... 7

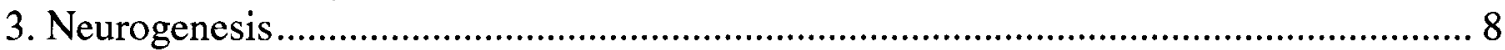

3.1 Importance of neurogenesis for learning and memory .................................. 9

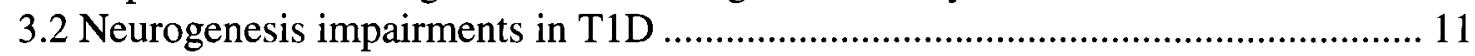

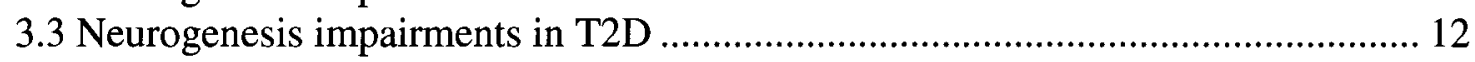

4. Factors affecting neurogenesis in the diabetic brain ........................................ 12

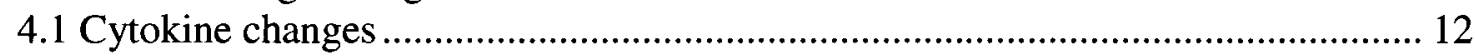

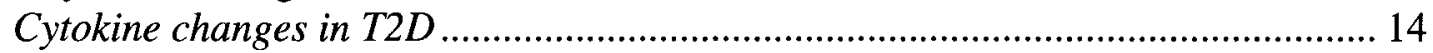

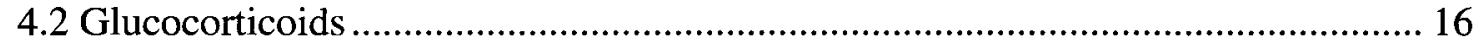

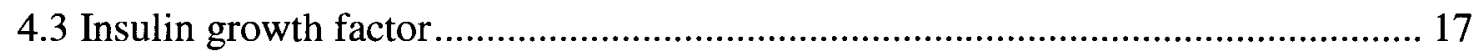

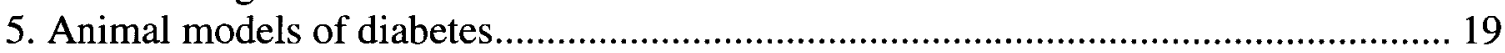

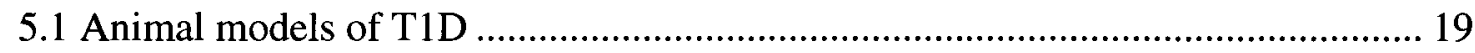

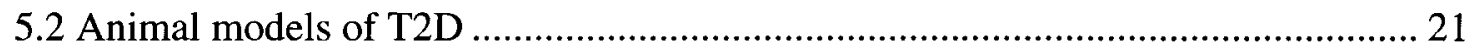

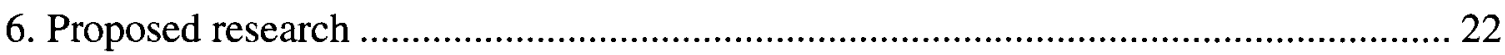

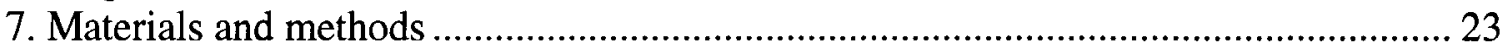

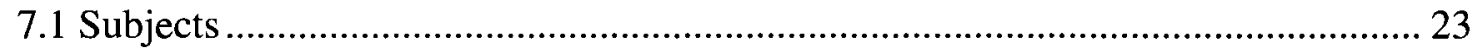

7.2 Experiment 1: Behavioral and physiological assessment of T2D mice................. 23

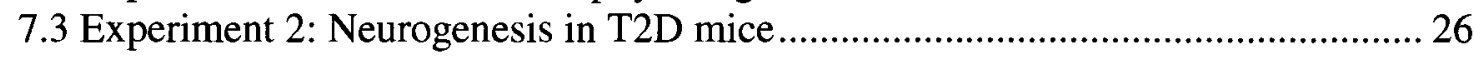

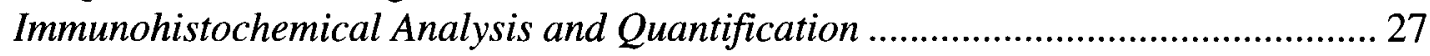

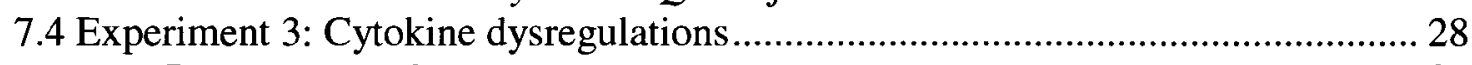

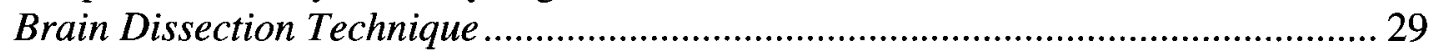

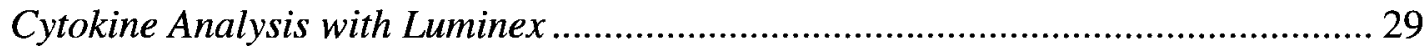

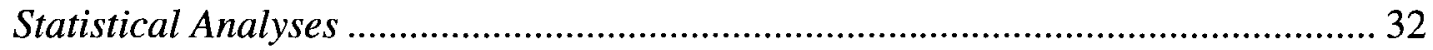

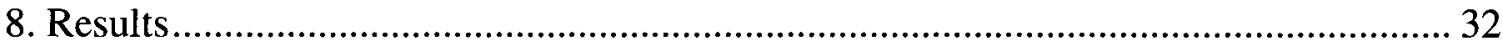

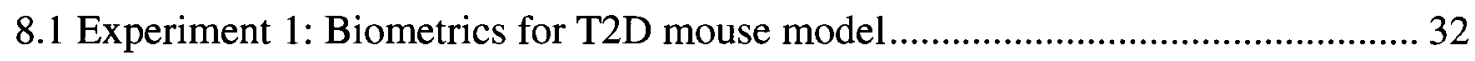

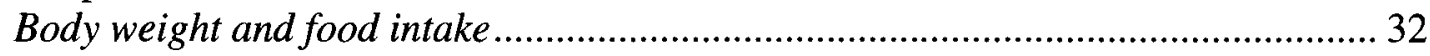

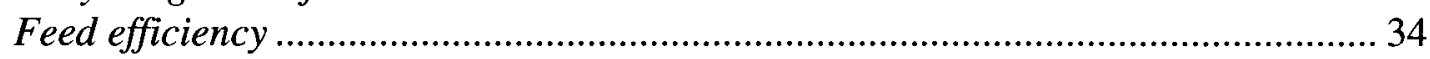

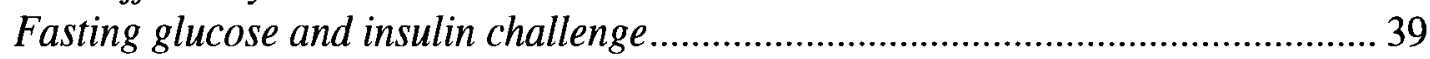

8.2 Experiment 1: Behavioral measurements for T2D mouse model ......................... 43

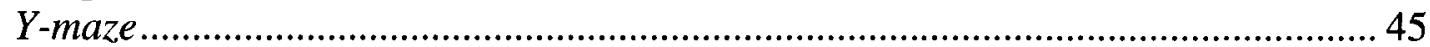

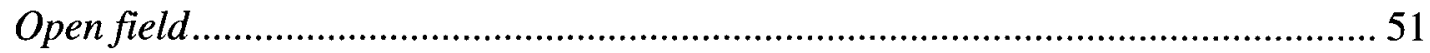

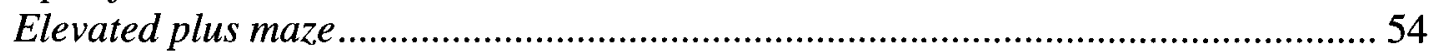

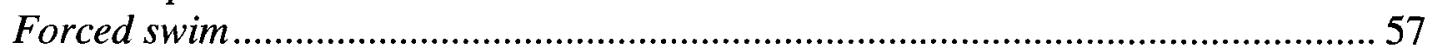

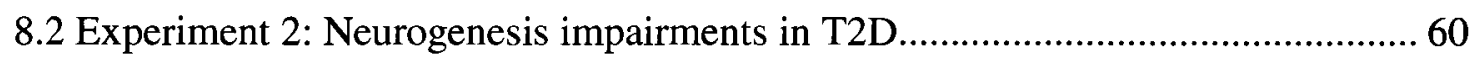

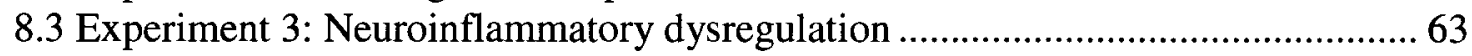

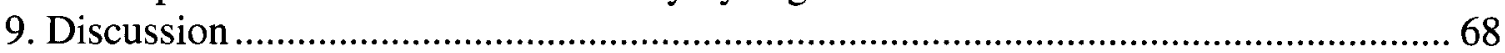

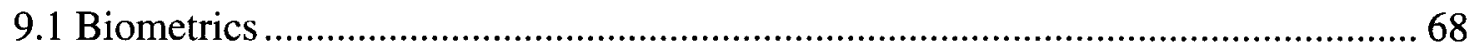

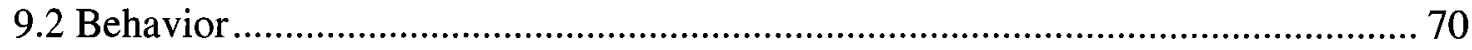




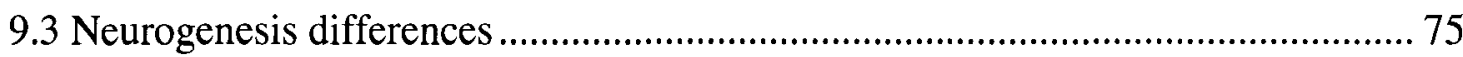

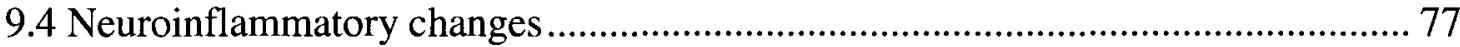

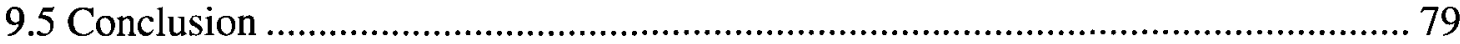

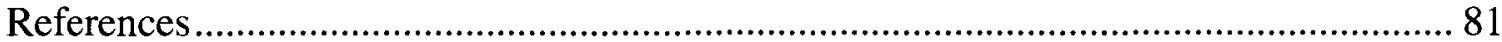




\section{List of Tables}

Table 1. T2D experimental design

Table 2. Mean plasma glucose levels (mmol/L) 0, 30 or 60 minutes following an insulin challenge over 4 months in $\mathrm{C} 57 \mathrm{BL} / 6 \mathrm{~J}$ and $\mathrm{A} / \mathrm{J}$ mice by diet groups.

Table 3. Mean cytokine protein levels $(\mathrm{pg} / \mathrm{mL})$ by strain, stress or diet groups. All data are mean \pm standard deviation. $\mathrm{HH}=$ high-fat/high-sugar, LL=low-fat/low-sugar 


\section{List of Figures}

Figure 1. Changes in body weight. A. Diabetes-prone C57BL/6J mice gain significantly more weight than diabetes resistant mice $\mathrm{A} / \mathrm{J}$ when fed a high-fat/high-sugar diet, as well as low-fat fed groups. $(F(1,20)=15.67, \mathrm{p}<0.01)$. B. C57 mouse after 3 months fed a $\mathrm{HH}$ diet compared with a mouse fed a LL diet. HH=high-fat/high-sugar, LL=low-fat/lowsugar

Figure 2. Weekly food intake. There was no significant difference between subjects in food intake, however, a significant within-subjects week $\mathrm{x}$ strain $\mathrm{x}$ diet interaction $(\mathrm{F}(17,136)=3.12, \mathrm{p}<0.001)$ suggests that high-fat fed $\mathrm{A} / \mathrm{J}$ mice significantly increase their food intake during the first 8 weeks on the diet, after which they reduce their food intake to the same level of the other groups. HH=high-fat/high-sugar, LL=low-fat/lowsugar.

Figure 3. Weekly caloric intake. High-fat fed mice of either strain consumed significantly more kilocalories than low-fat fed mice $(\mathrm{F}(1,16)=12.34, \mathrm{p}<0.01)$. HH=highfat/high-sugar, LL=low-fat/low-sugar

Figure 4. Feed efficiency. High-fat fed C57BL/6J mice show a significant increase in feed efficiency $(\mathrm{F}(1,16)=19.48, \mathrm{p}<0.001)$. HH=high-fat/high-sugar, LL=low-fat/lowsugar

Figure 5. Fasting blood glucose levels collapsed across the four months. Blood glucose levels are significantly higher in $\mathrm{C} 57 \mathrm{BL} / 6 \mathrm{~J}$ mice fed a high fat diet than they are in A/Js or C57BL/6J mice fed a low-fat diet (two-way ANOVA (strain $\mathrm{x}$ diet) interaction, $\mathrm{F}(1,24)=2.72, \mathrm{p}<0.0001)$. HH=high-fat/high-sugar, LL=low-fat/low-sugar

Figure 6. Graph of changes in blood glucose levels in the two strains at the 0,30 or 60 minutes following the insulin injection over the 4 months. C57BL/6J mice showed higher levels of blood glucose and decreased sensitivity to insulin over the four months when compared to A/Js ( repeated measures three-way ANOVA (month $\mathrm{x}$ time $\mathrm{x}$ strain) withinsubjects interaction $(\mathrm{F}(6,144)=4.71, \mathrm{p}<0.001))$.

Figure 7. Changes in blood glucose levels in A/J and C57 mice fed high-fat or low-fat diets at 0,30 and 60 minutes following the insulin challenge. C57BL/6J mice fed a highfat diet exhibited fasting hyperglycemia and, as a result, a decreased response to the insulin challenge (repeated measures three-way ANOVA within-subjects (time $\mathrm{x}$ diet $\mathrm{x}$ strain) interaction $(\mathrm{F}(2,48)=9.60, \mathrm{p}<0.001))$. $\mathrm{HH}=$ high-fat/high-sugar, LL=low-fat/lowsugar

Figure 8. Changes in weight for animals used for cognitive experiments. Diabetes-prone C57BL/6J mice gain significantly more weight than diabetes resistant mice $\mathrm{A} / \mathrm{J}$ when fed a high-fat/high-sugar diet, as well as low-fat fed groups. $(F(1,36)=28.87, p<0.001)$. $\mathrm{HH}=$ high-fat/high-sugar, LL=low-fat/low-sugar 
Figure 9. Locomotor activity showing significant differences in the number of visits $A / J$ and C57BL/6J made in the two arms during the acquisition phase (zone $2 \mathrm{~F}(1,33)=29.24$, $\mathrm{p}<0.001$, zone $3 \mathrm{~F}(1,33)=22.74)$. HH=high-fat/high-sugar, LL=low-fat/low-sugar

Figure 10. Time spent in the novel versus familiar arms of the $\mathrm{Y}$-maze. Data for $\mathrm{A} / \mathrm{J}$ are on top, with data for C57 on the bottom. C57BL/6J mice showed a preference for the novel arm, while $\mathrm{A} / \mathrm{J}$ mice showed avoidance of the novel $\operatorname{arm}(\mathrm{F}(1,33)=135.14$, $\mathrm{p}<0.0001)$. HH=high-fat/high-sugar, LL=low-fat/low-sugar

Figure 11. Discrimination index in the Y-maze. Discrimination index is expressed as the absolute value of the surplus or detriment of time spent in the novel arm during the second session compared to the other 2 familiar arms of the Y-maze. The index varies between 0 (no discrimination) and 60 seconds (full avoidance or preference of the novel arm). A/J mice seemed to discriminate better than C57 mice between the novel and the familiar arms $(F(1,33)=75.43$, p $<0.0001)$. HH=high-fat/high-sugar, LL=low-fat/lowsugar

Figure 12. Spontaneous alternations in the Y-maze show a trend for the high-fat fed C57BL/6J mice animals to make less spontaneous alternations, however this trend did not reach significance. $\mathrm{HH}=$ high-fat/high-sugar, LL=low-fat/low-sugar

Figure 13. Open field. Percentage of time spent in each of the 3 areas of the open field during the 5 minutes test period for $\mathrm{C} 57$ (A) and A/J (B) mice. Panel C depicts latency to explore all four corners, the center and the periphery. Panel D represents mean speed during the trial. All data are mean \pm standard error. $\mathrm{HH}=$ high-fat/high-sugar, $\mathrm{LL}=$ lowfat/low-sugar

Figure 14. Elevated plus maze. Percentage of time spent in each of the 3 areas of the elevated plus maze during the 5 minutes test period for C57 (A) and A/J mice (B). Latency to explore the open arms of the maze (C). Speed of exploration (D). All data are mean \pm standard error. $\mathrm{HH}=$ high-fat/high-sugar, $\mathrm{LL}=$ low-fat/low-sugar

Figure 15. Forced swim test. A. Floating time during the 3 minutes test period. B. Distance swam during the test. All data are mean \pm standard error. $\mathrm{HH}=$ high-fat/highsugar, LL=low-fat/low-sugar

Figure 16. BrdU labeled cells in the dentate gyrus. Representative micrographs of BrdU immunodetection in the subgranular layer of the dentate gyrus in high-fat or low-fat fed C57 and A/J mice. A single BrdU injection was administered 24 hours before perfusion. The arrows indicate BrdU positive cells. HH=high-fat/high-sugar, LL=low-fat/low-sugar

Figure 17. Number of BrdU labeled cells in the subgranular layer of the dentate gyrus. C57 mice show increased proliferation compared to $\mathrm{AJ}$ mice $(\mathrm{F}(1,16)=26.83, \mathrm{p}<0.05)$. There is a non-significant trend towards increased proliferation in high-fat-fed C57 mice. All data are mean \pm standard error. $\mathrm{HH}=$ high-fat/high-sugar, LL=low-fat/low-sugar 
Figure 18. Weight of mice whose brains were stained with BrdU. C57 mice showed increased weight gain when fed a high-fat diet. All data are mean \pm standard error. $\mathrm{HH}=$ high-fat/high-sugar, LL=low-fat/low-sugar

Figure 19. IL-10 hippocampal protein levels. A/J mice show increased IL-10 levels in response to stress, while C57 mice show no change in IL-10 levels when stressed. All data are mean \pm standard error. $\mathrm{HH}=$ high-fat/high-sugar, LL=low-fat/low-sugar

Figure 20. Weight change during the two weeks of chronic mild unpredictable stress. Mice receiving no stress gained more weight than stressed mice $(F(1,27)=8.37, p<0.01)$. High-fat fed mice showed increased weight compared to low-fat-fed mice $(F(1,27)=106.63, \mathrm{p}<0.01)$. C57 mice fed a high-fat diet showed increased weight $(\mathrm{F}(1,27)=44.61)$. All data are mean \pm standard error. $\mathrm{HH}=$ high-fat/high-sugar, $\mathrm{LL}=$ lowfat/low-sugar 


\section{Introduction}

Diabetes mellitus is a severe metabolic disorder characterized by hyperglycemia and associated abnormalities in the metabolism of proteins, carbohydrates and fats (Musselman, Betan, Larsen and Phillips, 2003). There are two major types of the disorder: Type 1 (T1D), which occurs in children and young adults and accounts for 10\% to $15 \%$ of all cases, and Type 2 (T2D) which is more common in individuals over the age of 30 , and accounts for $85 \%$ to $90 \%$ of cases (Statistics Canada, 2003).

Although both diabetic sub-types share a number of functional consequences, their etiological mechanisms are clearly different. T1D stems from an autoimmune destruction of the insulin-producing pancreatic $\beta$ cells, resulting in a severe deficiency of insulin secretion. In contrast, T2D results from a combination of inadequate insulin secretion and resistance (Musselman, Betan, Larsen and Phillips, 2003). Ultimately both of these diabetic conditions lead to an insulin dysfunction and chronic hyperglycemia, which over time is associated with damage to several organs, such as the kidneys, eyes and the central nervous system (Biessels and Gispen, 2005).

Diabetes is typically thought of as a disease of the periphery; however the condition constitutes a major stressor for the central nervous system (CNS), and can therefore affect its functioning. Indeed, diabetes mellitus is highly correlated with neurodegenerative and functional disorders of the CNS. Both T1D (Falcone \& Sarvetnick, 1999; Pankewycz, Guan \& Benedict, 1995; Rabinovitch, 1998) and T2D (Donath et al, 2005; Mito et al. 2000; Fishel et al., 2005) are associated with impairments in learning and memory, inflammatory changes, as well as with a higher incidence of 
developing neurodegenerative disorders, depression and stress-related pathology (Ristow, 2004).

The high incidence of neurodegenerative pathology (Ristow, 2004) and cognitive impairments observed in diabetic individuals (Bjorgaas et al., 1997; Brands et al., 2005; Lobnig et al., 2006; Strachan et al., 1997) suggests that diabetes may have a neurodegenerative impact on the brain. The mechanisms underlying the association of diabetes with neurodegenerative pathology are unclear but they may include alterations of brain glucose utilization and sensing, insulin deficiency, microvascular abnormalities and inflammatory changes, all of which are thought to contribute to changes in cell proliferation and neurotransmitter dysregulation (Craft \& Watson, 2004; Surwit et al., 1995).

In addition to neurodegenerative changes, diabetes may also be associated with disturbances of neuroplasticity, including impaired dendritic branching (Baran et al., 2005) and alterations of neurogenesis (Jackson-Guilford et al., 2000; Kang et al., 2006; Revsin et al., 2005; F. Saravia et al., 2004; F. E. Saravia et al., 2006). Disrupted neurogenesis (the generation of new neurons in the brain) may be a particularly important, yet often overlooked, aspect of neurodegenerative pathology and it has been hypothesized to arise from a failure of the endogenous neuronal stem cells to respond appropriately to neuronal loss and replace the dying populations of neurons (Armstrong \& Barker, 2001). This failure to replace neuronal loss could arise from several dysfunctions. One aspect could be a decrease in proliferation, migration or differentiation of the new neurons. A second possibility is a greater rate of neurodegeneration than cell replacement. And finally, degeneration fails to send appropriate signals to stimulate 
neurogenesis, or alternatively, neurogenesis is inhibited by signals in the neuronal microenvironment (Armstrong \& Barker, 2001).

Chronic inflammation has been proposed as one potential mechanism influencing neurogenesis (Ekdahl et al., 2003). Moreover, given that increased activation of inflammatory cascades is associated with neurodegenerative pathology (Hayley \& Anisman, 2005), as well as peripheral changes in diabetes (Almawi et al., 1999), it is conceivable that inflammatory factors may be influencing the development of neurodegenerative pathology in diabetic individuals. In this regard, cytokines may be important messengers common to the evolution of such co-morbid states.

Importantly, by virtue of their provocative actions upon central monoamines and the hypothalamic-pituitary-adrenal axis (HPA), cytokines have been proposed to act as systemic stressors. In this respect, diabetes may be viewed as a systemic stressor activating neurochemical processes similar to those influenced by more traditional psychologically relevant stressors (Asaba et al., 2006; Herman \& Cullinan, 1997).

Both acute and chronic stressors may influence brain plasticity. However, while acute stressors may cause reversible changes in plasticity that may even be positive for the organism (e.g. facilitate memory formation), chronic stress often leads to maladaptive plasticity, which over time can result in disease (Czeh et al., 2006; Miller \& O'Callaghan, 2005; Warner-Schmidt \& Duman, 2006). Moreover, prolonged stressor exposure leads to inflammatory responses (Kiecolt-Glaser et al., 2003; Maes et al., 1998; Wilson et al., 2002), which are detrimental to neurogenesis and contribute to cognitive impairments (Ekdahl et al., 2003). Therefore it was of interest to investigate the impact of a 
psychological stressor, and the metabolic stressor, diabetes, upon the central neuroinflammatory processes, and hippocampal functioning.

This proposal seeks to assess changes in hippocampal neurogenesis and cognitive functioning in a mouse model of diabetes. Since it is hypothesized that inflammatory processes may be fundamental in the central effects systemic and traditional stressors, changes in cytokines and associated signaling factors will also be evaluated in the diabetic-stressor model.

\section{Cognitive impairments in diabetes}

Both T1D and T2D are associated with an increased prevalence of cognitive impairments and neurodegenerative disorders. In fact, of the 100 known neurodegenerative disorders, diabetes is associated with more than 20 (Ristow, 2004). This section highlights some of the most common neurodegenerative disorders associated with diabetes as well as the cognitive impairments present in T1D and T2D, their similarities and their differences.

\subsection{Comorbidity of diabetes with neurodegenerative disorders}

The most common neurodegenerative disorder and frequent form of dementia is Alzheimer's disease (AD). Diabetic patients are twice as likely to develop AD, compared to the general population. For subjects with both diabetes and the AD-predisposing apoliprotein $\mathrm{E}$ allele the relative risk of developing $\mathrm{AD}$ increases to five times compared to the general population. Furthermore, the risk for $\mathrm{AD}$ remains high in these studies even after controlling for vascular risk factors, suggesting that the pathogenesis of $A D$ in diabetes is independent of vascular function (Grossman, 2003). 
There are several pathogenic similarities between diabetes and AD that may help account for the co-morbidity. First, the amyloid protein aggregates characteristic of $\mathrm{AD}$ are also found in the pancreatic islets of diabetic patients and treatment with insulin lowers the concentrations of these deposits. Secondly, like diabetes, AD is associated with insulin resistance, hyperinsulinemia and impaired glucose utilization. Finally, cholesterol clearance and metabolism is decreased in both diabetes and AD. Cholesterol has also been implicated in $\beta$-amyloid synthesis and drugs modulating cholesterolemia by regulating lipid metabolism may offer a possible treatment option for $\mathrm{AD}$ (Ristow, 2004).

Another neurodegenerative disorder showing a strong association with diabetes is Huntington's disease (HD), which is characterized by progressive neuronal death coupled with dementia in addition to the choreic movements typical of the disease. The pathogenesis of this genetic disease is attributed to cleavage and accumulation of aminoterminals of the huntingtin protein. Interestingly, HD patients are 7 times more likely to develop diabetes than matched healthy individuals. Moreover, HD patients and animal models show increased oxidative stress and mitochondrial dysfunction, also evident in diabetes (Ristow, 2004). Brain mitochondrial dysfunction is believed to be a direct effect of increased glucose oxidation due to a hyperglycemic environment in the brain, and it results in increased reactive oxygen species (ROS) and nitric oxide (NO) production, which in turn lead to neuronal damage. Oxidative stress is a central feature of diabetic encephalopathy (Mastrocola et al., 2005).

Parkinson's disease (PD) is the second most frequent neurodegenerative disorder. Interestingly, $80 \%$ of PD patients also exhibit impaired glucose tolerance. Like AD and HD, PD exhibits filamentous deposits, which are believed to be the result of degradation 
of the neurofilaments through elevated oxidative stress (Q. Liu et al., 2004). These filamentous deposits have also been found in the diabetic brain (Fernyhough et al., 1999).

This high comorbidity of diabetes with neurodegenerative disorders suggests a common pathogenic pathway, however, this is a controversial topic and it is not clear whether the neuronal death represents a primary pathological feature, a secondary complication arising during the disease, or a protective response (Armstrong \& Barker, 2001). One feature all these disorders do share is cognitive deterioration, which, as a growing body of literature suggests, is also present in diabetic and pre-diabetic individuals.

\subsection{Cognitive impairments associated with T1D}

T1D is associated with cognitive impairment in both humans and animal models. The majority of studies on cognitive problems stemming from T1D in humans have found a negative effect on attention, psychomotor speed, mental flexibility and delayed memory (Bjorgaas et al., 1997; Brands et al., 2005; Lobnig et al., 2006; Strachan et al., 1997).

Neurocognitive decline is present in juvenile diabetes, even as early as 2-3 years after diagnosis, prior to development of cardiovascular disease (Northam et al., 2001). Northam et al. (2001) followed a group of newly diagnosed children for 6 years and compared them with a group of healthy controls. They found that while there were no differences at baseline, at a two years follow-up, the children diagnosed before the age of 4 , showed developmental delays on vocabulary and abstract reasoning tests (Northam et al., 1998). At 6 years follow-up all diabetic children regardless of age of diagnosis 
experienced deficits in attention, processing speed, long-term memory and executive functioning (Northam et al., 2001).

As in humans, animal models of diabetes also show cognitive impairments in complex tasks such as Morris water-maze and spatial object learning, but preserved performance in simple tasks such as passive avoidance paradigms. These deficits are influenced by the duration and severity of diabetes and hyperglycemic episodes, and they can be prevented but not reversed by insulin treatment (Biessels and Gispen, 2005).

The evidence for cognitive impairments in T1D is strong in both humans and animals and suggests dysregulation of executive functioning, attention and delayed memory implicating a breakdown in communication between the hippocampus and the prefrontal cortex.

\subsection{Cognitive impairments associated with T2D}

In contrast to $\mathrm{T} 1 \mathrm{D}, \mathrm{T} 2 \mathrm{D}$ is associated with impairments in learning and working memory (Reaven et al., 1990; Strachan et al., 1997; Strachan et al., 2003). Despite heterogeneous designs and methodological limitations, most studies in people with T2D found cognitive impairments, which were especially accentuated by poor glycemic control, early onset of the disease, micro- and macrovascular complications and age. The majority of the studies found significant impairments in immediate noncontextual verbal memory, such as word recall lists, processing speed/reaction time and brief cognitive measures such as the Mini Mental State Examination (MMSE) in diabetic subjects as compared to controls. In contrast to impairments associated with $\mathrm{T} 1 \mathrm{D}$, attention, language and semantic functioning were relatively spared in T2D (Awad et al., 2004; Strachan et al., 1997). 
Studies in rats fed high-fat diets have found impairments in the radial arm maze, an operant test of delayed alternation performance with variable time intervals between trials (VIDA), and blind-alley maze tasks. The radial arm maze is a measure of spatial memory and is hippocampal dependent. The VIDA measures procedural rule learning and is sensitive to frontal lobe damage and long-term memory impairments that depend on hippocampal involvement. The blind-alley maze task addresses intellectual function in general and is affected by widespread brain-impairment (Winocur \& Greenwood, 2005). When compared to controls, the rats fed high-fat diets showed impairments similar to aged and brain-damaged rats in the same conditions, on all cognitive tasks. The rats fed diets high in saturated fats, such as those found in coconut oil, showed particularly affected cognitive functioning, whereas rats fed diets high in polyunsaturated fats, such as omega-3 fatty acids found in fish oil, performed similar to the controls (Greenwood \& Winocur, 1990).

Human and animal studies of T2D uncovered impairments in hippocampal dependent functions such as working memory and learning, suggesting a different mechanism may be responsible for these deficits than that implicated in T1D.

\section{Neurogenesis}

The hippocampal formation is a highly plastic brain structure essential to learning and memory processes and is especially vulnerable to a host of stressors. In particular, disturbances of neurochemical activity, as well as neurogenesis and dendritic branching have been reported following psychosocial, neurogenic and even metabolic stressors (Prickaerts et al., 2004). Neurogenesis is an umbrella term, which encompasses cell 
proliferation, migration, differentiation, death of some of the newly generated neurons and maturation of the remaining neurons. Of these, cell proliferation and cell death are independently regulated, and are influenced by both the internal and the external environment of the organism, with important implications for learning and memory, aging and neuronal loss - neurodegeneration (Christie \& Cameron, 2006; Prickaerts et al., 2004).

\subsection{Importance of neurogenesis for learning and memory}

The evidence relating neurogenesis to learning and memory falls in three categories: 1 . studies suggesting a correlation between neurogenesis and learning abilities, 2 . studies suggesting that learning influences the number of new neurons produced following the specific task and finally, 3. evidence suggesting that a decrease in the number of new neurons born has a deleterious impact on learning (Leuner et al., 2006).

Although the existing evidence is controversial, several studies have reported an increase in the number of new neurons correlates with better performance on spatial memory tasks such as the Morris Water Maze (Drapeau et al., 2003). Moreover, conditions such as stress, aging and increased levels of corticosteroids were associated with decreased neurogenesis and learning impairments (Gould et al., 1998; Tanapat et al., 2001). However, there is also conflicting evidence suggesting that in rats these same conditions do not necessarily lead to cognitive impairments (Leuner et al., 2006).

Some studies have found that hippocampal specific learning such as spatial learning was associated with increased neurogenesis (Gould et al., 1999), while hippocampal independent learning tasks such as active shock avoidance, had no effect on 
neurogenesis (Van der Borght et al., 2005). In contrast, some studies report no effect or even a decrease in neurogenesis associated with learning. This discrepancy may be explained by variations in the age of the labeled neurons, or by differences in the training protocols employed (Leuner et al., 2006). Finally, some studies found that reductions in the number of new neurons induced by the antimitotic agent methylazomethanol (Shors et al., 2001) or irradiation exposure (Gazzara \& Altman, 1981) were associated with impaired learning and memory. However, the side effects of these neurogenesis blocking treatments are not known, and thus there is a possibility they may be affecting other cellular processes or general health (Leuner et al., 2006).

Further complicating the association between neurogenesis and learning, is the fact that the precise role which neurogenesis plays in learning has still not been elucidated. However, several hypotheses have been advanced, including the possibility that new neurons increase the opportunity for learning simply through their availability to form new circuits (Kempermann, 2002). Support for this theory comes from the observation that newborn neurons exhibit lower LTP thresholds and are less sensitive to GABAergic inhibition. A second hypothesis posits that new neurons are used for temporary storage of information. Some support for this theory comes from the belief that the hippocampus is involved in the short term storage of information and the observation that lesions to the hippocampus become less disruptive as the period between acquisition and memory recall increases (Leuner et al., 2006). However, currently the amount of conclusive evidence supporting these hypotheses and linking neurogenesis to learning and memory is still small. 
We suggest there are several factors, which may act together to synergistically influence neurogenesis and ultimately lead to cognitive deterioration. In support of this contention, psychological stressors have been suggested to interact with hyperglycemic toxicity and neurotrophic changes within the context of diabetes to influence neurogenesis.

\subsection{Neurogenesis impairments in T1D}

To date there are only a handful of studies investigating the relationship between T1D and neurogenesis (Jackson-Guilford et al., 2000; Kang et al., 2006; Revsin et al., 2005; Saravia et al., 2004; Saravia et al., 2006). However, all studies agree that T1D leads to a decrease in neuronal proliferation in the dentate gyrus and marked astroglyosis. Some studies have investigated factors that can increase cell proliferation in spite of the hostile microenvironment in the dentate gyrus in diabetes, and found that estrogen (F. Saravia et al., 2004; F. E. Saravia et al., 2006), antidepressant treatment (Beauquis et al., 2006) and low doses of radiation (Kang et al., 2006) can restore proliferation levels. However, the mechanisms through which each of these factors restores neurogenesis may be slightly different. Whereas estrogen and antidepressants such as fluoxetine increase production of new neurons (Beauquis et al., 2006; Saravia et al., 2004; Saravia et al., 2006), low doses of radiation suppress expression of apoptotic factors such as caspase 3, thereby allowing neurogenesis to replace the dying populations of neurons (Kang et al., 2006). 


\subsection{Neurogenesis impairments in T2D}

Despite the evidence that T2D causes cognitive impairments in both humans and animals, to date there is only one study (Lindqvist et al., 2006) investigating the effects of T2D on neurogenesis. This study brings compelling evidence that intake of high dietary fats negatively affects neurogenesis. New cells in the dentate gyrus were double-labeled with bromodeoxyuridine (BrdU) and a neuron-specific nuclear protein (NeuN). BrdU is a thymidine analogue, which upon injection is incorporated into the newly synthesized DNA of replicating cells. NeuN is an endogenous marker expressed by mature neurons. Male rats fed a high-fat diet for 4 weeks had significantly reduced numbers of dentate neurons co-expressing BrdU and NeuN., as compared to rats fed a control standard rat chow. The authors suggest that the increased levels of corticosterone observed in the male rats fed a high-fat diet may be responsible for the reduced neurogenesis (Lindqvist et al., 2006).

\section{Factors affecting neurogenesis in the diabetic brain}

Several factors are known to negatively impact neurogenesis in the dentate gyrus. Among these are changes in cytokines, glucocorticoids, and insulin growth factor (IGF). These changes are particularly relevant in the context of diabetes.

\subsection{Cytokine changes}

Recent evidence (Ekdahl et al; 2003), suggests that chronic inflammatory responses mediated by cytokines may be detrimental to regenerative processes such as neurogenesis. Furthermore, inflammation-suppressed neurogenesis may play a 
pathophysiological role in many disorders associated with cognitive impairment including AD and PD (Perry et al., 2003).

Cytokines are a group of proteins, which act as signaling compounds in the periphery and the CNS and are implicated in innate and adaptive immune responses (Perry et al., 2003). Two T helper (Th) cell types play an important role in maintaining adaptive immunity. Th1 produce tumor necrosis- $\alpha$ (TNF- $\alpha$ ), interleukin 1 and 2 (IL-1, IL2) and interferon- $\gamma(\mathrm{INF}-\gamma)$, all of which promote cell mediated responses and have primarily pro-inflammatory actions. In contrast Th2 produce IL-5, IL-4, IL-10 and IL-13, which in turn promote humoral immunity and have primarily anti-inflammatory actions (Almawi et al., 1999). Cytokines are also produced in the CNS by the brain's resident immune cells, the microglia, activated in response to injury or stress (Liberto et al., 2004).

While at low concentrations cytokines have neuroprotective and pro-regenerative effects through their stimulatory effects on astrocytes, which produce trophic substrates for neurons, restore the blood-brain barrier, promote remyelination and stimulate neurogenesis, at higher levels following chronic exposure to an insult, cytokines can have devastating effects on the brain (Liberto et al., 2004). In a study on the effects of central inflammation on basal neurogenesis, Ekdahl et al (2003) found that chronic infusion with the inflammatory agent lipopolysaccharide caused an $85 \%$ reduction in the number of new neurons labeled with BrdU over the course of a week in the dentate gyrus, while the number of mature neurons was not significantly affected, suggesting that chronic inflammation decreases neuronal survival rather than differentiation. When BrdU was injected 2 hours prior to euthanasia to label proliferating neurons, no difference was 
observed between animals that received LPS infusions and controls, suggesting that proliferation was not significantly affected by inflammation. Furthermore, inflammation attenuated neurogenesis triggered by status epilepticus. Similarly, other studies (Fan et al., 2005; Monje et al., 2003; Ryu et al., 2004) have found that an inflammatory blockade with nonsteroidal anti-inflammatory drugs can restore hippocampal neurogenesis.

The deleterious effects of inflammation on neurogenesis are believed to be mediated by the pro-inflammatory cytokines IL-6, TNF- $\alpha$, and IL- $1 \beta$, which together with increases in nitric oxide and reactive oxygen species production create a neurotoxic microenvironment, thereby decreasing survival of new neurons. Moreover systemic inflammation in people with already existing inflammation in the brain accelerates disease progression and contributes to cognitive impairments (Perry et al., 2003).

$\mathrm{T} 2 \mathrm{D}$ is associated with dysregulated cellular and humoral immunity and peripheral increases in Th1 cytokines (IL-1 $\beta$, TNF- $\alpha$ and $I L-6$ ) and decreased levels of Th2 cytokines (IL-4, IL-10).

\section{Cytokine changes in $T 2 D$}

Metabolic stress such as in T2D leads to the activation of cellular inflammatory pathways. One possible mechanism suggested by Chen (2006) is that a high-fat diet leads to a nutrient overload in the adipose tissue, which in turn increases secretion of free fatty acids (FFA) and pro-inflammatory cytokines which lead to the activation of macrophages. The macrophages themselves produce more pro-inflammatory cytokines, which cause insulin resistance by triggering endoplasmic reticulum (ER) stress and activating several pro-inflammatory signaling pathways such as the c-Jun NH2-terminal kinase 1 (JNK1), pro-inflammatory kinase $\theta(\mathrm{PKC}-\theta)$ and I-Kappa-B Kinase $\beta$ (IKK $\beta)$. 
The activation of these pathways leads to a decrease in insulin receptor substrate (IRS) phosphorylation needed for the activation of the AKT2 cascade responsible for the recruitment of the Glut- 4 transporters to the plasma membrane, which ultimately results in a decrease in glucose uptake from the blood (Chen, 2006).

T2D associated elevations of the Th1 cytokines IL-1 $\beta$, TNF- $\alpha$ and IL-6 are strongly influenced by various stimuli, such as nutrition, age, stress and/or a genetic predisposition (Pickup \& Crook, 1998). Thus, the central impact of these cytokines is markedly shaped by the environmental and individual conditions present.

Two Th2 cytokine seem to play an important role in T2D: IL-10 and IL-4. IL-10 is a powerful inhibitor of TNF- $\alpha$ and IL-6, and reduced levels of IL-10 were associated with increased levels of glucose in serum. In fact, elderly patients with reduced $\mathrm{IL}-10$ production (358-396 pg/ml) were more than twice as likely to have T2D when compared with elderly patients with high $\mathrm{IL}-10$ production $(1331-1474 \mathrm{pg} / \mathrm{ml})$. Serum from T2D patients also shows reduced $\mathrm{IL}-10$ response to LPS stimulation (van Exel et al., 2002). This suggests that due to its reduced levels, IL-10 may fail to protect against increases in pro-inflammatory cytokines such as TNF- $\alpha$ and IL-6.

IL-4 has an anti-inflammatory role and influences the viability, proliferation and differentiation of $\mathrm{B}$ and $\mathrm{T}$ cells. Insulin receptor substrate 1 and 2 (IRS-1 and -2) are large adaptor proteins implicated in insulin and IGF signaling. IL-4 requires IRS-2 in order to induce proliferation of B and $\mathrm{T}$ cells (Hartman et al., 2004). Hyperinsulinemia and hyperglycemia inhibit IL-4 dependent insulin receptor substrate 2 (IRS-2) signaling in T2D by increasing phosphorylation of (IRS-2). Decreased IRS-2 and IRS-1 signaling results in insulin resistance which in turn results in macrophage resistance to anti- 
inflammatory cytokines, thus contributing to the development of chronic inflammation in T2D (Hartman et al., 2004).

While it is now accepted that cytokines play an essential role in the pathogenesis and associated complications of diabetes in the periphery, very little is known about their impact on the CNS and associated cognitive impairments in diabetes. Indeed cytokines are found in the brain as evidenced by cytokine receptors on neurons and glia (Maier \& Watkins, 1998), particularly in the hippocampus (Cunningham et al., 1992). Furthermore there is evidence suggesting that cytokines are being produced centrally by microglia (Maier \& Watkins, 1998). Several neurodegenerative disorders, as well as chronic stress paradigms (Hayley \& Anisman, 2005) have been associated with central (Taishi et al., 1998) and peripheral (Cao et al., 2007) cytokine dysregulations. Interestingly, diabetes is associated with a high incidence of neurodegenerative disorders (Ristow, 2004), suggesting that cytokines could be the mechanism involved in the predisposition of diabetes to neurodegenerative disorders, and could be potentiated by the effects of chronic stressors. The proposed research explores this possibility.

\subsection{Glucocorticoids}

Diabetes has been associated with enduring elevations of corticosterone levels, (Black, 2006; Huang et al., 2006), which have well established inhibitory effects upon neurogenesis. Similarly, chronic stress exposure results in protracted elevations of corticosterone which inhibit hippocampal neurogenesis (Kloeth, 1998). Elevations of glucocorticoid hormones, such as corticosterone, may influence neurogenesis by altering GABA receptor expression and release of glutamate (McEwan, 1999). Indeed, GABA 
regulates proliferation and migration of progenitor cells, and can limit the progression of stem cells through the cell cycle, thereby inhibiting neurogenesis (X. Liu et al., 2005).

\subsection{Insulin growth factor}

Insulin is essential to neuronal plasticity and survival, while insulin growth factor (IGF) signaling plays an important role in both proliferation and differentiation of neuronal types. Learning and normal memory functioning depend on the up-regulation of insulin receptor expression in the dentate gyrus and CAl area of the hippocampus. T1D is associated with decreased insulin production, while $\mathrm{T} 2 \mathrm{D}$ is accompanied by hyperinsulinemia - overproduction of insulin, which down-regulates the blood brain barrier (BBB) insulin receptors thereby leading to hypoinsulinemia in the CNS (G. S. Watson \& Craft, 2006).

IGF1 and IGF2 are polypeptides genetically related to insulin, which promote central glucose utilization in the brain by activating similar pathways to the ones activated by insulin. Unlike insulin, which peaks after meals and is low most other times, IGF1 and 2 levels are high and stable most of the time (Bondy \& Cheng, 2004). IGF1 and 2 are produced in the periphery as well as the brain, in the hippocampus, cerebellum and the hypothalamus and are is critical to neuronal proliferation and maturation (Anderson et al., 2002), by promoting anabolic growth and homeostasis (Bondy \& Cheng, 2004). The anabolic pathway of IGF-I in the brain involves the binding of IGF-I to the IGF-I receptor, which triggers the autophosphorylation of the receptor and association of the insulin receptor substrate (IRS) adaptor protein. This in turn activates phosphatidylinositol 3 kinase (PI3K), which activates protein kinase B/Akt, leading to 
enhanced expression of Glut-1, 3 and 4 in the plasma membranes of neurons, thus promoting glucose entry in the neurons. Concurrently, IGF-I inhibits glycogen synthase kinase $3 \beta$ GSK $3 \beta$, a protein responsible for inhibition of glycogen synthase, and has been implicated in apoptosis (Bondy \& Cheng, 2004).

Endogenous expression of IGF1 and IGF2 are reduced in the hippocampi of T1D rats, whereas the expression of IGF1 only is altered in T2D rats ( $\mathrm{Li}$ et al., 2005). Interestingly, IGF-I also mediates neuroinflammation, as suggested by the attenuation of sickness behavior induced by the cytokine stimulator lipopolysaccharide by administration of IGF-I. Conversely a pathogenic increase in proinflammatory cytokines can silence IGF-I survival signals (Bluthe et al., 2006). Therefore decreased IGF-I expression diminishes the neuroprotective effects of IGF-I. Similarly, reduced expression of IGF-1 was associated with increases in pro-inflammatory cytokines, particularly interferon- $\gamma$ (IFN- $\gamma$ ) and deficits in long-term potentiation (LTP). In fact, there is evidence suggesting that IGF-1 inhibits IFN- $\gamma$, which in turn has a negative impact on synaptic plasticity (Maher et al., 2006).

When IGF is injected peripherally in mice, significant increases in proliferation in the dentate gyrus are observed (Aberg et al., 2000). Furthermore, when added to progenitor cell cultures IGF induces neuronal phenotype, suggesting it also has a role in differentiation (Anderson et al., 2002).Thus, IGF signaling appears to be important for both proliferation and differentiation and hence, may play a role in modulating any changes in neurogenesis associated with diabetic states. 


\section{Animal models of diabetes}

Several genetic and induced animal models have helped us advance our knowledge about diabetes. These include several spontaneous models of T1D, the streptozotocin T1D model, the diet-induced T2D model and a variety of genetic models. However, no animal model can fully explain the complex and heterogeneous nature of this disorder, therefore it is prudent to use more than one model to ensure reliability and validity of the results.

\subsection{Animal models of T1D}

Both spontaneous and induced T1D animal models have been created, however, surprisingly few studies have investigated the impact of T1D on neurogenesis. Two of the most common spontaneous T1D animal models are non-obese diabetic (NOD) mouse and the bio-breeding $(\mathrm{BB})$ rat. Both strains have been created through inbreeding over many generations and selecting for hyperglycemia. The NOD mouse develops insulitis at 4 to 5 weeks of age and overt symptoms of diabetes between 12 and 30 weeks of age (Atkinson \& Leiter, 1999). Unlike human T1D, this strain of mice can survive without exogenous administration of insulin for many weeks. This model has been very useful in determining the role of cytokines in T1D and the associated immunological cascade (Meagher et al., 2003; Thomas \& Kay, 2000). The BB rat is more representative of T1D in humans, since once frank diabetes is present around 12 weeks of age, it cannot survive without administration of insulin (Rabinovitch et al., 1996). Both the BB and the NOD models have led to the identification of several genes and markers associated with T1D (Rees \& Alcolado, 2005). 
One of the most common induced T1D models is the streptozotocin (STZ) model. $\mathrm{STZ}$ is an antibiotic compound, isolated from the soil microbe Streptomyces achromogenes (Rees \& Alcolado, 2005). Toxic to cells, STZ is similar enough to glucose to be transported by Glut- 2 into $\beta$ cells of the pancreas, which express high levels of Glut-2, making them particularly vulnerable to the effects of STZ (Biessels \& Gispen, 2005). The toxicity of STZ to the $\beta$ cells of the pancreas is believed to be mediated through an increase in NO production within the islets, which leads to mitochondrial dysfunction and ultimately to $\beta$ cells destruction and impaired insulin secretion in the body. This process is similar to the effects of $\mathrm{IL}-1$ on the islets, also mediated through increased production of NO (Turk et al., 1993). Furthermore, hyperglycemia enhances the destructive effects of both STZ and cytokines on pancreatic $\beta$ cells (Mellado-Gil \& Aguilar-Diosdado, 2005). Since the BBB lacks Glut-2, systemic administration of STZ has a limited if any effect on the brain (Biessels \& Gispen, 2005). This suggests that the alterations in cognition and neuronal plasticity seen in this T1D model are due to diabetes rather than the toxic effects of STZ.

The STZ diabetes model has also been successfully used to study the impact of T1D on neurogenesis (Revsin et al., 2005; F. Saravia et al., 2004; F. E. Saravia et al., 2006), and the results of this research suggest reduced proliferation, astrogliosis and neuronal dysfunction in the hippocampi of STZ-diabetic mice. However, to date the process through which T1D disturbs neurogenesis has not been elucidated. 


\subsection{Animal models of T2D}

T2D animal research uses both genetic and diet-induced models to investigate the etiology and pathophysiology of this disorder. Some of the inbred mouse strains used in T2D research are the ob/ob, fa/fa and $\mathrm{db} / \mathrm{db}$ mouse strains. All three strains harbor mutations on the leptin gene (Rees \& Alcolado, 2005). Leptin mediates energy homeostasis by inhibiting food intake and increasing thermogenesis. In obesity, leptin resistance in the body and reduced leptin transport in the CNS have been reported (Pelleymounter et al., 1995). Leptin resistance leads to increased food intake, and therefore hyperglycemia and ultimately insulin resistance (Rees \& Alcolado, 2005). However, the validity of these models is limited because they approach the study of diabetes one gene at a time.

Diet induced models carry more validity than genetic models because they represent a combination of environmental (diet) and genetic (vulnerability) influences. The diet induced diabetes model was introduced in 1988 by Surwit et al. and it is a clinically relevant experimental model because it leads to increased weight gain and over time a stable hyperglycemia and hyperinsulinemia suggesting the progressive development of insulin resistance (Winzell \& Ahren, 2004). C57BL/6J mice are susceptible to diet induced diabetes, and are therefore appropriate experimental animals for this model while $\mathrm{A} / \mathrm{J}$ mice in contrast are resistant to diet induced diabetes and thus are good controls.

Several hypotheses have been advanced to explain this strain-specific susceptibility to the effects of high-fat diets. One of these hypotheses is the differential thermogenic capacity of the two strains in response to a high-fat diet. This is supported 
by the finding that $\mathrm{A} / \mathrm{J}$ mice express higher leptin mRNA values in their adipose tissue when compared to C57BL/6J (Watson et al., 2000). Taken together with the fact that $\mathrm{C} 57 \mathrm{BL} / 6 \mathrm{~J}$ mice gain significantly more weight and at a faster rate than $\mathrm{A} / \mathrm{J}$ mice, the finding that $\mathrm{A} / \mathrm{J}$ mice show increased levels of leptin mRNA suggests leptin increases peripheral energy utilization in $\mathrm{A} / \mathrm{Js}$ (Watson et al., 2000).

Another hypothesis was that $\mathrm{A} / \mathrm{J}$ mice differ in their acute response to the high-fat diet. Indeed, Bullen et al. (2004) found that after just 2 days of high-fat feeding A/Js show a significant decrease in hypothalamic mRNA IL-1 $\beta$ levels, as well as a downregulation of its receptors, but the levels returned to levels comparable to those of A/J mice fed a low fat diet after 1 week. This downregulation in the IL-1 $\beta$ pathway is associated with an initial upregulation of leptin levels and increased food intake in $\mathrm{A} / \mathrm{J} s$ fed a high-fat diet (Bullen et al., 2004).

\section{Proposed research}

The objective of the proposed research is to investigate the neurodegenerative aspect of diabetes. Firstly, it is hypothesized that diabetes leads to hippocampal dependent behavioral abnormalities such as impaired working memory, anxiety and depression-like behavior. Secondly, behavioral changes are accompanied by disturbances in neurogenesis, which is one feature of neurodegenerative pathology. Finally, we postulate that one molecular mechanism mediating the effects of diabetes on neurogenesis, and subsequently on behavior, is a dysregulation in the central and peripheral cytokine system. 
Behavioral changes will be investigated using a T2D mouse model. The Y-maze, open field/elevated plus maze, and forced swim will be used to assess, working memory, anxiety and depressive-like behaviors, respectively. Two aspects of neurogenesis proliferation and migration - will be assessed in a T2D mouse model using an exogenous (bromodeoxyuridine) and endogenous (doublecortin) neuronal marker. The synergistic impact of T2D and stress on central and peripheral cytokine systems will be explored.

\section{Materials and methods}

\subsection{Subjects}

For the T2D experiments, male C57BL/6J and A/J mice 4 weeks of age were obtained from Jackson Laboratories (Bar Harbor, Maine) and allowed to acclimatize for a week prior to the start of the experiment. Mice were housed 2 per cage. All mice were maintained on a 12 -hour light/dark (7AM -7PM) cycle at $21^{\circ} \mathrm{C}$ with ad libitum access to food and water. All experiments were in agreement with the guidelines set by the Canadian Council on Animal Care and were approved by the Carleton University Animal Care Committee.

\subsection{Experiment 1: Behavioral and physiological assessment of T2D mice}

This experiment was designed to assess the impact of T2D on physiology and behavior. In order to establish the time course in which alterations in insulin sensitivity occur following a high-fat/high-sugar diet, thirty-two four-week-old male C57BL/6J and A/J mice were maintained on either a high-fat/high-sugar diet $(\mathrm{HH})$ or a low-fat/low-sugar diet (LL) for 18 weeks. Diets were purchased from Research Diets (New Brunswick, NJ). 
The high-fat diets contained $58 \%$ of the calories from fat, while the low-fat diets contained $11 \%$. The main source of the fat in the high-fat diets was hydrogenated coconut oil (Research Diets Inc., NJ).

Body weight was determined weekly and food intake was measured twice a week for each cage. Fasting glucose levels and insulin sensitivity in these animals were tested monthly starting at 6 weeks for a period of 4 months after exposure to the diets. After a period of 4 hours fasting, a blood sample was obtained via tail nick in non-anaesthetized animals and the plasma glucose concentration was determined using a OneTouch Ultra blood glucose monitoring system (LifeScan Inc., Milipitas, CA). The blood was collected at baseline ( 0 minutes), 30 and 60 minutes following an intraperitoneal insulin $(0.75$ $\mathrm{U} / \mathrm{kg}$ ) in saline challenge. A mouse was considered hyperglycemic if fasting plasma glucose levels measured $>11 \mathrm{mmol} / \mathrm{L}$ (200 mg/dl) (Surwit et al., 1995).

In order to determine whether exposure to high-fat/high-sugar diets is sufficient to cause deficits in tasks known to depend on an intact hippocampus, as well as to induce anxiety and depression-like behavior, the behavior of twenty C57BL/6J and twenty $\mathrm{A} / \mathrm{J}$ mice fed the HH or the LL diet was assessed. Thirty minutes before each test session, the mice were transferred to a quiet room adjacent to the testing room. At the beginning of the testing session, cages were individually brought into the testing room. All testing was performed between 8:00 AM and 12:00 PM in the same dimly lit testing room.

\section{Y-maze}

To assess spatial working memory, mice were tested in a Y-maze with $18.7 \mathrm{~cm}$ long, 9.3 $\mathrm{cm}$ wide and $16.2 \mathrm{~cm}$ high arms. The Y-maze spontaneous alternation test is based on the natural tendency of mice to explore a new environment. In order to remember which area 
they have already explored, mice need to use their working memory. A mouse with impaired working memory cannot remember which arm of the Y-maze it has last visited and shows reduced spontaneous alternations (SA), defined as consecutive entries into each of the arms of the maze on overlapping triplet sets (eg. 123, 231, etc.) (Wietrzych et al., 2005).

Each mouse was placed in one arm of the maze facing the wall and allowed to explore the maze freely for 5 minutes with one arm blocked by a plastic door (Bluthe $e t$ al., 2005). The mouse was then placed in its home cage for 1 minute, after which the mouse was placed back in the same starting arm, with the block removed and allowed to explore freely for 2 minutes. The number of spontaneous alternations and the time spent in each arm was then recorded using a computerized video-tracking system (SMART Videotracking System, San Diego Instruments, CA). The mice were video taped and SA assessed at a later time. SA was recorded using a blind procedure, whereby the order of recording and the identification numbers of the mice were randomized.

\section{Open field and elevated plus maze}

To identify differences in exploratory behavior, anxiety and locomotor activity the mice were tested in the open field and the elevated plus maze. In the open field test, the mice were placed in a 50x50x40cm plastic box. The open field area was divided in 16 equal squares and behavior was monitored for 5 minutes using the SMART System, which recorded time spent in the center, periphery or corners of the apparatus, distance traveled and latency to enter the center.

The elevated plus maze was constructed of black Plexiglas with four elevated arms arranged in a cross. The maze was raised $45 \mathrm{~cm}$ off the ground, the arms were 65 
$\mathrm{cm}$ long and $5 \mathrm{~cm}$ wide. The intersection of the maze gave access to all the arms. At the beginning of the 5 minutes test, each mouse was placed in the center of maze facing the open arm. The latency to enter the open arms, time spent in closed and open arms, and total distance traveled was recorded using the SMART System.

\section{Forced Swim}

To assess floating behavior (measure of depressive-like behavior), mice were tested in a forced swim apparatus. The apparatus was a $28 \mathrm{~L}$ bucket with a diameter of $28 \mathrm{~cm}$, filled with water at a temperature of $23{ }^{\circ} \mathrm{C}$. Testing began with the mouse being placed in the water, and speed $(\mathrm{cm} / \mathrm{sec})$ and floating versus swimming time monitored using the SMART System for a three 3 min session.

\subsection{Experiment 2: Neurogenesis in T2D mice}

Neurogenesis is reduced by chronic stress (Li et al., 2005) and by STZ-induced diabetes in mice (Saravia et al., 2006), however, to date very little is known about the impact of T2D on neurogenesis. This experiment was designed to explore this relationship. Experiment 2 involved a $2 \times 2$ design with four groups $(\mathrm{N}=10$ per group) in which, C57BL/6J and $\mathrm{A} / \mathrm{J}$ mice were maintained on either $\mathrm{HH}$ or the $\mathrm{LL}$ diet for twelve weeks. At the end of the twelve weeks, all the mice received a single i.p. injection of $200 \mathrm{mg} / \mathrm{kg}$ bromodeoxyuridine (BrdU). After 24 hours the mice were deeply anaesthetized with sodium pentobarbital and perfused transcardiacally with $0.9 \% \mathrm{NaCl}$, followed by $4 \%$ paraformaldehyde in $0.1 \mathrm{M}$ phosphate buffer (PB), $\mathrm{pH} 7.4$. Brains were collected and postfixed overnight at $4^{\circ} \mathrm{C}$, after which the tissue was washed every 4 hours in $0.1 \mathrm{M} P B$ and azide, $\mathrm{pH} 7.4$ and then stored for 2 days at $4^{\circ} \mathrm{C}$. The tissue was then dehydrated in a series of increasing concentrations alcohol, clearene and paraffin and embedded in a 
matrix filled with paraffin wax and tissue was then sectioned at $40 \mu \mathrm{m}$ using a microtome.

\section{Immunohistochemical Analysis and Quantification}

On the day of staining, the paraffin sections containing the hippocampal slices were dewaxed in a series of clereane and alcohol and rehydrated in distilled water. The sections were then rinsed in 10mM PBS pH 7.2 for 5 minutes. The slides were then placed in sodium citrate buffer pH 6 and microwaved for 12 minutes, after which they were rinsed in cold running tap water for 10 minutes. Next, the slides were placed in $1 \%$ $\mathrm{H}_{2} \mathrm{O}_{2}$ for 10 minutes in the dark, followed by 15 minutes in PBS with azide. The slides were incubated in the dark overnight at room temperature with $60 \mu \mathrm{l}$ of the primary antidoublecortin antibody (Santa Cruz Biotechnology Cat. \# SC-8066, 1:150, raised in goat).

The next day, the primary antibody was washed off with PBS with azide for 15 minutes, after which the slides were incubated for 2 hours at room temperature with $60 \mu \mathrm{l}$ of the secondary anti-goat antibody (Vector labs Cat. \# BA-9500, 1:100, raised in horse). Next, the secondary antibody was washed off with PBS without azide for 15 minutes. Finally $60 \mu \mathrm{l}$ of the tertiary complex (Amersham Biosciences Cat. \# RPN1051, 1:100, streptavidin-botinylated horseradish peroxidase) was applied to each section and incubated for 2 hours at room temperature. The tertiary complex was then washed off with PBS without azide for 15 minutes.

Finally, a diaminobenzidine (DAB) reaction was then performed to color the peroxidase and allow visualization of the antibody complex. The slides were soaked for 5 minutes in $50 \mathrm{ml}$ of $50 \mathrm{mM}$ Tris $\mathrm{HCl}$ mixed with $1 \mathrm{ml}$ of $10 \mathrm{mg} / \mathrm{ml}$ of DAB. After 5 minutes, the slides were placed back in the PBS wash, while $40 \mu \mathrm{l}$ of $6 \% \mathrm{H}_{2} \mathrm{O}_{2}$ were 
added to DAB solution. The slides were then soaked for 7 minutes in the DAB solution and hydrogen peroxide, after which another $40 \mu \mathrm{l}$ of hydrogen peroxide and the slides soaked for another 7 minutes. After catalyst reaction was performed, the slides were washed in PBS, dehydrated and cleared in alcohol and clearene and mounted.

\subsection{Experiment 3: Cytokine dysregulations}

Experiment 3 was designed to investigate the impact of diabetes, combined with exposure to psychological stressors, on hippocampal cytokines.

To assess the importance of a chronic mild stressor in the pathology of T2D, four-weekold male C57BL/6J and A/J mice were maintained on either a high-fat/high-sugar diet (HH) or a low-fat/low-sugar diet (LL) for 18 weeks (see Table 1).

Table 1. T2D experimental design

\begin{tabular}{|l|l|l|l|}
\hline \multicolumn{2}{|c|}{ C57BL/6J } & \multicolumn{2}{c|}{ A/J } \\
\hline HH + Chronic stress & LL + Chronic stress & HH + Chronic stress & LL + Chronic stress \\
\hline HH + No stress & LL + No stress & HH + No stress & LL + No stress \\
\hline
\end{tabular}

Body weight was determined weekly and food intake was measured twice a week for each cage. The mild chronic unpredictable stress started after 16 weeks, lasted 14 days and consisted of two stressors per day. Longer and milder stressors such as a cage tilt were paired with a shorter and more noxious stressor such as the forced swim. The stressors consisted of:

1. two occasions (10 minutes) of free exploration in an open field,

2. two occasions (10 minutes) of free exploration in a elevated plus maze,

3. two occasions ( 24 hours) of 45 degree cage tilt,

4. two occasions of 5 minutes of air puffs, 
5. three sessions of forced swim ( $3 \mathrm{~min})$ with 1 minute rest periods in between

6. two 24 hours sessions in a cage soiled by another mouse

7. one instance of free exploration in the $\mathrm{Y}$-maze $(10 \mathrm{~min})$

8. two period (1 hour) of social housing, which involved housing mice in groups of 4 in a standard cage divided into compartments by wire mesh in order to prevent fighting

9. one 10 minutes session of restraint in a triangular plastic bag

After two weeks of stress, the animals were sacrificed at 90 minutes following restraint in the plastic bag and blood and brain tissue collected as described for the T1D model.

\section{Brain Dissection Technique}

Following decapitation of the animals, brains were removed and sectioned coronally using razor blades and a stainless steel dissection block with slots separated by $0.5 \mathrm{~mm}$. Brain sections were then placed on a glass Petri dish over ice and the hypothalamus (HYP), prefrontal cortex (PFC), hippocampus (HPP) removed following the mouse atlas by Franklin and Paxinos (1997). The tissue was stored at $-80^{\circ} \mathrm{C}$ for cytokine analyses.

\section{Cytokine Analysis with Luminex}

The Luminex 100 is a compact analysis system which uses principles of flow cytometry to simultaneously detect cytokines in a plasma or tissue sample. Luminex 100 uses colorcoded 5.6 micron polystyrene beads called microspheres which are internally dyed with different intensities of two fluorophores, thus creating up to 100 microsphere sets, each with its own unique signature. The surface of the microspheres allows chemical coupling with different analytes such as cytokines, antibodies, or other peptides. Once bound to the 
reagent, the microsphere passes through a detection chamber where a red laser beam excites the infrared dye within the microsphere, thus allowing it to be classified as one of the 100 sets, while a green laser beam excites the fluorescence associated with the binding of the reagent, which identifies the analyte (xMAP Technology, 2004).

Tissue preparation for cytokine analysis

Plasma samples were diluted using a mouse serum diluent kit (Cat \# 43-007). For the brain samples, the protein concentrations were determined for each sample using a BioPlex Cell Lysis kit (Bio Rad, Cat\# 171-304011) to lyse the cells. $50 \mu$ l of cell lysis buffer were added to each sample and the tissue sonicated for 5 seconds and stored at $-80^{\circ} \mathrm{C}$ for 20 minutes, and then sonicated again. The homogenized tissue was then centrifuged at $4^{\circ} \mathrm{C}$ at $6000 \mathrm{rpm}$ for 5 minutes. All the supernatant was then removed making sure not to disturb the tissue and placed in new tubes. Sample was diluted 1:5, by adding $10 \mu \mathrm{l}$ of supernatant to $40 \mu \mathrm{l}$ of Milli-Q water, while the rest was saved and stored at $-80^{\circ} \mathrm{C}$ for the cytokine assay overnight. Bio-Rad Protein Assay Dye Reagent Concentrate (Cat. \# $500-0006$ ) was diluted $1: 4$, by adding $10 \mathrm{ml}$ of reagent to $30 \mathrm{ml}$ of distilled water. Then $10 \mu \mathrm{l}$ of the diluted sample was added to $800 \mu \mathrm{l}$ of diluted dye and $190 \mu \mathrm{l}$ of Milli-Q water for a total volume of $1 \mathrm{ml}$. Standards were prepared by adding $0,3,5$ and $10 \mu \mathrm{l}$ of $1 \mathrm{mg} / \mathrm{ml}$ bovine serum albumin (BSA) to $200,197,195$ and $190 \mu l$ of water respectively to tubes containing $1 \mathrm{ml}$ of the diluted dye and allowed to sit at room temperature for 5 minutes. Each standard and then sample was transferred to a quartz cuvette and the amount of protein in each was read on a spectrophotometer (Bio-Rad SmartSpec 3000). Based on the spectrophotometer readings, the desired concentration of protein from each sample to be added to the wells of the multi-screen plate was then calculated. 


\section{Cytokine detection and quantification}

A 10 cytokine (IL-1 $\beta$, IL-2, IL-4, IL-5, IL-6, IL-10, IL-12, TNF- $\alpha$, INF- $\gamma$, GMCSF) detection kit (Beadlyte Mouse Multi-Cytokine Detection System 2, Upstate Cell Signaling Solutions, Cat. \# 48-004) was used in combination with the Luminex 100 system. First, 5000pg of Multi-Cytokine 2 standard was suspended in $1 \mathrm{ml}$ of Standard Serum Diluent (SSD), vortexed on medium speed for 15 seconds and placed on ice for 5 minutes. Serial dilutions were then performed to cover a range of standards from 5000 to $0 \mathrm{pg} / \mathrm{ml}$. The filter plate was then soaked with $25 \mu \mathrm{l}$ of Beadlyte Cytokine Assay Buffer per well, vortexed gently, vacuumed and blotted on paper towel. Consequently, $50 \mu \mathrm{l}$ of sample for the tissue or $25 \mu \mathrm{l}$ of plasma and $25 \mu$ l of plasma diluents were then added to each well and the plate incubated for 20 minutes on a plate shaker. The plate was then vortexed at medium speed for 15 seconds and $25 \mu \mathrm{l}$ of Beadlyte Anti-Mouse MultiCytokine Beads 2 solution added to each well after having been vortexed and sonicated in a sonication bath, and then the plate vortexed again at low speed. The plate was then incubated over night in the dark at $4^{\circ} \mathrm{C}$ on a plate shaker.

The next day excess liquid was vacuumed off and the tissue or plasma resuspended in $50 \mu$ of Beadlyte Cytokine Assay Buffer, vortexed and then vacuumed again. For the plasma samples this step was repeated. Then the tissue or plasma resuspended in $75 \mu$ of Beadlyte Cytokine Assay Buffer and plate vortexed at low speed making sure not to overdry the solution. Next, $25 \mu \mathrm{l}$ of Beadlyte Anti-Mouse MultiCytokine 2, Biotin was added to each well, vortexed and incubated at room temperature on a plate shaker for 1.5 hours. The Beadlyte Streptavidin-Phycoerythrin was then diluted 1:25 in Beadlyte Cytokine Assay Buffer, and $25 \mu$ l of the diluted solution added to each 
well. The plate was then vortexed at low speed and incubated for 30 minutes in the dark at room temperature on a plate shaker. $25 \mu \mathrm{l}$ of the Beadlyte Stop Solution was then added to each well, vortexed gently and left for 5 minutes in the dark at room temperature. Excess liquid was then vacuumed and tissue or plasma suspended in $125 \mu 1$ of sheath fluid, vortexed at low speed and placed on a plate shaker for 1 minute. The plate was then placed in the Luminex 100 instrument and the results read when ready. The cytokine assay was performed by Ming Yan Yang.

\section{Statistical Analyses}

Behavioral analyses and neurogenesis data was analyzed using a two-factor between subjects ANOVA: strain (C57B1/6J, A/J) X diet (HH, LL). Weight, blood levels of glucose and brain cytokines in Experiment 3 was analyzed independently using threefactor between subjects ANOVAs: strain $(\mathrm{C} 57 \mathrm{Bl} / 6 \mathrm{~J}, \mathrm{~A} / \mathrm{J}) \mathrm{X} \operatorname{diet}(\mathrm{HH}, \mathrm{LL}) \mathrm{X}$ stress (stress, no stress).

\section{Results}

\subsection{Experiment 1: Biometrics for T2D mouse model}

\section{Body weight and food intake}

Initial experiments assessed the impact of a high-fat/high-sugar diet on body weight, fasting glucose levels and insulin sensitivity in 24 mice (ie: C57 or A/J on high or low fat diets, $n=6$ per group). Diet had minimal effect on the rate of weight gain in $A / J$ mice, with mice on both high- and low-fat diets showing similar rates of weight gain to C57 mice on the low fat diet (Figure 1). However, close inspection of Figure 1 suggests that 
initially high-fat fed A/J mice had a similar weight gain to high-fat fed C57 mice, although this did not reach significance. In contrast, C57 mice on high fat diets showed a marked increase in weight gain compared with the other three groups, starting from approximately the fourth week on the diets (two-way repeated measures ANOVA (strain $x$ diet $), F(1,20)=15.67, p<0.01)$. This increase after 4 weeks on the diet is consistent with results obtained by Surwit et al. (1988).

To determine if weight gain in C57 mice was due to increased food consumption (due for example to increased palatability of this diet) weekly food intake was measured (Figure 2). Over the 18 weeks, food intake differed for $\mathrm{A} / \mathrm{J}$ mice on the high-fat diet compared with the other three groups as suggested by a significant repeated measures ANOVA within-subjects interaction (week $x$ strain $x$ diet) $(F(17,136)=3.12, p<0.001$ ) Figure 2 suggests that $\mathrm{A} / \mathrm{J}$ mice may have initially found the high fat diet to be more palatable. However, this effect was restricted to the first 8 weeks. This increase in food intake in A/J mice is puzzling, since other studies (Surwit et al., 1997; Watson et al., 2000) have found that at 4 weeks $\mathrm{A} / \mathrm{J}$ mice show a sharp increase in serum leptin levels which decreases their food intake. It is possible that the increased food intake in the present study happened prior to the increase in serum leptin levels, but since leptin levels were not measured in the present study, this is just a speculation.

The caloric content of the high-fat diet was $5.55 \mathrm{kcal} / \mathrm{g}$, while the caloric content of the low-fat diet was $4.07 \mathrm{kcal} / \mathrm{g}$. As a result, the high-fat fed mice were consuming more kilocalories per gram of food ingested than the low-fat fed mice (Figure 3), and is supported by a significant main effect of diet $(F(1,16)=12.34, p<0.01)$. This suggests that while the amount of food consumed was similar for all animals, the caloric intake 
differed due to the different caloric content of the diets. While the increased caloric intake in $\mathrm{C} 57 \mathrm{HH}$ mice could underlie their significantly faster weight gain, it does not account for the obvious lack of weight gain in the $\mathrm{A} / \mathrm{J}$ mice on the same diet.

\section{Feed efficiency}

Feed efficiency, which is a measure of metabolic rate, was calculated as the weekly weight gain per calories consumed and expressed as a percentage (Figure 4). There was a significant strain $\mathrm{x}$ diet interaction in feed efficiency $(\mathrm{p}<0.001)$ (Figure 4). Over the course of 18 weeks, the feed efficiency was greater in C57BL/6J mice fed a high-fat diet demonstrating increased weight gain per calorie consumed and suggesting a decreased metabolic rate as suggested by a significant repeated measures ANOVA (strain $\mathrm{x}$ diet), $\mathrm{F}(1,16)=19.48, \mathrm{p}<0.001$. The sharp increase in food intake seen in $\mathrm{A} / \mathrm{J}$ mice at week 5 is not reflected in their feed efficiency, since it is lost during the standardization. However, as Figure 1 suggests increased food intake in high-fat fed A/Js during the first few weeks did initially appear to translate to increased weight gain, but weight gain slowed after 4 weeks on the high-fat diet, and this was followed by reduced caloric intake. This could explain why increased caloric intake in $\mathrm{A} / \mathrm{J}$ mice does not result in increased feed efficiency. 
A

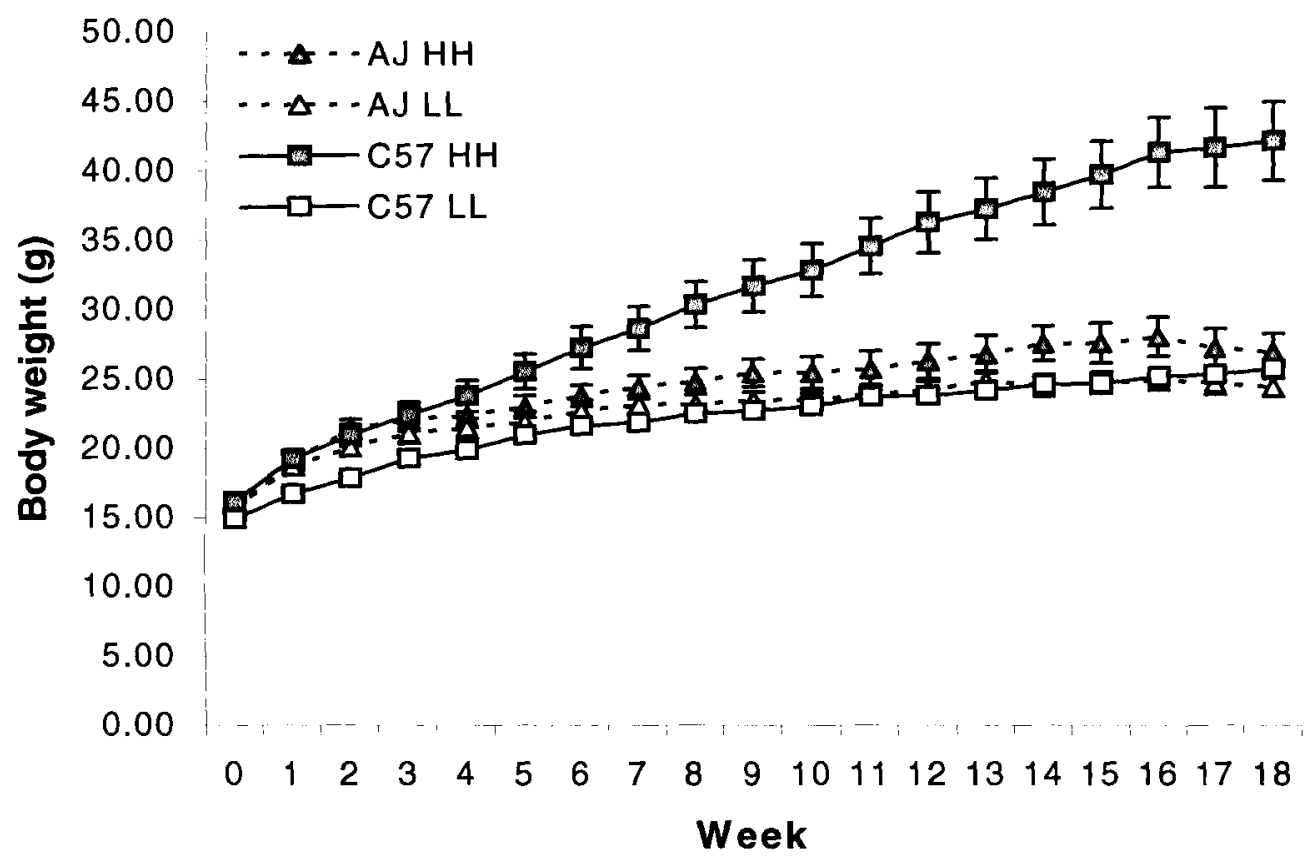

B

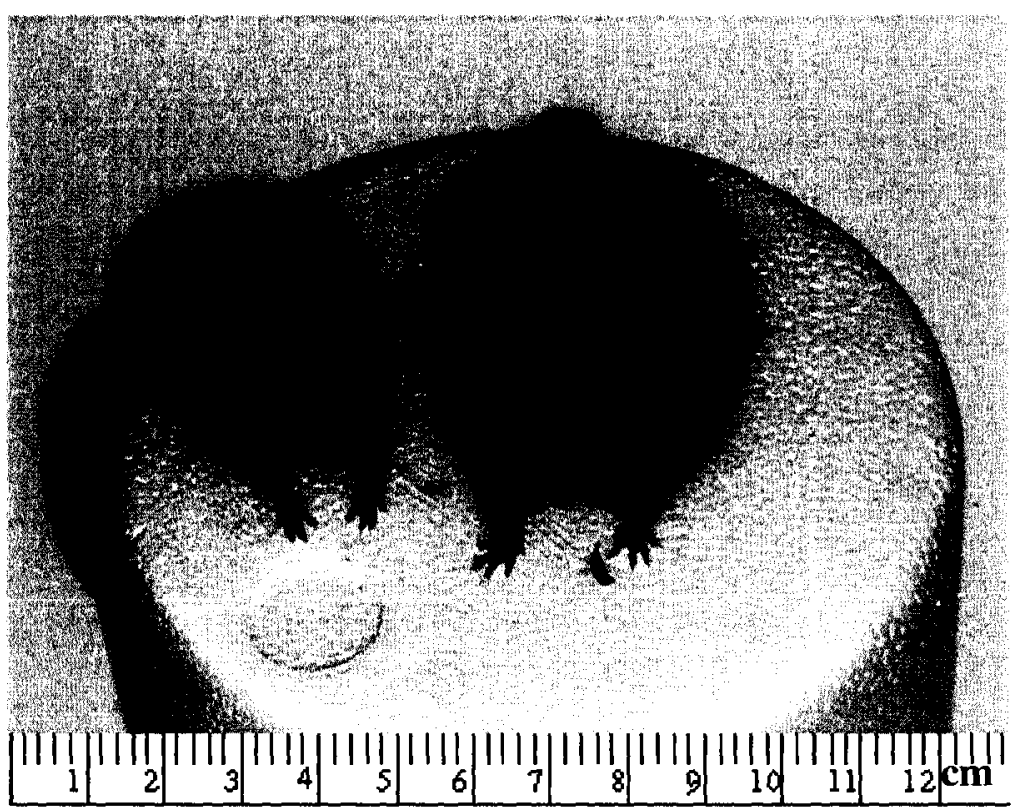

Figure 1. Changes in body weight. A. Diabetes-prone C57BL/6J mice gain significantly more weight than diabetes resistant mice $A / J$ when fed a high-fat/high-sugar diet, as well as low-fat fed groups. $(F(1,20)=15.67, p<0.01)$. B. C57 mouse after 3 months fed a $\mathrm{HH}$ diet compared with a mouse fed a LL diet. HH=high-fat/high-sugar, LL=low-fat/low-sugar 


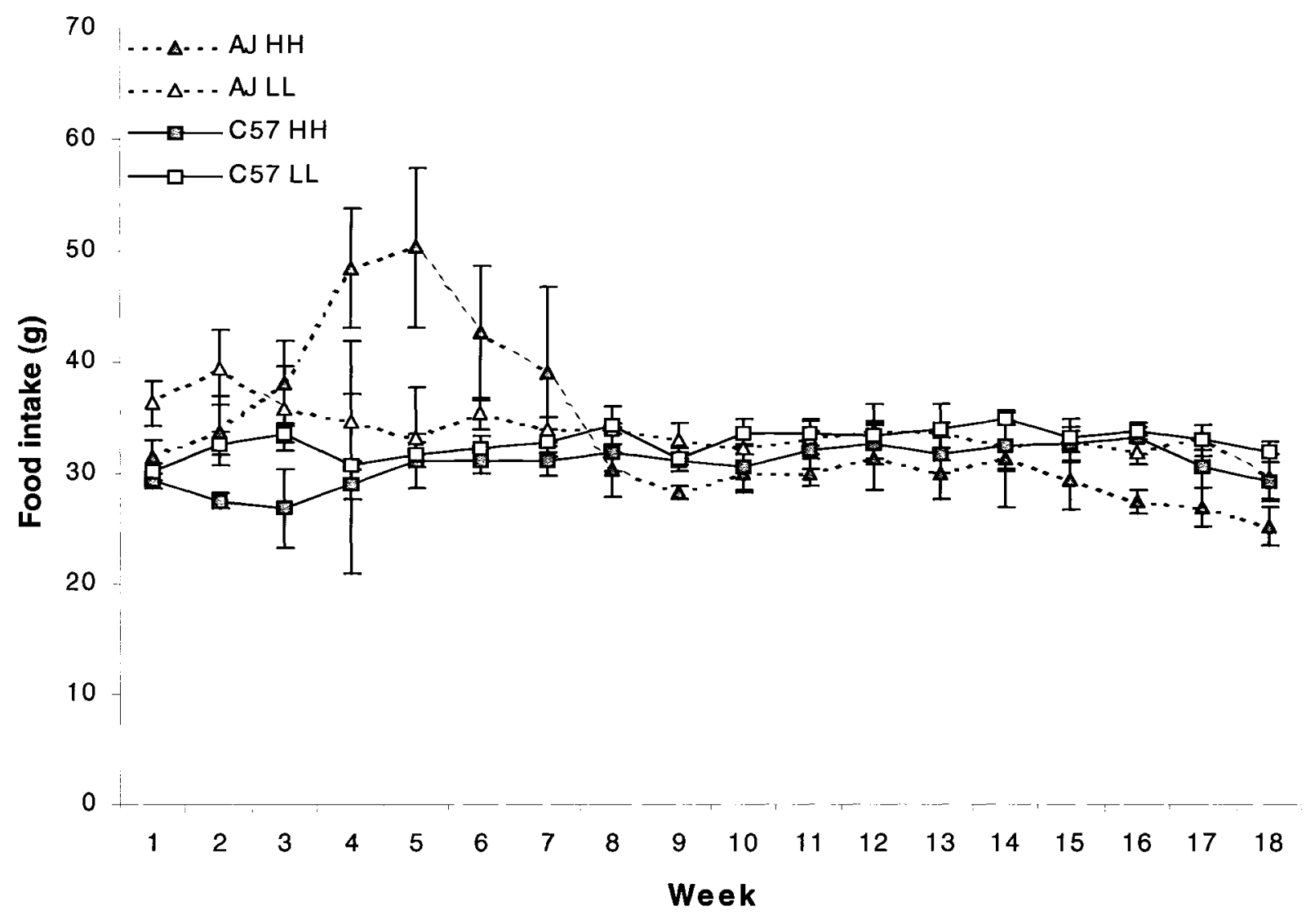

Figure 2. Weekly food intake. There was no significant difference between subjects in food intake, however, a significant within-subjects week $\mathrm{x}$ strain $\mathrm{x}$ diet interaction $(F(17,136)=3.12, p<0.001)$ suggests that high-fat fed $\mathrm{A} / \mathrm{J}$ mice significantly increase their food intake during the first 8 weeks on the diet, after which they reduce their food intake to the same level of the other groups. HH=high-fat/high-sugar, LL=lowfat/low-sugar. 


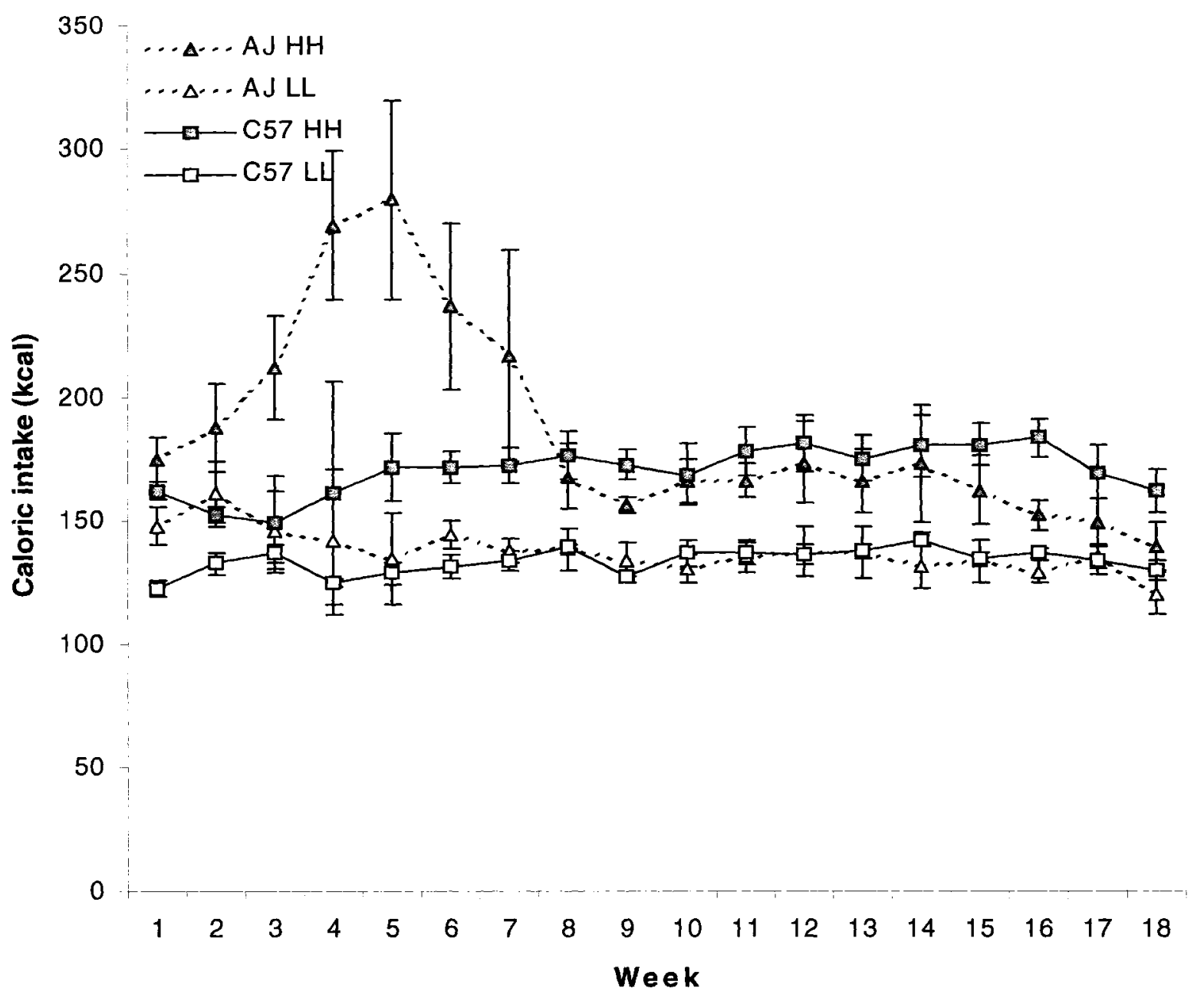

Figure 3. Weekly caloric intake. High-fat fed mice of either strain consumed significantly more kilocalories than low-fat fed mice $(F(1,16)=12.34, p<0.01)$. $\mathrm{HH}=$ high-fat/high-sugar, LL=low-fat/low-sugar 


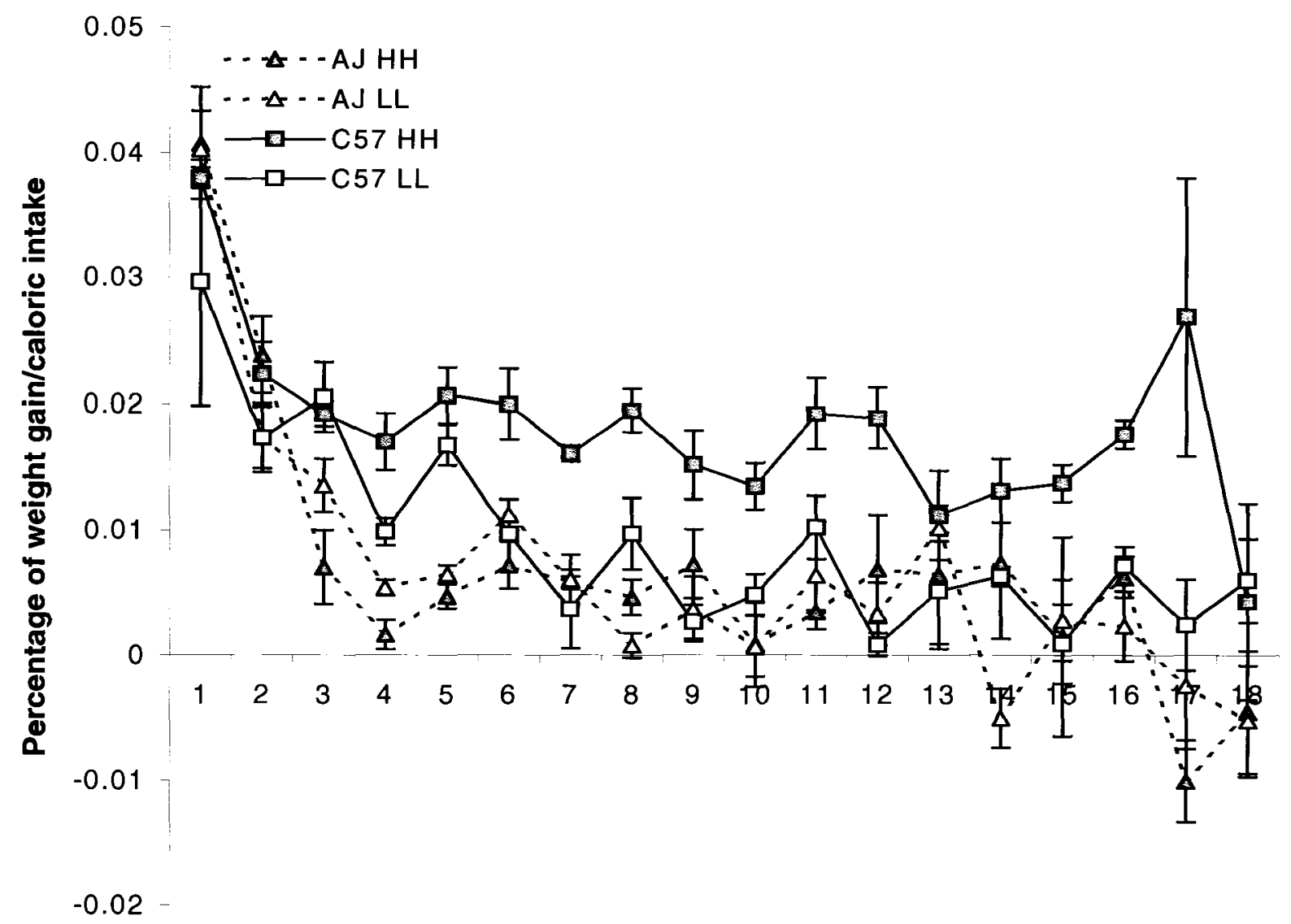

Week

Figure 4. Feed efficiency. High-fat fed C57BL/6J mice show a significant increase in feed efficiency $(\mathrm{F}(1,16)=19.48, \mathrm{p}<0.001)$. HH=high-fat/high-sugar, LL=low-fat/lowsugar 


\section{Fasting glucose and insulin challenge}

In a independent group of animals, we determined the impact of the high-fat diet on insulin sensitivity $(n=8)$. Table 2 presents all the mean plasma glucose levels, while interactions are depicted in Figures 5-7. Animals were fasted for 4 hours, injected with $0.75 \mathrm{U}$ of insulin and blood glucose was measured at 0,30 or 60 minutes following injection. As expected, high-fat-fed C57 mice were more susceptible than $\mathrm{A} / \mathrm{J}$ to developing fasting hyperglycemia (Figure 5). A two-way ANOVA (strain x diet) of the fasting glucose levels prior to the insulin challenge confirmed that blood glucose levels vary as a function of the strain $x$ diet interaction $(F(1,24)=2.72, p<0.0001)$. Furthermore, over the course of the 4 months C57 mice became less responsive to the insulin bolus injection indicating growing insulin resistance (Figure 6). A repeated measures three-way ANOVA (month $\mathrm{x}$ strain $\mathrm{x}$ time) within-subjects effect substantiates this claim $(\mathrm{F}(6,144)=4.71, \mathrm{p}<0.001)$. A significant repeated measures three-way ANOVA (time $\mathrm{x}$ diet $\mathrm{x}$ strain) within-subjects effect revealed that blood glucose levels of the high-fat-fed C57 mice also decreased more slowly in response to the insulin challenge $(\mathrm{F}(2,48)=9.60, \mathrm{p}<0.001)$ (Figure 7).

Table 2. Mean plasma glucose levels $(\mathrm{mmol} / \mathrm{L}) 0,30$ or 60 minutes following an insulin challenge over 4 months in $\mathrm{C} 57 \mathrm{BL} / 6 \mathrm{~J}$ and $\mathrm{A} / \mathrm{J}$ mice by diet groups.

\begin{tabular}{|c|c|c|c|c|c|c|c|c|c|c|c|c|}
\hline \multirow[t]{2}{*}{$\overline{\text { Strain }}$} & \multicolumn{3}{|c|}{1 month } & \multicolumn{3}{|c|}{2 months } & \multicolumn{3}{|c|}{3 months } & \multicolumn{3}{|c|}{4 months } \\
\hline & $\overline{0}$ & 30 & 60 & 0 & 30 & 60 & 0 & 30 & 60 & 0 & 30 & 60 \\
\hline \multicolumn{13}{|l|}{$\overline{\mathrm{A} / \mathrm{J}}$} \\
\hline $\mathrm{HH}$ & 5.91 & 4.86 & 5.09 & 7.25 & 5.24 & 4.08 & 6.68 & 5.21 & 4.20 & 7.25 & 5.75 & 4.60 \\
\hline LL & 6.00 & 3.60 & 3.51 & 6.78 & 3.90 & 3.40 & 6.70 & 4.14 & 2.93 & 6.76 & 4.24 & 3.00 \\
\hline \multicolumn{13}{|l|}{ C57 } \\
\hline $\mathrm{HH}$ & 10.10 & 7.10 & 5.39 & 12.23 & 8.44 & 7.86 & 11.81 & 8.08 & 7.74 & 11.06 & 8.16 & 8.95 \\
\hline $\mathrm{LL}$ & 7.88 & 4.95 & 3.94 & 7.80 & 4.89 & 4.56 & 7.58 & 5.51 & 5.53 & 8.73 & 6.44 & 5.74 \\
\hline
\end{tabular}




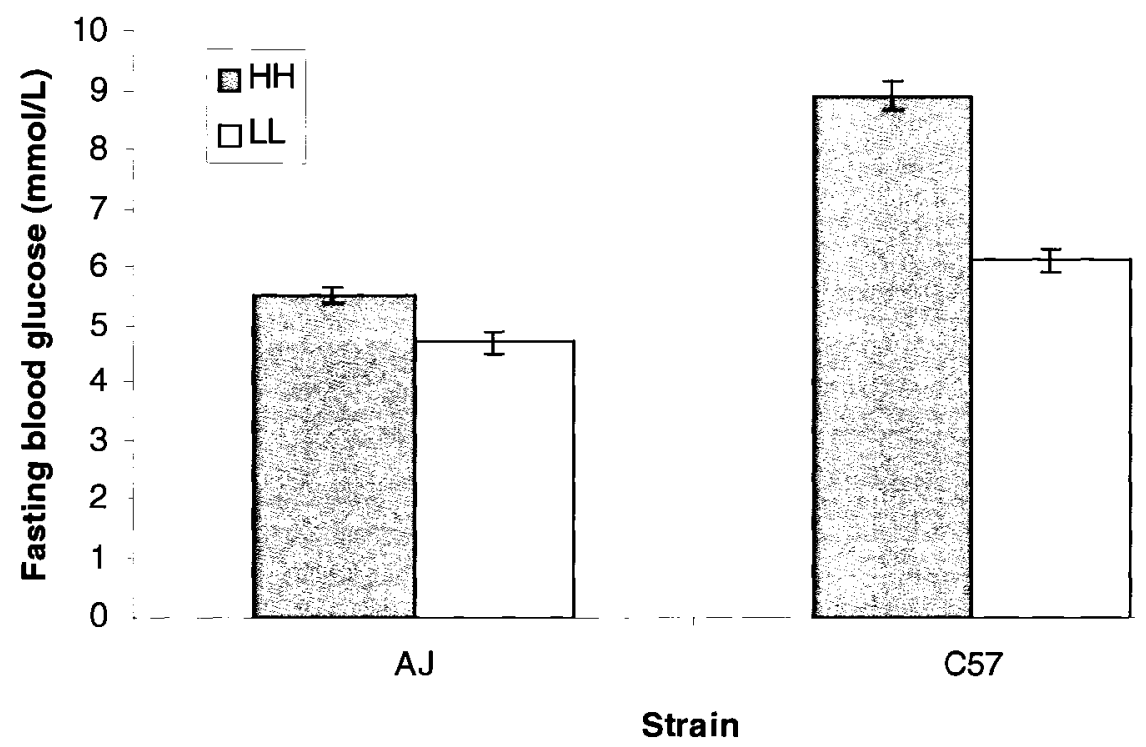

Figure 5. Fasting blood glucose levels collapsed across the four months. Blood glucose levels are significantly higher in C57BL/6J mice fed a high fat diet than they are in $\mathrm{A} / \mathrm{Js}$ or C57BL/6J mice fed a low-fat diet (two-way ANOVA (strain $\mathrm{x}$ diet) interaction, $\mathrm{F}(1,24)=2.72, \mathrm{p}<0.0001)$. HH=high-fat/high-sugar, $\mathrm{LL}=$ low-fat/low-sugar 


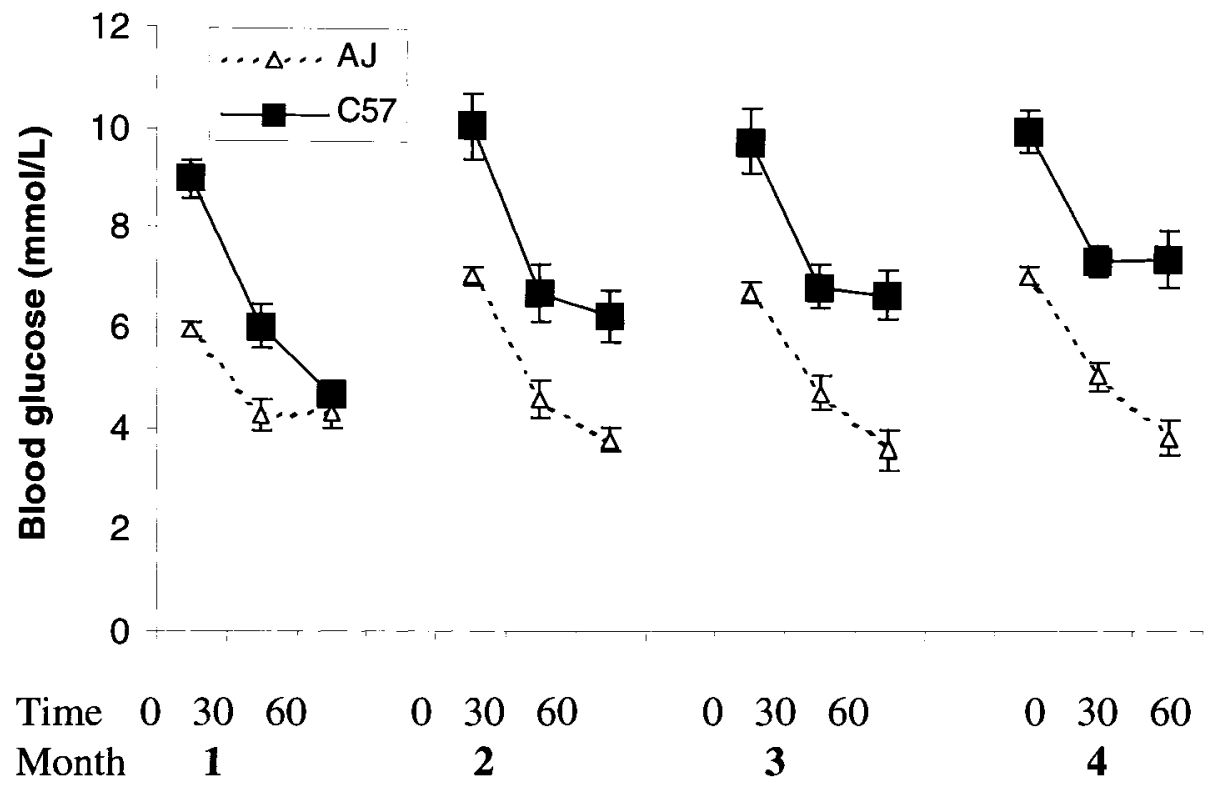

Figure 6. Graph of changes in blood glucose levels in the two strains at the 0,30 or 60 minutes following the insulin injection over the 4 months. C57BL/6J mice showed higher levels of blood glucose and decreased sensitivity to insulin over the four months when compared to A/Js ( repeated measures three-way ANOVA (month $\mathrm{x}$ time $\mathrm{x}$ strain) withinsubjects interaction $(F(6,144)=4.71, \mathrm{p}<0.001))$. 


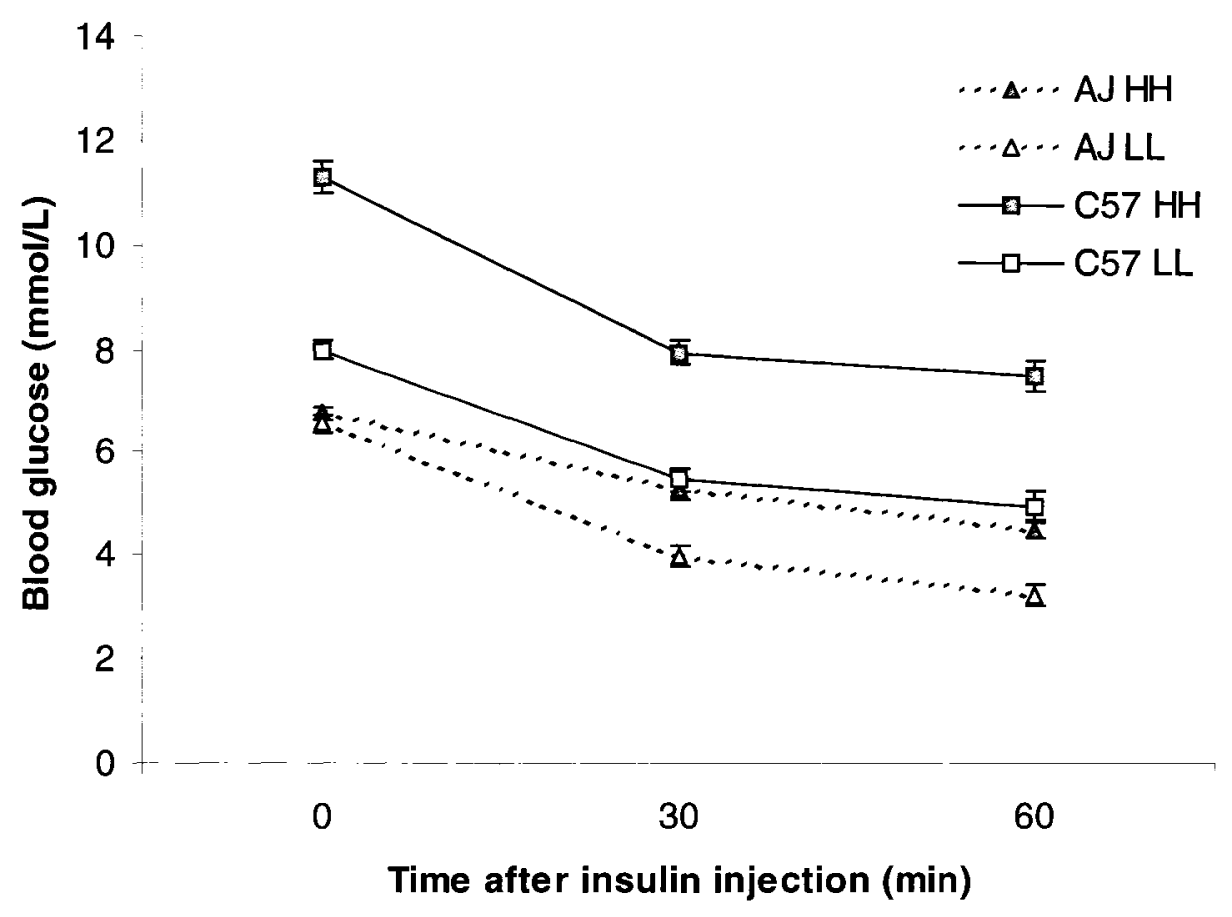

Figure 7. Changes in blood glucose levels in A/J and C57 mice fed high-fat or low-fat diets at 0,30 and 60 minutes following the insulin challenge. C57BL/6J mice fed a highfat diet exhibited fasting hyperglycemia and, as a result, a decreased response to the insulin challenge (repeated measures three-way ANOVA within-subjects (time $\mathrm{x}$ diet $\mathrm{x}$ strain) interaction $(F(2,48)=9.60, \mathrm{p}<0.001))$. HH=high-fat/high-sugar, LL=low-fat/lowsugar 


\subsection{Experiment 1: Behavioral measurements for T2D mouse model}

Behavioral measurements included memory assessments using Y-maze, anxiety-like behavior assessed with the elevated plus maze and the open field and depressive-like behavior in the forced swim test. Locomotor activity, time spent in each area of the apparatus and latency to enter an area were recorded for the Y-maze, elevated plus maze and open field test. Latency to float and swim speeds were recorded for the forced swim test. Generally, measures of anxiety in these tests are based on either time spent in anxiogenic areas of the apparatus, or latency to first enter these same areas. Given that latency may be confounded by alterations in overall locomotion, and that differences in locomotion may be anticipated due to differential obesity between groups, overall locomotion was measured in each test. The same animals A/J or C57 mice fed high-fat or low-fat chow ( $\mathrm{n}=10$ per group) were used for all behavioral testing. An analysis of changes in body weight revealed similar results to those described in experiment one. Specifically, diabetes-prone C57BL/6J mice gained significantly more weight than diabetes resistant mice A/J when fed a high-fat/high-sugar diet, as well as low-fat fed groups, $(\mathrm{F}(1,36)=28.87, \mathrm{p}<0.001$, Figure 8$)$. 
Forced swim

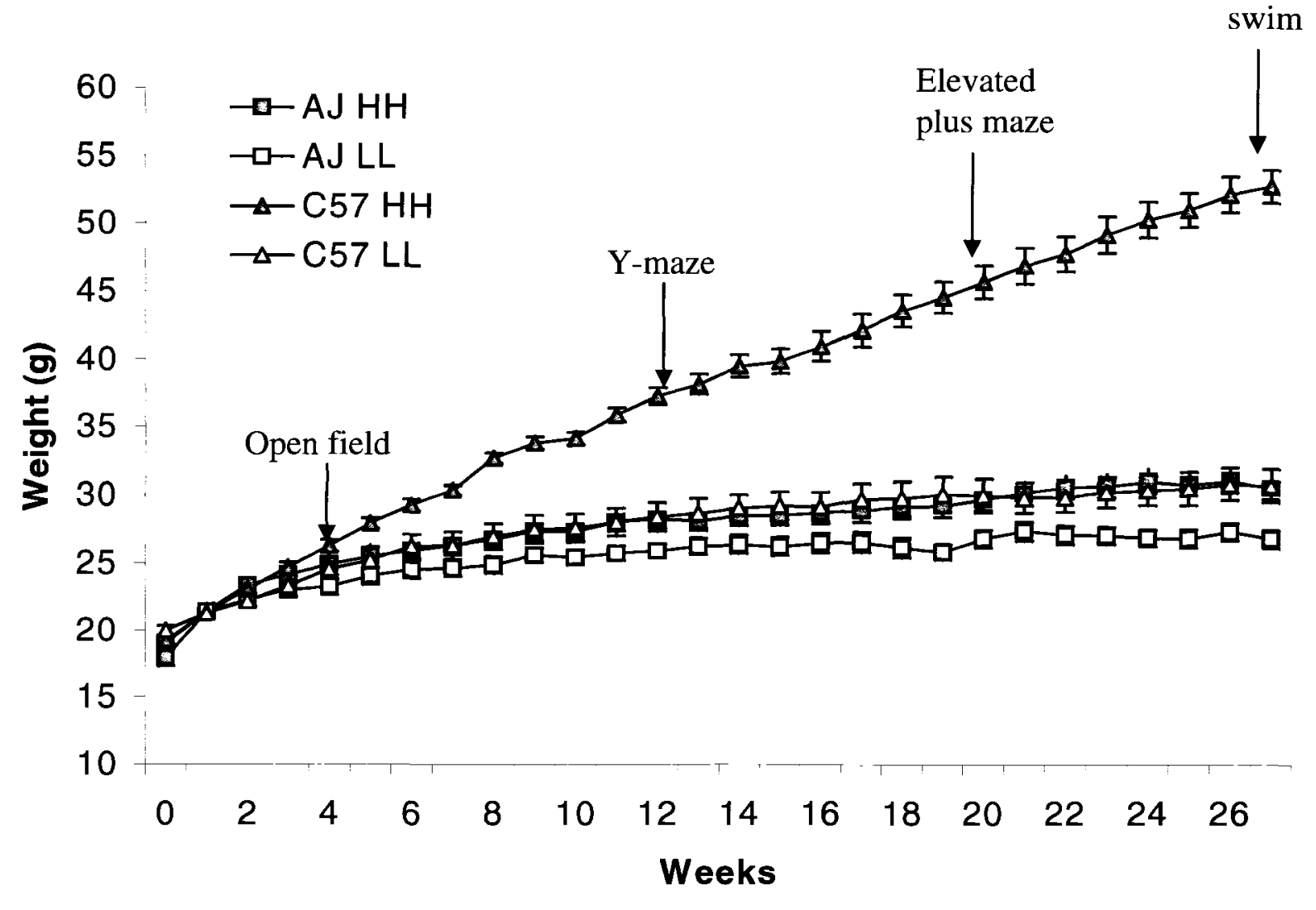

Figure 8. Changes in weight for animals used for cognitive experiments. Diabetes-prone C57BL/6J mice gain significantly more weight than diabetes resistant mice A/J when fed a high-fat/high-sugar diet, as well as low-fat fed groups. $(F(1,36)=28.87, \mathrm{p}<0.001)$. $\mathrm{HH}=$ high-fat/high-sugar, LL=low-fat/low-sugar 
Y-maze

The Y-maze was used to assess spatial and working memory in a two trial procedure (adapted from Bluthe et al., 2005). It consists of an acquisition phase during which the mice are allowed to freely explore two arms of the maze, while one arm is blocked by a plastic door. During the retrieval phase mice are allowed to explore all arms of the maze. In this paradigm, mice with normal spatial memory spend more time in the novel arm (previously blocked by the plastic door) than mice with impaired memory, i.e. they can discriminate between the novel and the familiar arms, while mice with impaired spatial memory cannot (Bluthe et al., 2005). Furthermore, mice with intact working memory tend to spontaneously alternate visits between the three arms and will explore the least recently visited arm, while mice with impaired working memory have difficulty remembering which arm they have last visited, and thus will show a decrease in spontaneous alternation behavior (Weitrzych et al., 2005).

The Y-maze analysis included an assessment of locomotor activity, time spent in the novel arm (discrimination) and spontaneous alternation. To ensure that exploration patterns during the acquisition phase were similar for the two arms of the Y-maze, exploratory behavior in the two arms was analyzed separately. While there were significant strain differences in locomotor activity in the two familiar arms (Arm 2 and Arm 3) (Arm $2 \mathrm{~F}(1,33)=29.24, \mathrm{p}<0.001$, Arm $3 \mathrm{~F}(1,33)=22.74, \mathrm{p}<0.001)$, the diet had no effect on locomotor activity (Figure 9). There was a significant main effect of strain $(\mathrm{F}(1,33)=135.14, \mathrm{p}<0.0001)$ on time spent in the novel arm versus time spent in the familiar zones during the testing trial, suggesting that $\mathrm{C} 57 \mathrm{BL} / 6 \mathrm{~J}$ mice have a preference for the novel arm, whereas $\mathrm{A} / \mathrm{J}$ s avoid the novel arm (Figure 10). While this finding would 
normally be interpreted as an avoidance of novel environments and therefore evidence of increased anxiety-like behavior, in this case the avoidance of the $\mathrm{A} / \mathrm{J}$ mice of the novel arm was primarily driven by the their reduced locomotor activity. Since the mice were randomly started in either of the familiar arms, the A/J mice tended to spend the majority of their time in the starting arm and not explore the other arms. The strain $\mathrm{x}$ diet interaction and main effect of diet were not significant $(\mathrm{p}=0.50$ and $\mathrm{p}=0.38$, respectively), suggesting locomotor activity did not vary as a function of the interaction between the strain and the diet, nor did the diet have an impact on locomotor activity. Similarly, when the discrimination index was calculated, there was a significant main effect of strain $(\mathrm{F}(1,33)=75.43, \mathrm{p}<0.0001)$, but no main effect of diet or strain $\mathrm{x}$ diet interaction (Figure 11). This would suggest that $\mathrm{A} / \mathrm{J}$ mice are better at discriminating between the novel and the familiar arms than are C57 mice. However, given the fact that $\mathrm{A} / \mathrm{J}$ mice spent the majority of their time in the starting arm during the retrieval phase and did not explore any of the other arms, it would be misleading to believe that they show increased discrimination. Their increased discrimination index is an artifact of their decreased locomotor activity.

Spontaneous alternations are calculated by counting the number of alternate arm visits. Since A/J mice spent the majority of their time in the starting arm, and did not visit other arms, their spontaneous alternation data yielded null values and as a result, only the spontaneous alternation data for the C57BL/6J mice were analyzed. Two of the high-fat fed C57BL/6J mice also spent the majority of their time in the starting arm during the retrieval phase, and as a result they also had null spontaneous alternation values. Since their values were significantly altering the variability of the dataset, they were considered 
outliers and were dropped from the analysis. A t-test for independent groups revealed no significant effect of diet $(\mathrm{t}(15)=1.553, \mathrm{p}=0.141)$ (Figure 12).

In conclusion, the Y-maze test did not reveal any diet effects on spatial memory, and the strain effects are confounded by the decreased locomotor activity of $\mathrm{A} / \mathrm{J}$ mice. Similarly diet did not affect working memory measured by the spontaneous alternation test in $\mathrm{C} 57$ mice and was not available in $\mathrm{A} / \mathrm{J}$ mice who did not exhibit spontaneous alternation behavior. 


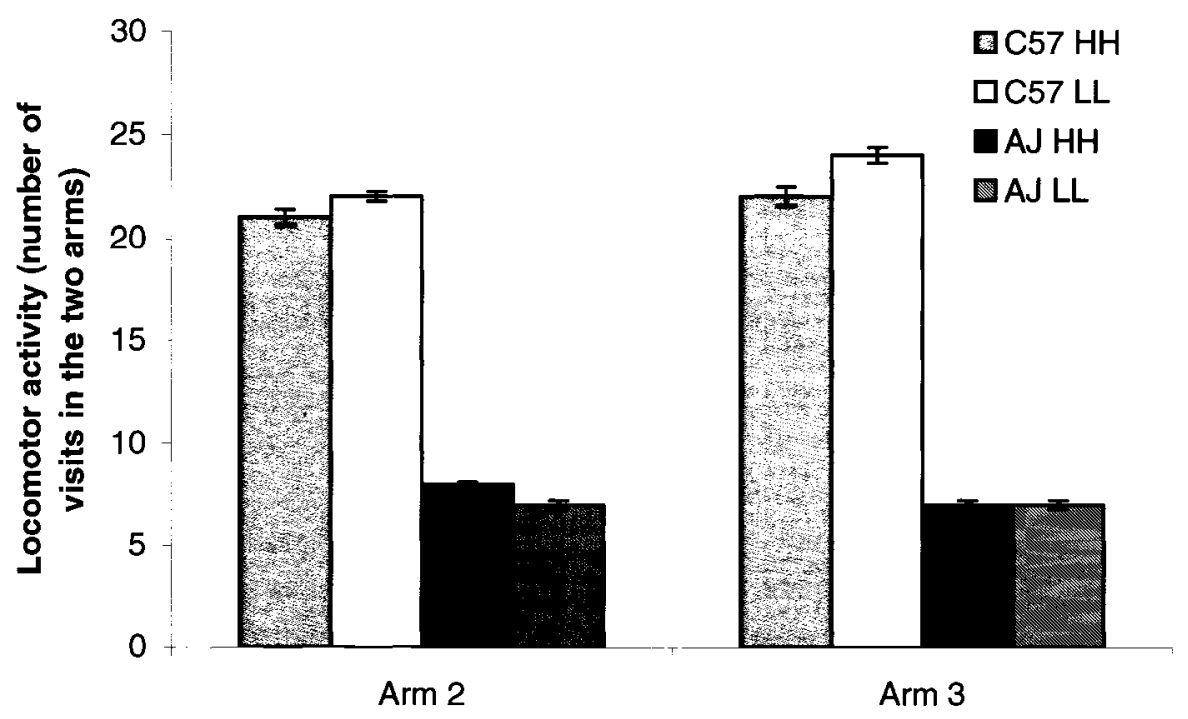

Figure 9. Locomotor activity showing significant differences in the number of visits $\mathrm{A} / \mathrm{J}$ and $\mathrm{C} 57 \mathrm{BL} / 6 \mathrm{~J}$ made in the two arms during the acquisition phase (zone $2 \mathrm{~F}(1,33)=29.24$, p $<0.001$, zone $3 \mathrm{~F}(1,33)=22.74)$. HH=high-fat/high-sugar, LL=low-fat/low-sugar 

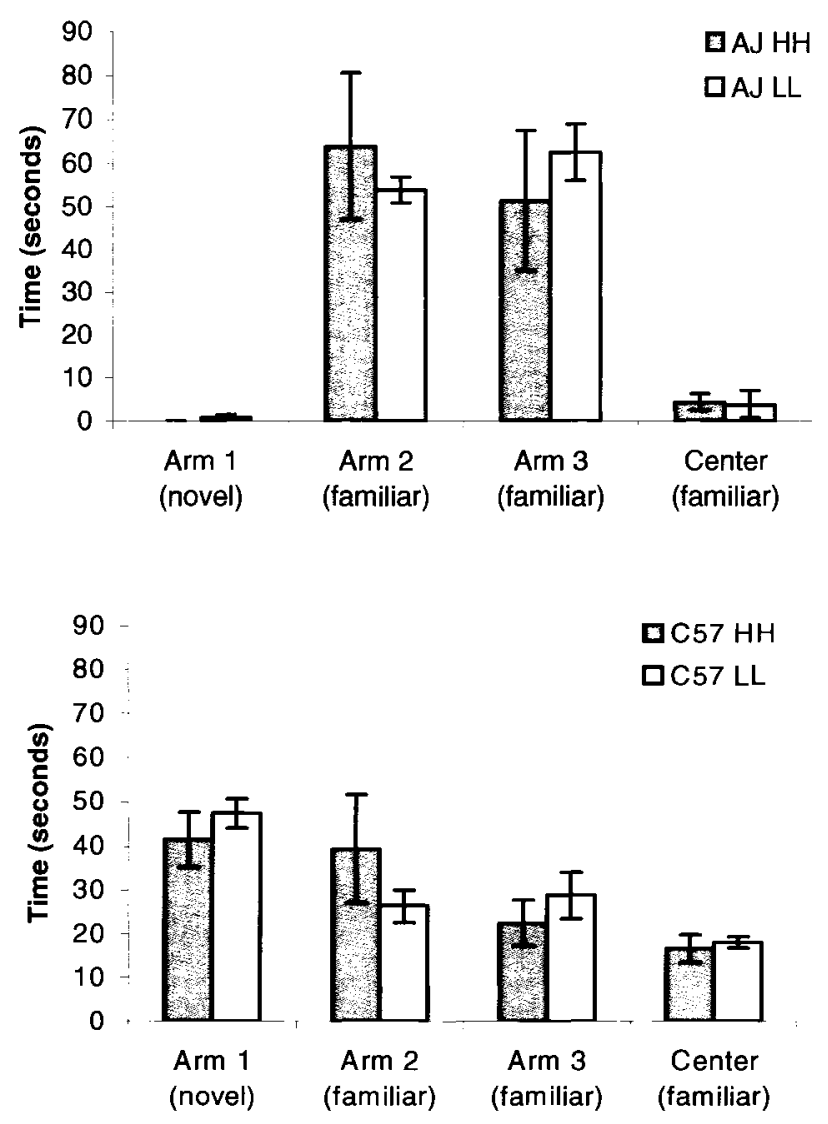

Figure 10. Time spent in the novel versus familiar arms of the $\mathrm{Y}$-maze. Data for $\mathrm{A} / \mathrm{J}$ are on top, with data for C57 on the bottom. C57BL/6J mice showed a preference for the novel arm, while $A / J$ mice showed avoidance of the novel arm $(F(1,33)=135.14$, $\mathrm{p}<0.0001$ ). HH=high-fat/high-sugar, LL=low-fat/low-sugar 


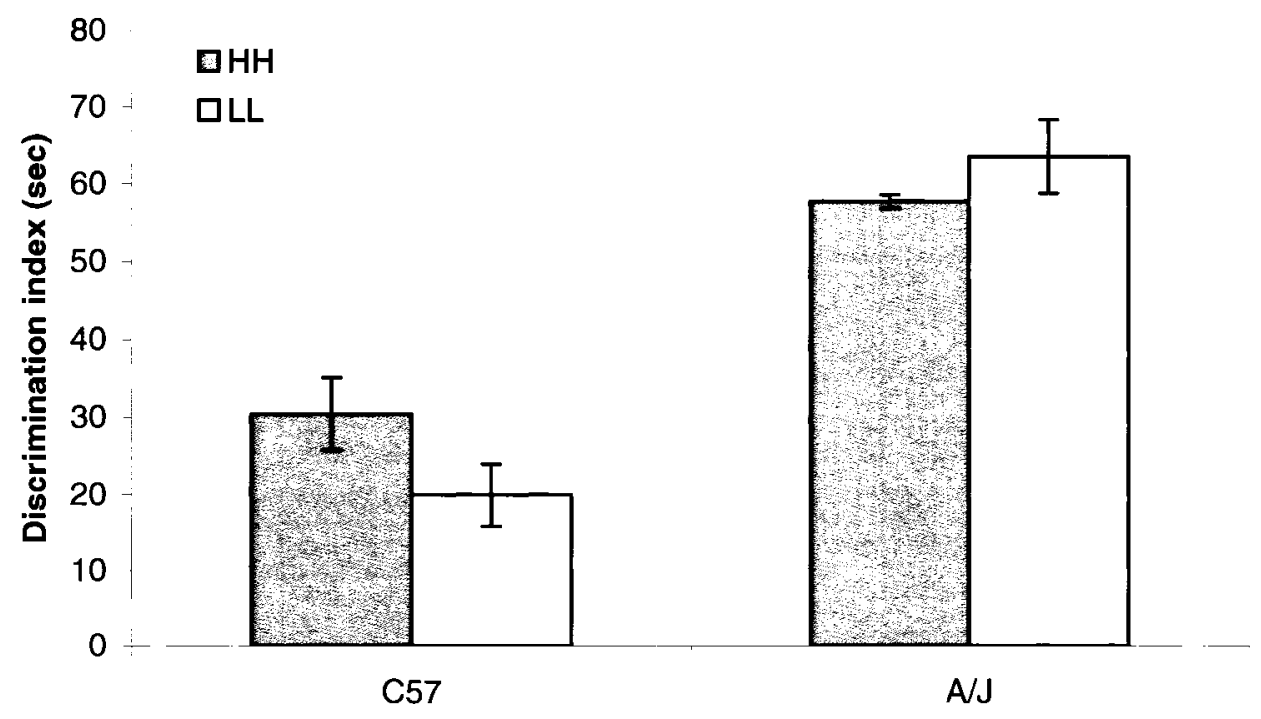

Figure 11. Discrimination index in the $\mathrm{Y}$-maze. Discrimination index is expressed as the absolute value of the surplus or detriment of time spent in the novel arm during the second session compared to the other 2 familiar arms of the Y-maze. The index varies between 0 (no discrimination) and 60 seconds (full avoidance or preference of the novel arm). A/J mice seemed to discriminate better than C57 mice between the novel and the familiar arms $(\mathrm{F}(1,33)=75.43, \mathrm{p}<0.0001)$. $\mathrm{HH}=$ high-fat/high-sugar, LL=low-fat/lowsugar

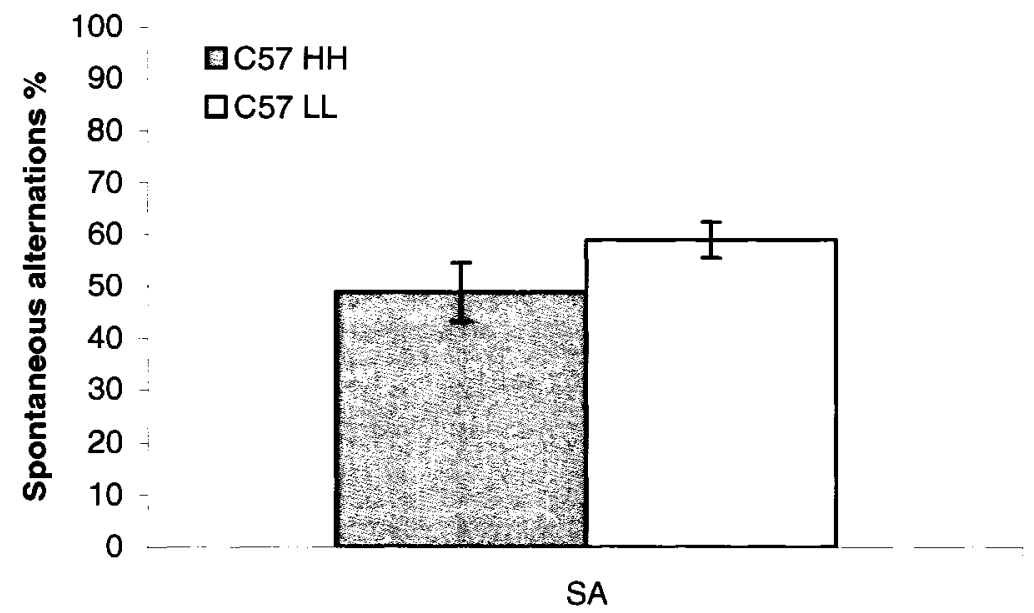

Figure 12. Spontaneous alternations in the $Y$-maze show a trend for the high-fat fed C57BL/6J mice animals to make less spontaneous alternations, however this trend did not reach significance. $\mathrm{HH}=$ high-fat/high-sugar, $\mathrm{LL}=$ low-fat/low-sugar 


\section{Open field}

The open field test was used to assess anxiety-like behavior, and included measures of the percentage of time spent in the corners, center and periphery of the apparatus, latency to enter the center and the speed of exploration. It is based on the natural tendency of mice to avoid open spaces in their exploration since they could be potentially dangerous to their survival (Choleris et al., 2001; Holmes et al., 2001). As a result, anxious mice will avoid the center of the open field apparatus and tend to spend the majority of their time in the corners and the periphery close to the walls of the open field.

A three-way MANOVA (strain $\mathrm{x}$ diet $\mathrm{x}$ area of the open field) revealed a significant main effect of strain on percentage of time spent in the corners $(F(1,35)=64.6$, $\mathrm{p}<0.0001)$, center $(\mathrm{F}(1,35)=21.8, \mathrm{p}<0.0001)$ and the periphery $(\mathrm{F}(1,35)=58.3, \mathrm{p}<0.0001)$. Furthermore, a two-way ANOVA (strain x diet) of latency to enter the center of the open field (Figure 13 B) revealed a significant main effect of strain $(F(1,36)=329.62, p<0.01)$. Together, the percentage of time spent in the different areas of the apparatus and latency to enter center suggest that strain, but not diet influenced anxiety-like behavior (Figure 13 A and C). C57 mice spent significantly more time in the periphery and the center of the apparatus compared to $\mathrm{A} / \mathrm{Js}$ who spent the majority of their time in the starting corner of the open field. Furthermore, A/J mice had increased latency to enter the center of the apparatus. While it is tempting to interpret this as an increased anxiety response in $\mathrm{A} / \mathrm{Js}$, given their reduced speed of exploration, it is simply an indication of their reduced locomotor activity. Indeed, analysis of the speed of exploration of the open field revealed that C57 mice had increased speed of exploration compared to A/J mice, and that the high-fat diet led to a decreased speed of exploration in C57 mice. Levene's test of 
homogeneity of variance revealed that the variances for the speed of exploration were not equal (Levene's statistic $=20.52, \mathrm{df}_{1}=3, \mathrm{df}_{2}=35, \mathrm{p}<0.001$ ). Log transformation of the data reduced the group difference in variance (Levene's statistic $=1.09, \mathrm{df}_{1}=3, \mathrm{df}_{2}=35$, $\mathrm{p}=0.365)$. Subsequent ANOVA revealed a significant strain $\mathrm{x}$ diet interaction $(\mathrm{F}(1,35)=$ 5.91, $\left.\mathrm{p}<0.05, \eta^{2}=0.15\right)$. The main effect of strain was significant, $F(1,35)=310.16$, $\left.\mathrm{p}<0.0001, \eta^{2}=0.90\right)$, while the main effect of diet was not significant $(\mathrm{F}(1,35)=0.0198$, $\mathrm{p}=0.66, \eta^{2}=0.01$ ). The interaction suggests that $\mathrm{C} 57$ mice were faster than $\mathrm{A} / \mathrm{J}$ mice, and that they were affected by the high-fat diet, which lead to a slower speed of locomotion in the C57 HH mice. The effect size associated with the strain $\left(\eta^{2}=0.90\right)$ was larger than the interaction effect size $\left(\eta^{2}=0.15\right)$, suggesting that the interaction effect was driven by the strain effect (Figure 13 D). 
A

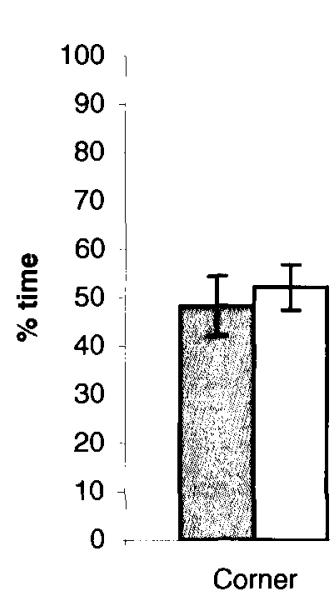

$\mathbf{C}$

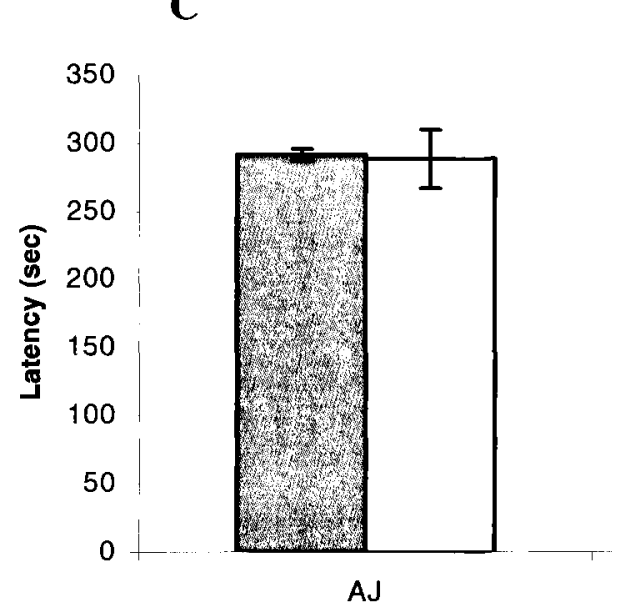

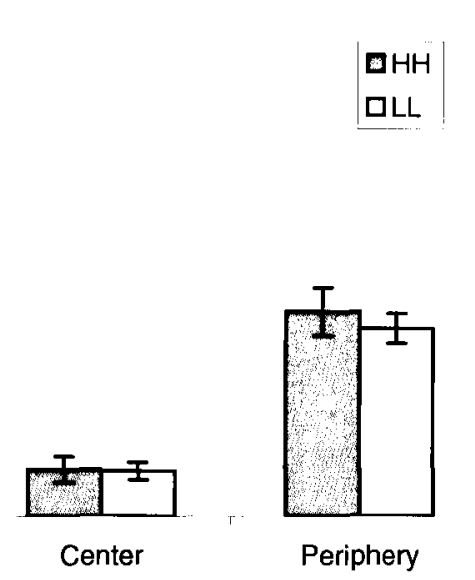

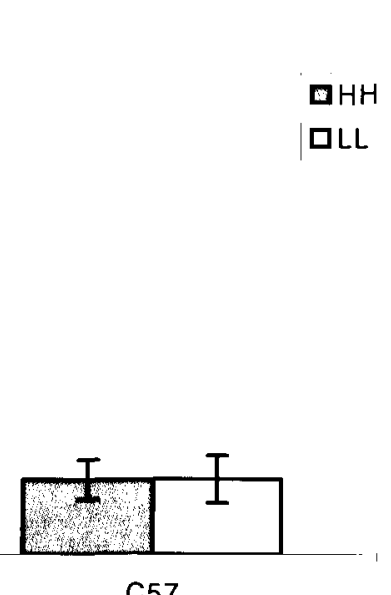

B

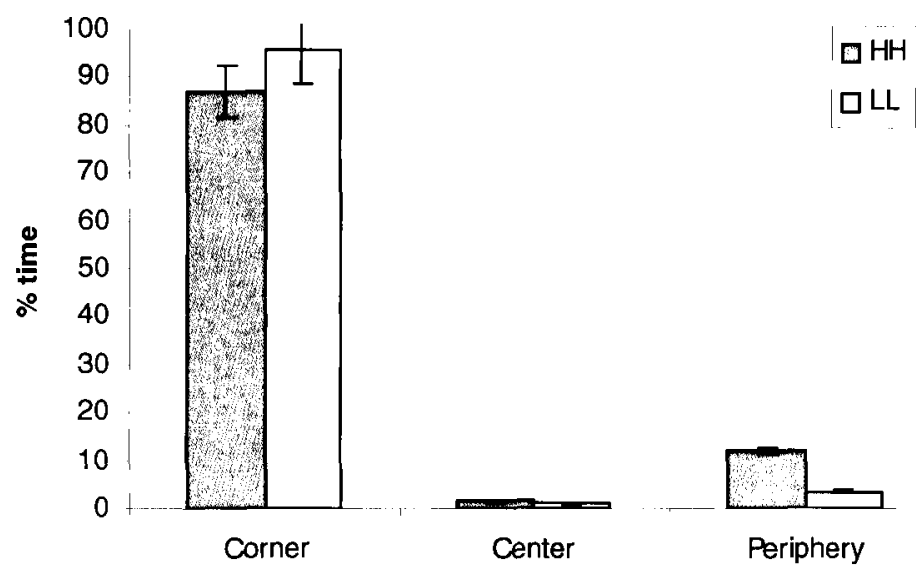

5. D
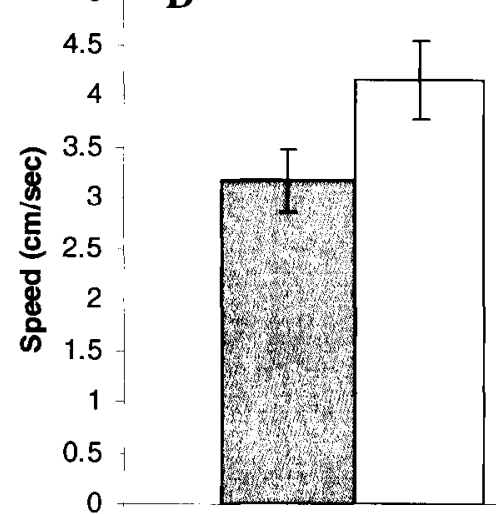

C57 $\square \mathrm{HH}$

$\square \mathrm{LL}$

Figure 13. Open field. Percentage of time spent in each of the 3 areas of the open field during the 5 minutes test period for C57 (A) and A/J (B) mice. Panel C depicts latency to explore all four corners, the center and the periphery. Panel D

represents mean speed during the trial. All data are mean \pm standard error. HH=high-fat/high-sugar, LL=low-fat/low-sugar 


\section{Elevated plus maze}

The elevated plus maze investigates the balance between the natural exploratory tendency of mice and their fear of exposed spaces. Decreased activity in the open arms of the elevated plus maze would suggest increased anxiety-like behavior (Hogg, 1996). Results of the elevated plus maze suggest that C57 mice tend to explore the open arms more than $\mathrm{A} / \mathrm{J}$ mice and that diet does not influence the behavior of either strain. However, this could be a result of the decreased locomotor activity of $\mathrm{A} / \mathrm{J}$ mice rather than an increased anxiety response.

The analysis of speed revealed a significant strain $\mathrm{x}$ diet interaction $\left(F(1,35)=12.17, p<0.01, \eta^{2}=0.25\right)$, a significant main effect of strain $(F(1,35)=137.44$, $\left.p<0.01, \eta^{2}=0.79\right)$, and a significant main effect of diet $\left(F(1,35)=4.41, p<0.05, \eta^{2}=0.11\right)$. The interaction suggests that $\mathrm{C} 57$ mice were faster than $\mathrm{A} / \mathrm{J}$ mice, and that they were affected by the high-fat diet, which lead to a slower speed of locomotion in the C57 HH mice. The effect size associated with the strain $\left(\eta^{2}=0.79\right)$ was larger than the interaction effect size $\left(\eta^{2}=0.25\right)$, suggesting that the interaction effect was driven by the strain effect (Figure $14 \mathrm{D}$ ). Furthermore, the decreased speed of exploration of $\mathrm{A} / \mathrm{J}$ mice suggest that decreased time spent in the open arms and the increased latency to enter the open arms may simply be a result of the decreased locomotor activity of $\mathrm{A} / \mathrm{J} \mathrm{s}$.

A two-way ANOVA revealed a significant main effect of strain $(F(1,36)=21.43$, $\mathrm{p}<0.01$ ) for percentage of time spent in the open arms, suggesting that $\mathrm{A} / \mathrm{J}$ mice are more fearful of the open arms than are C57 mice, but no significant main effect of diet or diet x strain interaction (Figure 14 A, B). Similarly, A/J mice showed increased latency to enter the open arms of the elevated plus maze compared to C57 mice as suggested by a 
significant main effect of strain in latency to enter the open arms $(F(1,30)=9.74, p<0.01)$ (Figure $14 \mathrm{C}$ ).

To summarize, the data suggests that diet does not affect anxiety behavior in the elevated-plus maze, and while $\mathrm{A} / \mathrm{J}$ mice appear more fearful of the open arms of the apparatus through their increased latency and decreased time spent in the exposed areas, this strain effect could simply be a result of the decreased locomotor activity exhibited by $\mathrm{A} / \mathrm{J} s$. 
A

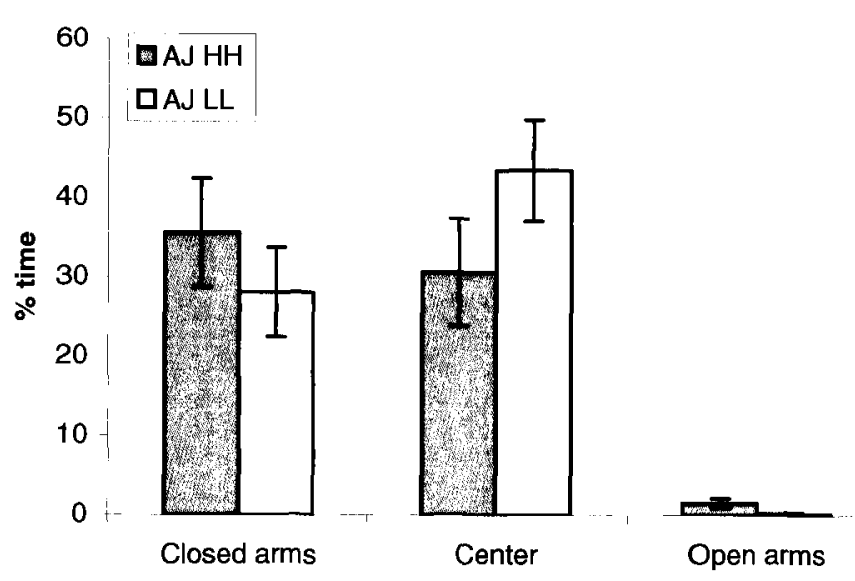

C

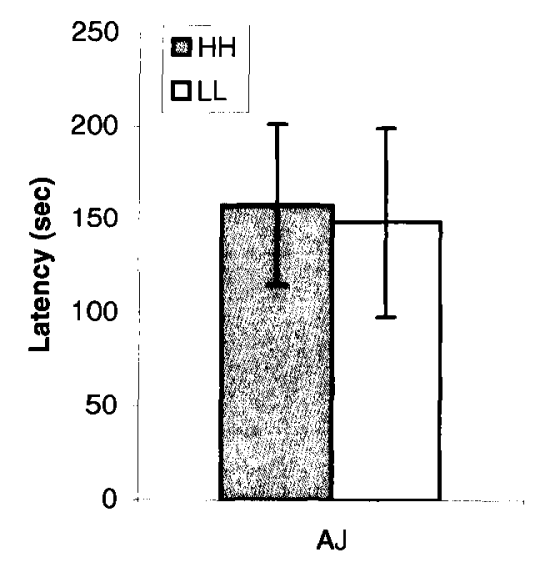

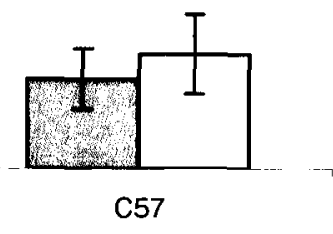

B

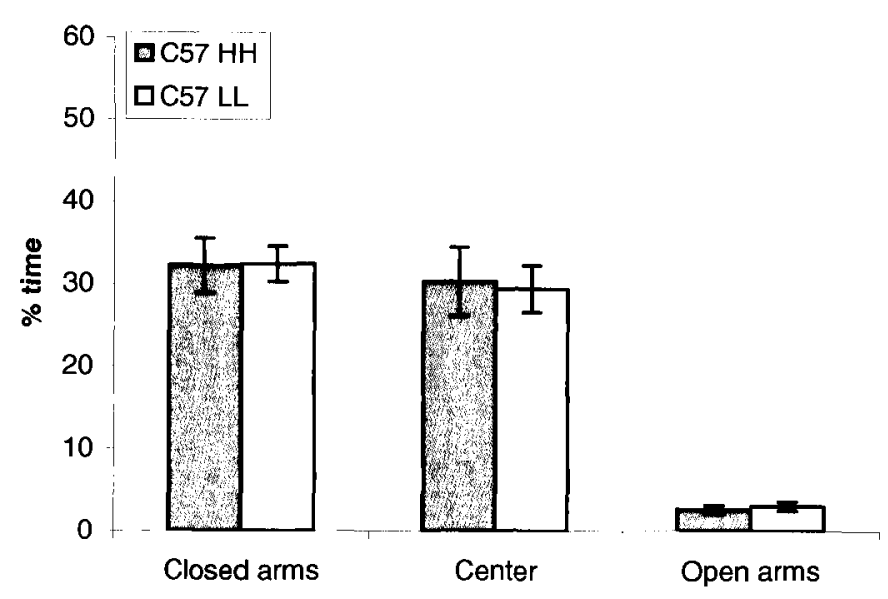

D

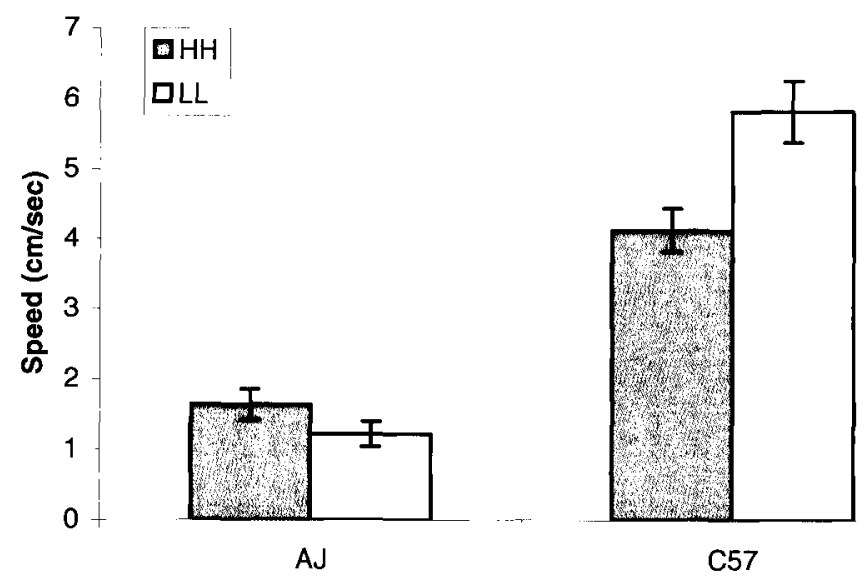

Figure 14. Elevated plus maze. Percentage of time spent in each of the 3 areas of the elevated plus maze during the 5 minutes test period for C57 (A) and A/J mice (B). Latency to explore the open arms of the maze (C). Speed of exploration (D). All data are mean \pm standard error. $\mathrm{HH}=$ high-fat/high-sugar, $\mathrm{LL}=$ low-fat/low-sugar 


\section{Forced swim}

The forced swim test, also known as the behavioral despair test is used to assess depression-like behavior in rodents. The test is based on the tendency of mice to become immobile in a cylinder filled with water following initial escape-oriented movements. Mice exhibiting depressed-like behavior tend to spend more time immobile and make less escape movements (Cryan \& Mombereau, 2004). In this study both distance swum and floating time (immobility) were assessed. Distance swum was assessed in order to determine locomotor activity, while floating time was assessed in order to determine depressive-like behavior.

Analysis of floating time (Figure $15 \mathrm{~A}$ ) revealed that high-fat-fed animals had increased floating time irrespective of strain. Levene's test of homogeneity of variance revealed that the variances for floating time were not equal (Levene's statistic $=3.04, \mathrm{df}_{1}$ $\left.=3, \mathrm{df}_{2}=36, \mathrm{p}<0.05\right)$. Log transformations of the data reduced the group differences in variance (Levene's statistic $=2.55, \mathrm{df}_{1}=3, \mathrm{df}_{2}=36, \mathrm{p}=0.07$ ). Subsequent ANOVA revealed a non-significant strain $\mathrm{x}$ diet interaction $(\mathrm{F}(1,36)=0.006, \mathrm{p}>0.05)$. The main effect of strain was not significant, $(F(1,36)=1.44$, $p>0.05)$, however the main effect of diet was significant, $(\mathrm{F}(1,36)=8.207, \mathrm{p}<0.05)$. This suggests that diet affected both strains equally, with high-fat fed mice exhibiting longer floating behavior. This was unexpected because differences in floating behavior were assumed to be due to the susceptibility or resistance to diabetes and/or obesity. The results suggest this is not the case since both diabetes prone and diabetes resistant high-fat-fed mice exhibit similar behavior in the forced swim test. 
Analysis of the distance swum data (Figure 15 B) revealed that C57 mice swam longer than $\mathrm{A} / \mathrm{J}$ mice and that high-fat-fed animals swam shorter distances. Levene's test of homogeneity of variance revealed that the variances for distance swam were not equal (Levene's statistic $=3.36, \mathrm{df}_{1}=3, \mathrm{df}_{2}=36, \mathrm{p}<0.05$ ). Log transformation of the data reduced the group difference in variance (Levene's statistic $=.668, \mathrm{df}_{1}=3, \mathrm{df}_{2}=36$, $\mathrm{p}=0.56)$. Subsequent ANOVA revealed a non-significant strain $\mathrm{x}$ diet interaction $(\mathrm{F}(1,36)$ $=0.135, \mathrm{p}>0.05)$. The main effect of strain was significant, $\mathrm{F}(1,36)=22.66, \mathrm{p}<0.01)$, as was the main effect of diet, $F(1,36)=16.90, p<0.01$. This suggests that strain had an impact on distance swam, with $\mathrm{A} / \mathrm{Js}$ swimming a shorter distance than C57s (1781.08 \pm 552.62 vs. $2859.46 \pm 1083.94$ ) and that diet had an impact on both strains, with animals fed a high-fat diet swimming a shorter distance than the low-fat fed animals (1872.14 \pm 669.12 vs. $2768.40 \pm 1088.58$ ). It is tempting to conclude that high-fat animals showed increased floating time and swam shorter distances due to their increased weight gain, however, A/J mice did not gain as much weight as C57 mice when fed a high-fat diet. Thus, the increased depressive-like behavior manifested by the high-fat-fed animals cannot be explained by the development of diabetes, nor can it be explained by increased weight gain of the animals. 

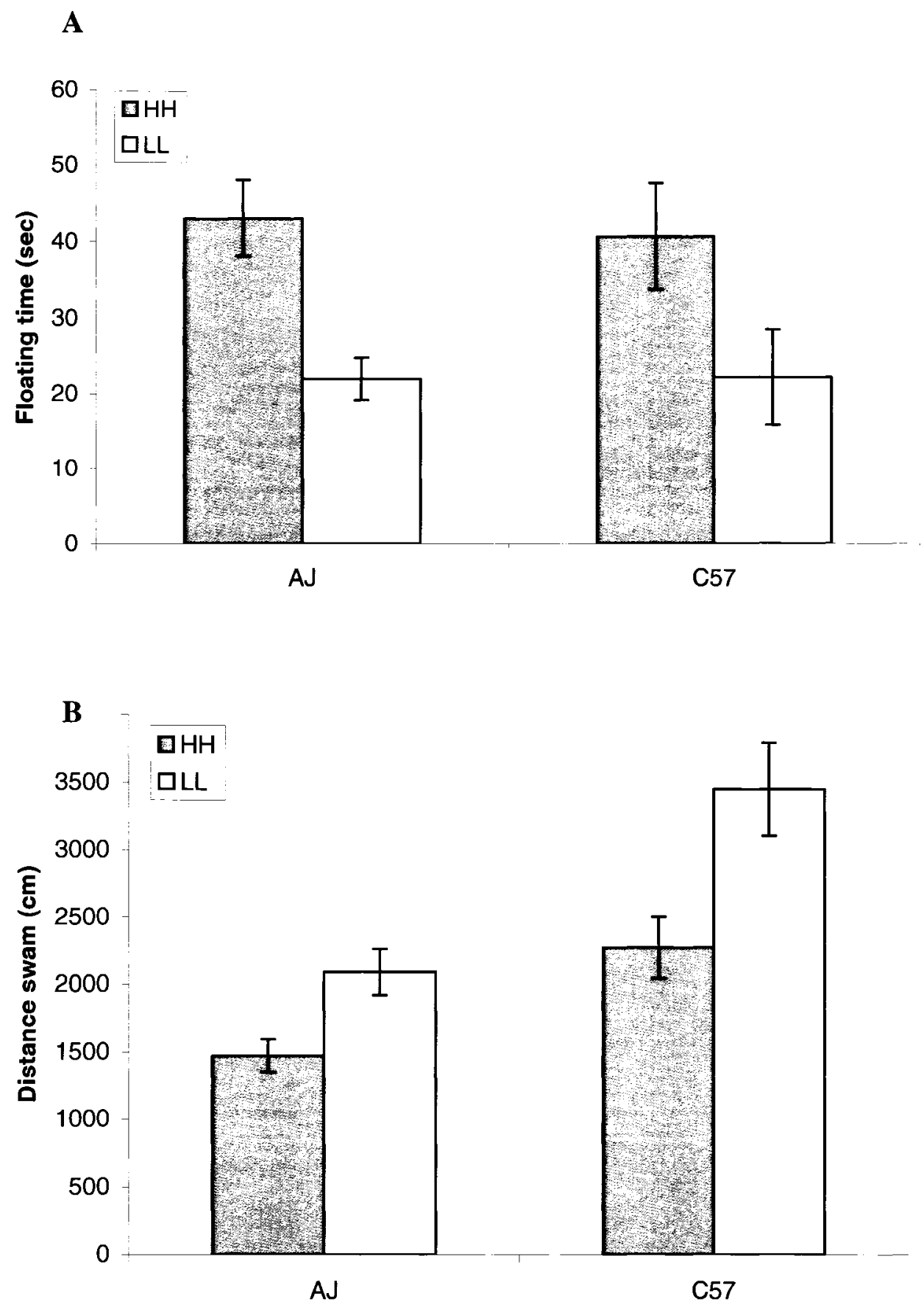

Figure 15. Forced swim test. A. Floating time during the 3 minutes test period.

B. Distance swam during the test. All data are mean \pm standard error.

$\mathrm{HH}=$ high-fat/high-sugar, LL=low-fat/low-sugar 


\subsection{Experiment 2: Neurogenesis impairments in T2D}

The proliferative stage of neurogenesis was assessed using BrdU labeling in the dentate gyrus in order to determine if the high-fat fed diabetes-prone mice would show decreased cellular proliferation (Figure 16). Twenty A/J and 20 C57 mice were fed a high-fat/highsugar or a low-fat/low-sugar diet for 3 months. A significant strain $\mathrm{x}$ diet interaction in weight $(F(1,16)=6.82, p<0.05$, Figure 17), suggests that after 3 months only C57 mice gained weight in response to the high-fat diet. In a pilot study tissue from 20 of 40 animals was stained for BrdU. As Figure 18 shows, a two-way (strain x diet) ANOVA results revealed no significant strain $\mathrm{x}$ diet interaction $(F(1,16)=3.81, \mathrm{p}>0.05)$, no significant diet main effects $(F(1,16)=3.18, p>0.05)$, but a significant strain effect $(\mathrm{F}(1,16)=26.83, \mathrm{p}<0.05)$, with $\mathrm{A} / \mathrm{J}$ s showing reduced proliferation $(81.40 \pm 21.92 \mathrm{vs}$. $130.50 \pm 25.83$ ). This suggests that $\mathrm{C} 57$ mice show increased proliferation compared to $\mathrm{A} / \mathrm{Js}$, but that diet does not significantly affect hippocampal proliferation in the diabetesprone mice. 

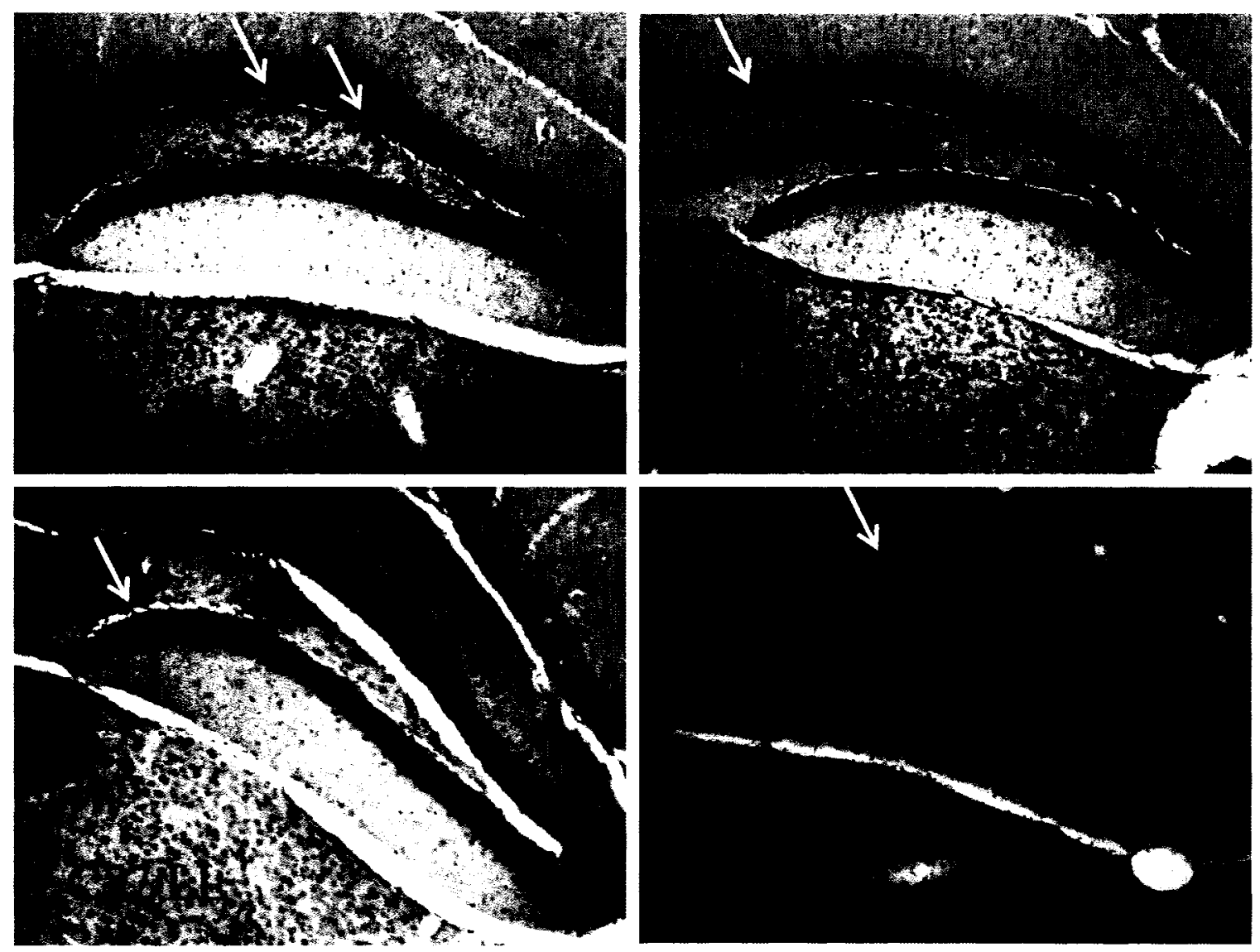

Figure 16. BrdU labeled cells in the dentate gyrus. Representative micrographs of BrdU immunodetection in the subgranular layer of the dentate gyrus in high-fat or low-fat fed C57 and A/J mice. A single BrdU injection was administered 24 hours before perfusion. The arrows indicate BrdU positive cells. $\mathrm{HH}=$ high-fat/high-sugar, $\mathrm{LL}=$ low-fat/low-sugar 


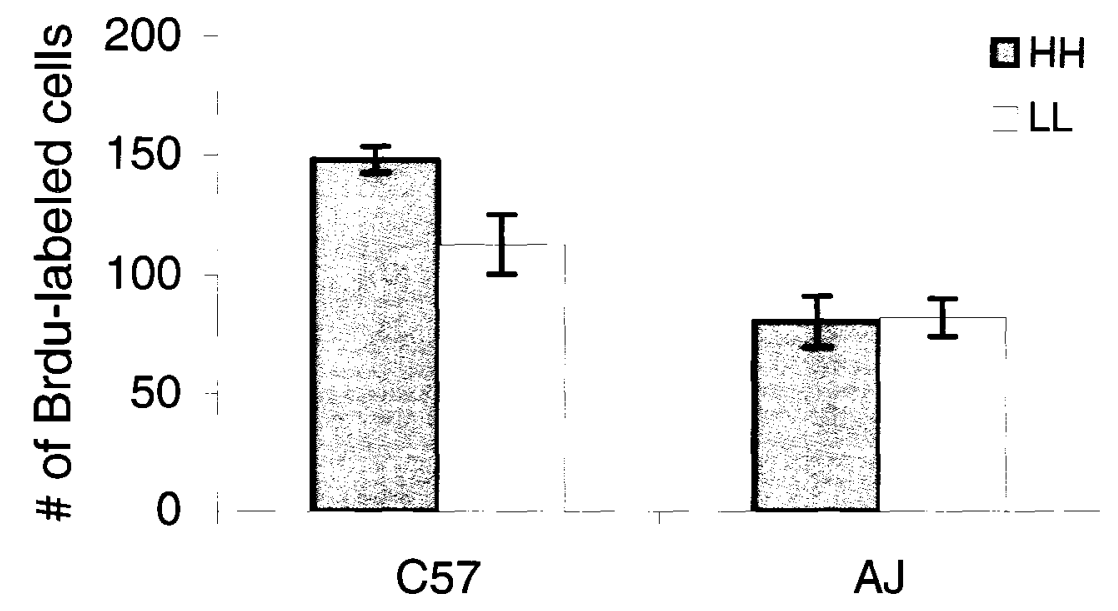

Figure 17. Number of BrdU labeled cells in the subgranular layer of the dentate gyrus. C57 mice show increased proliferation compared to AJ mice $(\mathrm{F}(1,16)=26.83, \mathrm{p}<0.05)$. There is a non-significant trend towards increased proliferation in high-fat-fed C57 mice. All data are mean \pm standard error. $\mathrm{HH}=$ high-fat/high-sugar, LL=low-fat/low-sugar

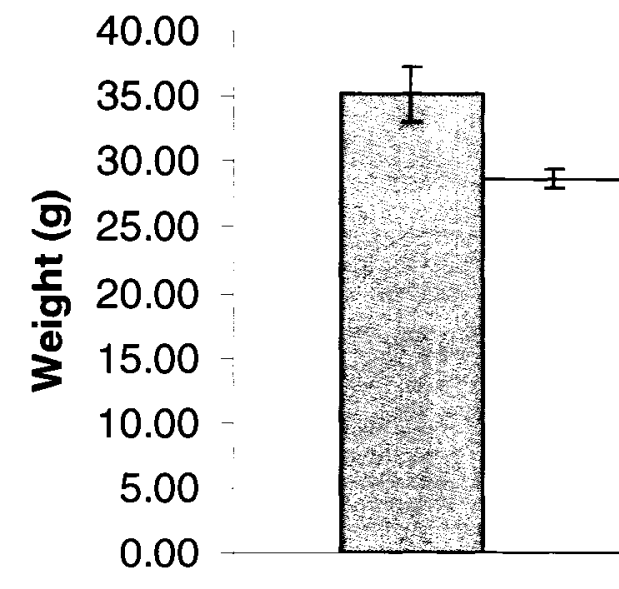

C57

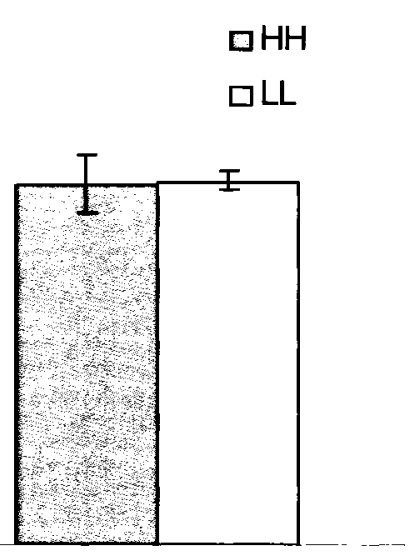

AJ

Figure 18. Weight of mice whose brains were stained with BrdU. C57 mice showed increased weight gain when fed a high-fat diet. All data are mean \pm standard error. $\mathrm{HH}=$ high-fat/high-sugar, LL=low-fat/low-sugar 


\subsection{Experiment 3: Neuroinflammatory dysregulation}

Given our interest in hippocampal neurogenesis, we also investigated neuroinflammatory dysregulations in the hippocampus, which may hinder neurogenesis (Kaneko et al., 2006; Vallieres et al., 2002). Specifically, we were interested in whether a high-fat diet may lead to neuroinflammatory changes in the hippocampus and whether these changes are potentiated by stress.

In a pilot study cytokine data from 36 high-fat or low-fat fed $\mathrm{C} 57$ or $\mathrm{A} / \mathrm{J}$ mice receiving chronic mild unpredictable stress or no stress was analyzed. A three-way ANOVA (strain $\mathrm{x}$ diet $\mathrm{x}$ stress) of individual cytokine levels in the hippocampus revealed no significant results for 9 of 10 cytokines studied (see Table 3), but yielded a significant strain $x$ stress interaction $(F(1,27)=4.47, p<0.05)$ for IL-10 and a significant main effect of stress $(\mathrm{F}(1,27)=5.09, \mathrm{p}<0.05)$ on IL-10 levels. This suggests that diabetes-prone $(\mathrm{C} 57)$ mice displayed no change in hippocampal IL-10 levels following chronic mild, unpredictable stressor exposure. Interestingly, diabetic-resistant $\mathrm{AJ}$ mice displayed an increase in the IL-10 levels in response to the stressor (Figure 19).

One potential explanation for the lack of differences in the majority of the cytokines is that the stressor regimen was too mild, and was unable to elicit a strong immune response. However, a three-way (strain $\mathrm{x}$ diet $\mathrm{x}$ stress) ANOVA of the biometrics data (Figure 20) suggests that the stressor was effective since stressed mice gained less weight over the duration of the two week chronic stress period compared to unstressed controls $(F(1,27)=8.37, p<0.01)$. One high-fat-fed $C 57$ mouse lost $27 \%$ of his body weight during the first week of stress and was considered an outlier and discarded 
from the analysis. Predictably, high-fat fed mice showed increased weight compared to low-fat-fed mice $(F(1,27)=106.63, \mathrm{p}<0.01)$ and $\mathrm{C} 57$ mice fed a high-fat diet showed increased weight compared to $\mathrm{A} / \mathrm{J}$ mice $(\mathrm{F}(1,27)=44.61)$. This data suggests that the lack of neuroinflammatory changes in the hippocampus is not due to an ineffective stressor regimen. 
Table 3. Mean cytokine protein levels (pg/mL) by strain, stress or diet groups. All data are mean \pm standard deviation. $\mathrm{HH}=$ high-fat/high-sugar, LL=low-fat/low-sugar

\begin{tabular}{|c|c|c|c|c|c|}
\hline \multirow{2}{*}{ Cytokines } & \multirow{2}{*}{ Strain } & \multicolumn{2}{|l|}{ Stress } & \multicolumn{2}{|l|}{ No Stress } \\
\hline & & $\mathrm{HH}$ & LL & $\mathrm{HH}$ & LL \\
\hline IFNg & $\begin{array}{l}\mathrm{C} 57 \\
\mathrm{~A} / \mathrm{J}\end{array}$ & $\begin{array}{l}11.40 \pm 0.30 \\
9.81 \pm 0.63\end{array}$ & $\begin{array}{l}10.02 \pm 0.96 \\
10.07 \pm 1.12\end{array}$ & $\begin{array}{l}10.11 \pm 0.78 \\
12.19 \pm 1.86\end{array}$ & $\begin{array}{l}10.59 \pm 1.42 \\
11.93 \pm 0.63\end{array}$ \\
\hline TNFa & $\begin{array}{l}\mathrm{C} 57 \\
\mathrm{~A} / \mathrm{J}\end{array}$ & $\begin{array}{l}9.32 \pm 0.13 \\
7.45 \pm 0.39\end{array}$ & $\begin{array}{l}9.53 \pm 1.15 \\
9.30 \pm 0.74\end{array}$ & $\begin{array}{l}8.28 \pm 0.60 \\
8.46 \pm 1.47\end{array}$ & $\begin{array}{l}9.12 \pm 0.35 \\
9.60 \pm 1.74\end{array}$ \\
\hline IL-1b & $\begin{array}{l}\mathrm{C} 57 \\
\mathrm{~A} / \mathrm{J}\end{array}$ & $\mid \begin{array}{l}151.82 \pm 16.79 \\
124.38 \pm 17.83\end{array}$ & $\begin{array}{l}149.27 \pm 20.23 \\
145.81 \pm 15.95\end{array}$ & $\begin{array}{l}118.74 \pm 10.77 \\
159.00 \pm 40.19\end{array}$ & $\begin{array}{l}140.77 \pm 9.16 \\
173.54 \pm 21.19\end{array}$ \\
\hline IL-2 & $\begin{array}{l}\text { C57 } \\
\mathrm{A} / \mathrm{J}\end{array}$ & $\begin{array}{l}93.71 \pm 4.26 \\
87.05 \pm 13.10\end{array}$ & $\begin{array}{l}90.72 \pm 9.29 \\
121.61 \pm 13.00\end{array}$ & $\begin{array}{l}82.78 \pm 16.11 \\
107.79 \pm 5.14\end{array}$ & \begin{tabular}{|l}
$99.37 \pm 7.62$ \\
$106.34 \pm 11.91$
\end{tabular} \\
\hline IL-4 & $\begin{array}{l}\mathrm{C} 57 \\
\mathrm{~A} / \mathrm{J}\end{array}$ & $\begin{array}{l}8.54 \pm 0.56 \\
5.62 \pm 0.63\end{array}$ & $\begin{array}{l}4.75 \pm 1.61 \\
7.95 \pm 0.97\end{array}$ & $\begin{array}{l}6.12 \pm 1.49 \\
7.45 \pm 0.61\end{array}$ & $\begin{array}{l}8.19 \pm 0.40 \\
6.97 \pm 1.07\end{array}$ \\
\hline IL-5 & $\begin{array}{l}\mathrm{C} 57 \\
\mathrm{~A} / \mathrm{J}\end{array}$ & $\begin{array}{l}8.25 \pm 0.33 \\
7.95 \pm 0.51\end{array}$ & $\begin{array}{l}8.25 \pm 0.95 \\
7.30 \pm 1.20\end{array}$ & $\begin{array}{l}7.67 \pm 0.68 \\
6.93 \pm 0.89\end{array}$ & $\begin{array}{l}8.40 \pm 0.65 \\
8.94 \pm 0.66\end{array}$ \\
\hline IL-6 & $\begin{array}{l}\text { C57 } \\
\text { A/J }\end{array}$ & $\begin{array}{l}26.72 \pm 1.96 \\
23.95 \pm 1.35\end{array}$ & $\begin{array}{l}22.56 \pm 2.27 \\
22.19 \pm 2.50\end{array}$ & $\begin{array}{l}21.12 \pm 2.27 \\
27.40 \pm 4.68\end{array}$ & $\begin{array}{l}20.03 \pm 4.60 \\
24.61 \pm 2.83\end{array}$ \\
\hline IL-10* & $\begin{array}{l}\text { C57 } \\
\text { A/J }\end{array}$ & $\begin{array}{l}135.89 \pm 10.57 \\
171.61 \pm 24.91\end{array}$ & $\begin{array}{l}115.76 \pm 16.02 \\
199.89 \pm 28.00\end{array}$ & $\begin{array}{l}128.77 \pm 20.31 \\
148.54 \pm 30.30\end{array}$ & $\begin{array}{l}169.28 \pm 7.13 \\
153.86 \pm 18.13\end{array}$ \\
\hline IL-12 & $\begin{array}{l}\text { C57 } \\
\mathrm{A} / \mathrm{J}\end{array}$ & $\mid \begin{array}{l}125.54 \pm 9.14 \\
111.54 \pm 4.05\end{array}$ & $\mid \begin{array}{l}103.20 \pm 11.12 \\
136.32 \pm 10.20\end{array}$ & $\mid \begin{array}{l}124.26+/-14.73 \\
142.60+/-32.24\end{array}$ & $\begin{array}{l}116.74 \pm 14.11 \\
119.24 \pm 8.18\end{array}$ \\
\hline
\end{tabular}




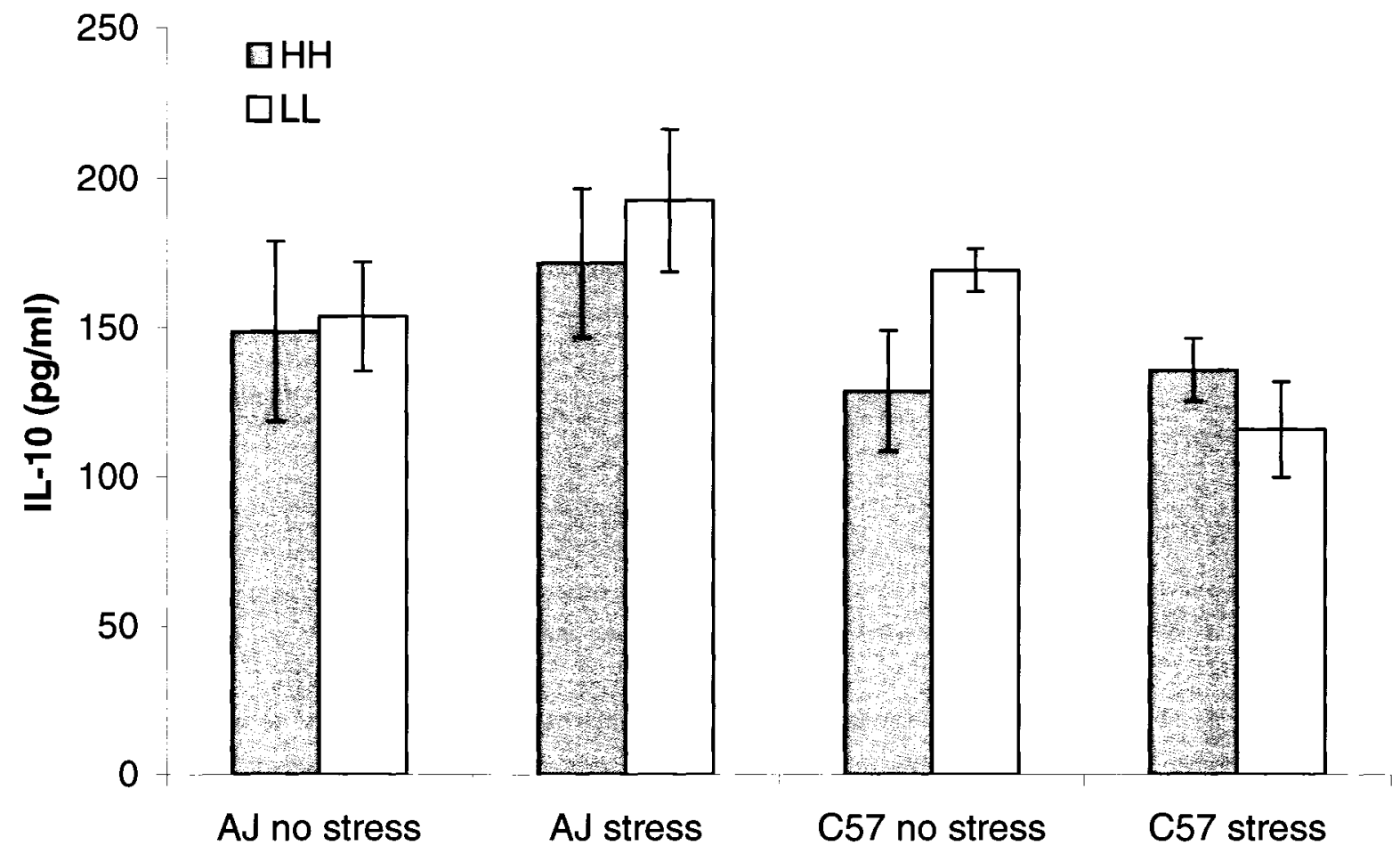

Figure 19. IL-10 hippocampal protein levels. A/J mice show increased IL-10 levels in response to stress, while C57 mice show no change in $\mathrm{IL}-10$ levels when stressed. All data are mean \pm standard error. $\mathrm{HH}=$ high-fat/high-sugar, LL=low-fat/low-sugar 


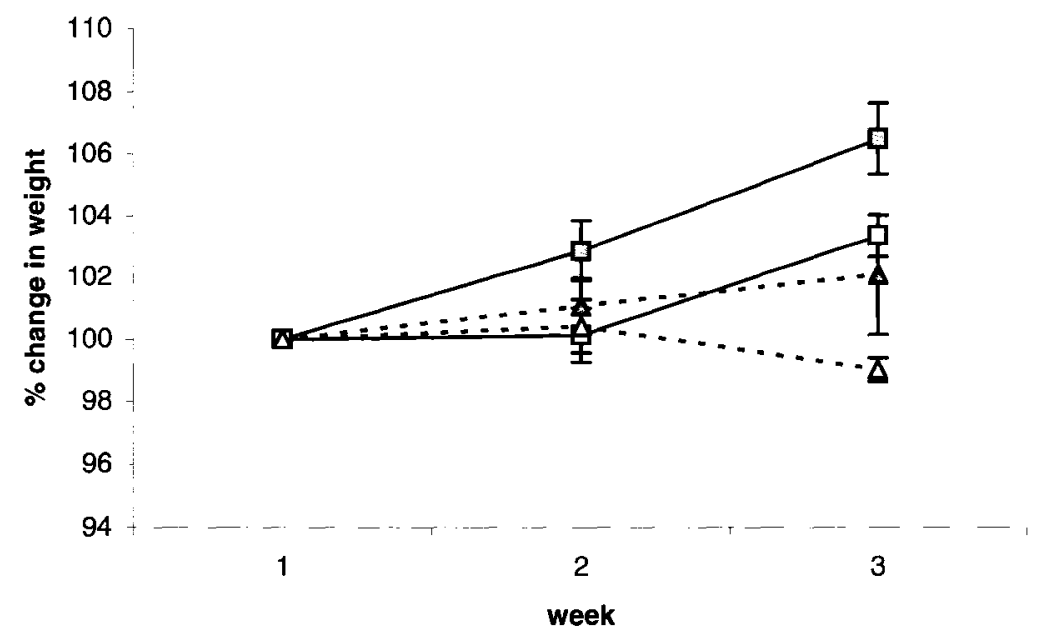

- C57 HH no stress $-\square-C 57$ LL no stress

- - - -AJ HH no stress - - - - AJ LL no stress

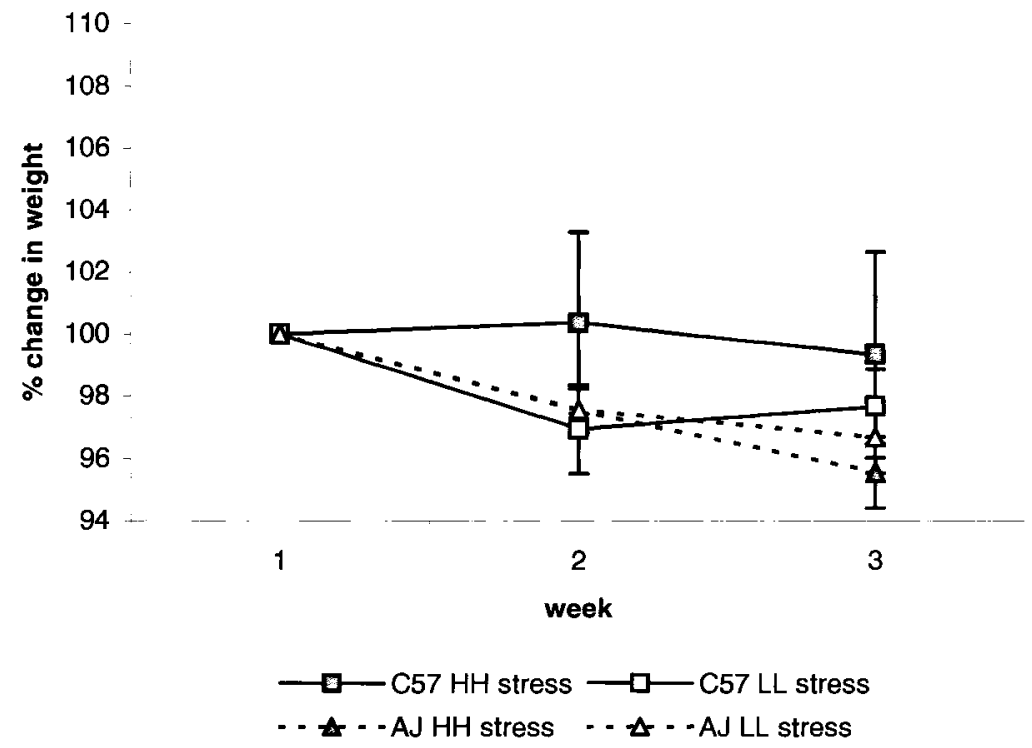

Figure 20. Weight change during the two weeks of chronic mild unpredictable stress. Mice receiving no stress gained more weight than stressed mice $(F(1,27)=8.37$, $\mathrm{p}<0.01)$. High-fat fed mice showed increased weight compared to low-fat-fed mice $(\mathrm{F}(1,27)=106.63, \mathrm{p}<0.01) . \mathrm{C} 57$ mice fed a high-fat diet showed increased weight $(\mathrm{F}(1,27)=44.61)$. All data are mean \pm standard error. $\mathrm{HH}=$ high-fat/high-sugar, LL=low-fat/low-sugar 


\section{Discussion}

Diabetes is one of the most prevalent and costly chronic diseases in North America (Narayan et al., 2003). Chronic dysregulation of glucose homeostasis leads to considerable wear and tear on the body, thus it may be viewed as a systemic stressor (Herman \& Cullinan, 1997) similar to that proposed previously for immune challenges. In fact, diabetes has been associated with marked changes in immune and endocrine factors, which would impact upon circulatory, cardiovascular and central processes in a manner consistent with the definition of a systemic stressor proposed by Herman \& Cullinan (1997). These systemic stressors generally activate neurochemical processes similar to those influenced by psychologically relevant stressors such as restraint, fear conditioning, or exposure to a novel environment, which activate multiple sensory modalities and do not involve an immediate threat to physiological homeostasis (Asaba et al., 2006; Herman \& Cullinan, 1997) and have even been associated with cognitive decline (Luine et al., 1994) and alterations of neuroplasticity including reductions of neurogenesis (Joels et al., 2004). Accordingly we used a mouse model to assess the impact of type II diabetes (T2D) upon indices of memory, anxiety, and depressive-like behavior, as well as changes in neurogenesis and cytokines that may accompany these behavioral variations.

\subsection{Biometrics}

Diet and nutrition play a significant role in the development of T2D (Schulze \& $\mathrm{Hu}, 2002)$. In particular, $\mathrm{C} 57$ mice are widely used as a model of T2D because exposure to a high-fat diet leads to obesity, hyperglycemia and insulin resistance in these mice. In 
contrast, $\mathrm{A} / \mathrm{J}$ mice are often used as a control for this paradigm given their resistance to diet induced diabetes (Surwit et al., 1995; Surwit et al., 1988).Accordingly, we found that diabetes-prone C57BL/6J mice fed a high-fat diet did gain more weight and had decreased feed efficiency (weekly weight gain per calories consumed ) despite a food intake similar to $\mathrm{A} / \mathrm{J}$ diabetes resistant mice. The $\mathrm{C} 57$ mice also exhibited fasting hyperglycemia and decreased insulin secretion after 3 months of being fed a high-fat diet. These results are consistent with previous studies (Collins et al., 2004; Surwit et al., 1995), and suggest that the high-fat diets had a significant impact specifically on the C57 mice.

For human patients, the American Diabetes Association (ADA, n.d.) defines normal fasting blood glucose as plasma levels below $100 \mathrm{mg} / \mathrm{dl}(5.5 \mathrm{mmol} / \mathrm{L})$, prediabetes as fasting plasma glucose levels between $100-125 \mathrm{mg} / \mathrm{dl} \quad(5.5-6.88 \mathrm{mmol} / \mathrm{L})$, and diabetes as $126 \mathrm{mg} / \mathrm{dl}(6.93 \mathrm{mmol} / \mathrm{L})$. In mice, Surwit et al. (1995) defined hyperglycemia as fasting glucose level values greater than or equal to $11 \mathrm{mmol} / \mathrm{L}$ (200 $\mathrm{mg} / \mathrm{dl}$ ) following an 8 hour fasting period (Surwit et al., 1995). The C57 mice in the present study met these criteria following ingestion of a high-fat diet for 3 months, with their fasting plasma glucose levels significantly exceeding those of either the low-fat fed controls or the $\mathrm{A} / \mathrm{J}$ s on either diet.

T2D is also accompanied by insulin resistance, characterized by a decreased responsiveness to normal circulating levels of insulin (Musselman et al., 2003). The C57 mice fed a high-fat diet did indeed display reduced response to insulin bolus injection, suggesting a decrease in insulin sensitivity, consistent with symptoms of T2D. The fact that C57 high-fat fed mice exhibited fasting hyperglycemia, yet still mounted a response 
to the bolus insulin injection, also suggests the possibility of reduced insulin secretion. However, this would have to be definitively determined using a glucose clamp technique (DeFronzo et al., 1979).

The obesity of C57 mice cannot be explained simply by hyperphagia or decreased physical activity (Collins et al., 2004), since they did not exhibit an increased food intake nor were they less active than the low-fat fed $\mathrm{C} 57$ mice, or $\mathrm{A} / \mathrm{J}$ mice as suggested by their locomotor activity in the open field and elevated plus maze. The obesity in these mice appears to be the direct consequence of increased feed efficiency (weight gained/kcal consumed) when fed a high-fat diet, which suggests that these mice store more fat despite food intake similar to the other three groups. In other words high-fat fed C57 mice gained even more weight than would have been expected based solely on their increased caloric consumption (Surwit et al., 1995). Such a genetic predisposition of C57 mice to store fat when dietary fat content is high makes them a more suitable model of T2D than other strains of mice such as the ob/ob and $d b / d b$ mice and the fa/fa rat, whose genetic background predisposes them to obesity following ingestion of regular mouse chow (Renold et al., 1971).

\subsection{Behavior}

Both T1D and T2D are associated with cognitive impairments in humans and animal models. Within the case of T1D, a dysregulation in executive functioning, attention and delayed memory has been reported, which may result from faulty communication between the hippocampus and the prefrontal cortex. In contrast, T2D studies have found impairments more specifically in hippocampal dependent functions, such as working 
memory and learning. In the current study, a series of behavioral tests revealed no effect of diet on a range of measures of spatial and working memory and anxiety, though we did observed significant differences between strains. In contrast, the forced swim test (which examines depressive-like behavior) did find a significant increase in depressive-like behavior in mice fed the high-fat diet, though this effect was seen in both C57 and A/J strains.

The Y-maze test of spatial and working memory revealed no significant effect of diet for either strain, but did reveal significant strain differences. Specifically, C57 mice spent significant more time in the novel arm, while $\mathrm{A} / \mathrm{J}$ mice seemed to avoid the novel arm. The discrimination index which is expressed as the absolute value of the extent of time spent in the novel arm compared to the 2 familiar arms of the Y-maze revealed that A/J discriminated better than C57 mice between the novel and the familiar arms. However, given that the retrieval phase of the Y-maze test was randomly started in either of the familiar arms and the fact that $\mathrm{A} / \mathrm{J}$ mice had decreased locomotor behavior, it is possible that the increased discrimination index could simply be an artifact of their decreased locomotor activity. There was a trend for decreased spontaneous alternations in the high-fat-fed C57 mice, but this trend did not reach significance. Overall, the A/J mice exhibited very low locomotor activity and so did not display any spontaneous alternation behavior. Essentially, the three-month regimen of high-fat diet did not have a significant effect on spatial memory as measured by time spent in the novel arm, nor did it affect working memory measured by spontaneous arm alternations during exploration.

The Y maze results were unexpected given studies in rats (Molteni et al., 2004; Winocur \& Greenwood, 2005), and evidence from human studies suggesting that high-fat 
diets do lead to memory impairments (Reaven et al., 1990; Strachan et al., 1997; Strachan et al., 2003). Given that C57 mice are particularly adept at spatial and working memory tasks (Crawley et al., 1997; B. Tannenbaum \& Anisman, 2003; B. M. Tannenbaum et al., 2003; Wolff et al., 2002), it is possible that the Y-maze was not sufficiently sensitive to any cognitive changes induced by the high-fat diet. This strain and species-specific aptitude may explain the contrasting findings in rats, which show deficits in spatial learning in the Morris water maze after 1 or 2 months on a high-fat diet (Molteni et al., 2004). Another possibility could be that the 1 minute interval between the acquisition and the retrieval phase of the Y-maze task was too short. Indeed, Greenwood et al. (2001) examined performance in rats on a delayed alternation task, and found that animals fed a high-fat diet were more severely impaired at longer inter-trial intervals than shorter intertrial intervals. Furthermore, it is possible that high-fat diet affects a different aspect of memory than the spatial and working memory tested using the Y-maze test. In future studies it might be beneficial to employ a different measure of memory such as the operant learning bar-pressing task, which involves the basal ganglia for acquisition of the task, and the hippocampus for the consolidation phase (Bertaina-Anglade et al., 2000). Indeed Mielke et al. (2006) found that high-fat fed strain mice fail to associate operant bar pressing to food reinforcement when compared to low-fat fed animals.

The open field data revealed no significant diet effects, but again a significant strain effect was evident, wherein $\mathrm{A} / \mathrm{J}$ mice were quite immobile, spending the majority of their time in the corner of the apparatus, whereas C57 mice had very high levels of exploratory behavior. Interestingly, high-fat-fed C57 had lower speeds when compared to their low-fat-fed counterparts, suggesting their weight gain may have slowed them down. 
These strain differences are consistent with other behavioral studies of anxiety (Crabbe, 1986; DeFries \& Plomin, 1978; Mathis et al., 1994), which found that C57 mice show high locomotor activity and low anxiety levels in the open field, while A/J mice exhibit the reverse pattern.

The performance of mice on the elevated plus maze suggested a stronger anxiogenic response in $\mathrm{A} / \mathrm{J}$ mice, with these mice having an increased latency to enter the open arms. Similarly, Trullas and Skolnick (1993), found that A/J mice had a stronger anxiogenic response compared to C57 mice. However, the results of the elevated plus maze are again confounded by the reduced locomotor activity of $\mathrm{A} / \mathrm{J} s$. Indeed, a significant strain by diet interaction in speed of exploration, suggests reduced locomotor activity in A/J and high-fat-fed C57 mice. The decreased locomotor activity in A/J compared to C57 mice is consistent to other reports (Jacobson \& Cryan, 2007; Shanks \& Anisman, 1988) and suggests underlying neurochemical differences between the two strains.

Interestingly, the depressive-like behavior measured in the forced swim apparatus revealed increased floating behavior in high-fat-fed animals irrespective of strain, however, this cannot be explained by the increased weight gain since only C57 mice gained an appreciable amount of weight. This would suggest that high-fat diet equally affected both strains in terms of depressive-like behavior. As a result, a diabetic-like state is not the determining factor, since $\mathrm{A} / \mathrm{J}$ mice do not develop insulin resistance. Nor is the weight-gain responsible for increased floating time in high-fat fed animals, since $\mathrm{A} / \mathrm{J}$ mice do not gain as much weight as C57 mice do when fed a high-fat diet. 
One possibility could be that the high-fat diet equally affects motivation in both strains, leading to a decrease in swimming activity. Indeed Huang et al. (2004) showed high-fat diet increases expression of serotonin receptor in the ventromedial hypothalamic nucleus, possibly indicating a decreased availability of synaptic serotonin. As a result, the increased floating may be an indication of decreased serotonin levels, which are associated with depressive-like behavior.

Another possibility could be that insulin resistance is slower to develop centrally than peripherally. Indeed, the results of this study suggest that peripherally insulin resistance is evident after 3 months, however, central insulin resistance was not measured. Mielke et al. (2006) found that a 12 month of high-fat regimen, did not significantly affect neural insulin sensitivity in C57 mice. Indeed if peripheral resistance develops at a faster rate then central insulin resistance, it may lead to increased insulin release in the periphery. This may result in increased central insulin, which may in turn lead to improved spatial learning and memory (Moosavi et al., 2006) and protect against stress-induced behavioral impairments (Moosavi et al., 2007). Therefore, the lack of behavioral differences between high-fat-fed and low-fat-fed C57 mice could be explained by an initial increased central availability of insulin in high-fat-fed C57.

The current study revealed that high-fat diet does not significantly affect spatial and working memory, nor does it affect anxiety-like behavior, but it significantly increases depressive-like behavior. 


\subsection{Neurogenesis differences}

Analysis of neurogenesis in $\mathrm{C} 57$ and A/J mice fed either high or low fat diets revealed significant difference in neuronal proliferation in the hippocampus between the two strains, with the C57 diabetes-prone mice showing increased neuronal proliferation when compared to the $\mathrm{A} / \mathrm{J}$ diabetes resistant mice. While there was no significant difference in proliferation between animals on high-fat- and low-fat-diets high-fat fed C57 mice did show a slight increase in proliferation compared with low-fat controls, although this trend did not reach significance.

This was unexpected because Lindqvist et al. (2006) have shown decreased neurogenesis in rats following just one month on the diet. Furthermore, T1D is associated with decreased neuronal proliferation and survival in the hippocampus (Beauquis et al., 2006). At first glance, the results of the current study appear to contrast those of Lindquist et al (2006), who found a reduction in BrdU labeled cells in the rat hippocampus following just one month of high-fat food intake. However, Lindquist et al (2006) investigated survival rather than proliferation, since they assessed BrdU and NeuN two weeks following BrdU injections. Therefore, the trend towards increased proliferation in the current study does not directly contradict the findings of Lindquist et al (2006). In fact, Lehmann et al. (2005) theorized that cell survival is determined by the rate of cell proliferation and the excitatory inputs from the perforant pathway, which is the main input to the hippocampus, so that optimal cell survival rates are achieved when either but not both of the two is increased. Indeed, increasing proliferation and excitation at the same time has a negative impact on the homeostasis of the neural network leading to degeneration and increases the vulnerability of the hippocampus to such disorders as 
Alzheimer's disease which is indeed frequently associated with T2D. High-fat diets lead to increased excitation due to a decrease in the inhibitory effects of $\mathrm{K}_{\mathrm{ATP}}$ channels which are defective or even absent in obesity prone rats (Levin et al., 1999). Thus, if the increased proliferation trend seen in the present study is substantiated by future studies, it will lend even more support to Lehmann's et al. (2005) theory, suggesting that increased proliferation associated with a high-fat diet coupled with increased excitation due to the metabolic or psychological stress may decrease neuronal survival. Indeed, (Baran et al., 2005) found that neither stress, nor high-fat diet alone had a significant impact on dendritic morphology in the hippocampus. However, when the two factors were combined, high-fat diet potentiated the effects of a three-week chronic stress period consisting of daily predator exposure and crowded cage conditions, and led to decreased dendritic arborization in CA3 neurons.

The increased adult neurogenesis rate in C57 compared to $\mathrm{A} / \mathrm{J}$ mice is similar to the findings of Kempermann \& Gage (2002), showing that C57 mice have increased proliferation and survival compared with $\mathrm{A} / \mathrm{J}$. Furthermore, these differences in neurogenesis were associated with hippocampal functioning, with improved learning in C57 versus $\mathrm{A} / \mathrm{J}$ mice. One possible explanation for the lack of difference between highfat and low-fat groups in the current study, is that the metabolic stress of the high-fat diet alone cannot produce changes in neurogenesis, but when paired with chronic physiological stressor it adversely affects neurogenesis.

Studies are currently underway to further verify the increase in proliferation in high-fat fed C57 and assess potential mediators of such an effect. In this respect, we will increase the number of subjects per group from 5 to 10 . In terms of potential mediators, 
the increased proliferation may be due to increases in central insulin levels, in the highfat-fed C57, resulting from peripheral insulin resistance and increased insulin production. Insulin and insulin growth factor (IGF) are known to induce proliferation in the adult hippocampus (Aberg et al., 2000).

Currently studies are also underway to determine the impact of high-fat diet feeding on neuronal survival and maturation using the endogenous neuronal marker doublecortin (DCX). This would allow us to determine whether a high-fat diet leads to alterations in the cell cycle by looking at dendritic morphology (Plumpe et al., 2006) and progenitor survival, previously observed in mouse models of type 1 diabetes (JacksonGuilford et al., 2000; Kang et al., 2006; Revsin et al., 2005; F. Saravia et al., 2004; F. E. Saravia et al., 2006).

Future studies will need to determine if T2D diabetes leads to the latter outcome with simultaneous increases in cell proliferation and excitation, as is the case with Alzheimer's disease in humans (Jin et al., 2004).

\subsection{Neuroinflammatory changes}

Type II diabetes is associated with low-grade inflammation in the periphery. However it is not clear whether this inflammation causes the disease, or arises as a consequence of the development of diabetes. Furthermore, this inflammation is exacerbated by exposure to stressors. Surprisingly little research has focused on central inflammatory changes which may play a putative role in the cognitive and behavioral deficits associated in diabetes. 
Diabetes is associated with peripheral elevations in pro-inflammatory cytokines such as IL-1 $\beta$, TNF- $\alpha$ and IL-6 (Pickup \& Crook, 1998) and decreases in antiinflammatory cytokines such as IL-10 and IL-4 (van Exel et al., 2002). While to date there are no studies investigating central cytokine levels in diabetes patients or animal models, pro-inflammatory cytokines are found in the brain as evidenced by cytokine receptors on neurons and glia (Maier \& Watkins, 1998), particularly in the hippocampus (Cunningham et al., 1992). Interestingly, cytokine dysregulations have been observed centrally (Taishi et al., 1998) and peripherally (Cao et al., 2007) in chronic stress paradigms and are associated with depression and neurodegenerative disorders (Hayley \& Anisman, 2005) which are also highly comorbid with diabetes (Ristow, 2004). These associations suggest cytokines could be the mechanism involved in the predisposition of diabetes to neurodegenerative disorders, and could be potentiated by the effects of chronic stressors.

Our results do not exclude the hypothesis that stress and central and systemic neuroinflammatory changes act synergistically in the development of diabetes. However, they do suggest that the initial phase of diabetes is not accompanied by marked neuroinflammatory changes. Analysis of hippocampal tissue revealed no significant effects of diet in any of the 10 cytokines investigated. However, stress and strain did have an effect on IL-10 levels, yielding a significant strain $\mathrm{x}$ stress interaction. Specifically, $\mathrm{A} / \mathrm{J}$ mice responded to chronic stress with an increase in IL-10 protein levels, while there was no change in C57 mice in hippocampal IL-10 levels in response to the insult. Interestingly, $\mathrm{A} / \mathrm{J}$ mice also show increased systemic production of anti-inflammatory cytokines, particularly IL-10, and decreased production of pro-inflammatory cytokines 
such as IL-1 beta, TNF alpha and IL-6 compared to C57 mice in response to an immune challenge such as moderate aerosol infections (Jagannath et al., 2000). Despite the fact that the current study has found no significant differences in hippocampal cytokine levels between diabetic and non-diabetic mice, other studies have found that T2D is associated with increased peripheral production of pro-inflammatory cytokines (Pickup \& Crook, 1998). The shift towards an anti-inflammatory production in $\mathrm{A} / \mathrm{J}$ mice (Jagannath et al., 2000) could be one protecting factor contributing to this strain's resistance to diabetes. Interestingly, human studies have shown that decreased IL-10 levels are associated with an increase risk of developing T2D in elderly patients (van Exel et al., 2002). Moreover, this protection may be extending to the hippocampus as suggested by the results of (Lynch et al., 2003), who showed that IL-10 counteracts the inhibitory effects of LPS induced increases of IL-1 beta on LTP. This cytokine may have such effects through its inhibitory actions on other cytokines, such as $\mathrm{IL}-1$ beta, as well as apoptotic factors including caspase-3.

In conclusion, diet had no effect on hippocampal cytokine levels, however, chronic mild stress led to an increase in IL-10 levels in $\mathrm{A} / \mathrm{J}$ mice and a decrease in C57 mice, suggesting a possible mechanism conferring $\mathrm{A} / \mathrm{Js}$ resistance while predisposing C57 mice to diabetes. Future studies are needed to determine whether later stages of diabetes lead to alterations in other cytokines besides IL-10 both centrally and peripherally, and whether stress potentiates their effects at those later stages.

\subsection{Conclusion}

The delicate balance between glucose, insulin, leptin, cytokines and neurotransmitters is upset in diabetes. This gives rise to several apparently contradictory conditions: on the 
one hand diabetes is considered an inflammatory condition, since it is associated with increased plasma levels of proinflammatory cytokines, on the other hand, diabetes leads to an increased incidence of infection and susceptibility to disease, including neurodegenerative disorders.

This thesis examined many potential inter-related markers of diabetes-mediated pathological change. Our theory was that diabetes will lead to central cytokine dysregulations, which in turn may create a toxic microenvironment for neurogenesis. Furthermore, changes in neurogenesis will manifest themselves in a host of behavioral problems such as decreased working memory, increased anxiety- and depression-like behavior. The present study suggests that the initial stage of diabetes is accompanied by fasting hyperglycemia and reduced insulin sensitivity. However, these changes are not sufficient to induce behavioral changes. A trend towards increased proliferation in highfat fed diabetes-prone mice suggests that diet may have an impact on neurogenesis. The mechanism affecting neurogenesis in the hippocampus does not depend, at least in the initial stage, on neuroinflammatory dysregulations, since there were no significant effects of diet on cytokine levels in the hippocampus. Interestingly, one aspect of the resistance of $\mathrm{A} / \mathrm{J}$ mice to diabetes may be related to a shift from pro-inflammatory to antiinflammatory cytokine production, shift which has been shown in the periphery in response to a immune challenge (Jagannath et al., 2000) and was also observed centrally in response to stress in the current study.

Future studies should determine a time course for changes in insulin, cytokines and their impact on neurogenesis in the brain, as well as the impact of neuronal proliferation and survival on behavior. 


\section{References}

Aberg, M. A., Aberg, N. D., Hedbacker, H., Oscarsson, J., \& Eriksson, P. S. (2000). Peripheral infusion of igf-i selectively induces neurogenesis in the adult rat hippocampus. J Neurosci, 20(8), 2896-2903.

Almawi, W. Y., Tamim, H., \& Azar, S. T. (1999). Clinical review 103: T helper type 1 and 2 cytokines mediate the onset and progression of type i (insulin-dependent) diabetes. J Clin Endocrinol Metab, 84(5), 1497-1502.

American Diabetes Association (n.d.). How to tell if you have diabetes. Retrieved April 02, 2007 from http://www.diabetes.org/pre-diabetes/pre-diabetes-symptoms.jsp

Anderson, M. F., Aberg, M. A., Nilsson, M., \& Eriksson, P. S. (2002). Insulin-like growth factor-i and neurogenesis in the adult mammalian brain. Brain Res Dev Brain Res, 134(1-2), 115-122.

Armstrong, R. J., \& Barker, R. A. (2001). Neurodegeneration: A failure of neuroregeneration? Lancet, 358(9288), 1174-1176.

Asaba, K., Iwasaki, Y., Asai, M., Yoshida, M., Nigawara, T., Kambayashi, M., et al. (2006). High glucose activates pituitary proopiomelanocortin gene expression: Possible role of free radical-sensitive transcription factors. Diabetes Metab Res Rev.

Atkinson, M. A., \& Leiter, E. H. (1999). The nod mouse model of type 1 diabetes: As good as it gets? Nat Med, 5(6), 601-604.

Awad, N., Gagnon, M., \& Messier, C. (2004). The relationship between impaired glucose tolerance, type 2 diabetes, and cognitive function. J Clin Exp Neuropsychol, 26(8), 1044-1080.

Baran, S. E., Campbell, A. M., Kleen, J. K., Foltz, C. H., Wright, R. L., Diamond, D. M., et al. (2005). Combination of high fat diet and chronic stress retracts hippocampal dendrites. Neuroreport, 16(1), 39-43.

Beauquis, J., Roig, P., Homo-Delarche, F., De Nicola, A., \& Saravia, F. (2006). Reduced hippocampal neurogenesis and number of hilar neurones in streptozotocininduced diabetic mice: Reversion by antidepressant treatment. Eur J Neurosci, 23(6), 1539-1546.

Bertaina-Anglade, V., Tramu, G., \& Destrade, C. (2000). Differential learningstage dependent patterns of $\mathrm{c}$-fos protein expression in brain regions during the acquisition and memory consolidation of an operant task in mice. Eur J Neurosci, 12(10), 3803-3812.

Biessels, G. J., \& Gispen, W. H. (2005). The impact of diabetes on cognition: What can be learned from rodent models? Neurobiol Aging, 26 Suppl 1, 36-41.

Bjorgaas, M., Gimse, R., Vik, T., \& Sand, T. (1997). Cognitive function in type 1 diabetic children with and without episodes of severe hypoglycaemia. Acta Paediatr, 86(2), 148-153.

Black, P. H. (2006). The inflammatory consequences of psychologic stress: Relationship to insulin resistance, obesity, atherosclerosis and diabetes mellitus, type ii. Med Hypotheses, 67(4), 879-891. 
Bluthe, R. M., Frenois, F., Kelley, K. W., \& Dantzer, R. (2005). Pentoxifylline and insulin-like growth factor-i (igf-i) abrogate kainic acid-induced cognitive impairment in mice. J Neuroimmunol, 169(1-2), 50-58.

Bluthe, R. M., Kelley, K. W., \& Dantzer, R. (2006). Effects of insulin-like growth factor$\mathrm{i}$ on cytokine-induced sickness behavior in mice. Brain Behav Immun, 20(1), 5763.

Bondy, C. A., \& Cheng, C. M. (2004). Signaling by insulin-like growth factor 1 in brain. Eur J Pharmacol, 490(1-3), 25-31.

Brands, A. M., Biessels, G. J., de Haan, E. H., Kappelle, L. J., \& Kessels, R. P. (2005). The effects of type 1 diabetes on cognitive performance: A meta-analysis. Diabetes Care, 28(3), 726-735.

Bullen, J. W., Jr., Ziotopoulou, M., Ungsunan, L., Misra, J., Alevizos, I., Kokkotou, E., et al. (2004). Short-term resistance to diet-induced obesity in $\mathrm{a} / \mathrm{j}$ mice is not associated with regulation of hypothalamic neuropeptides. Am J Physiol Endocrinol Metab, 287(4), E662-670.

Cao, L., Hudson, C. A., \& Moynihan, J. A. (2007). Chronic foot shock induces hyperactive behaviors and accompanying pro- and anti-inflammatory responses in mice. J Neuroimmunol.

Chen, H. (2006). Cellular inflammatory responses: Novel insights for obesity and insulin resistance. Pharmacol Res, 53(6), 469-477.

Christie, B. R., \& Cameron, H. A. (2006). Neurogenesis in the adult hippocampus. Hippocampus, 16(3), 199-207.

Collins, S., Martin, T. L., Surwit, R. S., \& Robidoux, J. (2004). Genetic vulnerability to diet-induced obesity in the $\mathrm{c} 57 \mathrm{bl} / 6 \mathrm{j}$ mouse: Physiological and molecular characteristics. Physiol Behav, 8I(2), 243-248.

Crabbe, J. C. (1986). Genetic differences in locomotor activation in mice. Pharmacol Biochem Behav, 25(1), 289-292.

Craft, S., \& Watson, G. S. (2004). Insulin and neurodegenerative disease: Shared and specific mechanisms. Lancet Neurol, 3(3), 169-178.

Crawley, J. N., Belknap, J. K., Collins, A., Crabbe, J. C., Frankel, W., Henderson, N., et al. (1997). Behavioral phenotypes of inbred mouse strains: Implications and recommendations for molecular studies. Psychopharmacology (Berl), 132(2), 107-124.

Cunningham, E. T., Jr., Wada, E., Carter, D. B., Tracey, D. E., Battey, J. F., \& De Souza, E. B. (1992). In situ histochemical localization of type $i$ interleukin-1 receptor messenger rna in the central nervous system, pituitary, and adrenal gland of the mouse. J Neurosci, 12(3), 1101-1114.

Czeh, B., Simon, M., Schmelting, B., Hiemke, C., \& Fuchs, E. (2006). Astroglial plasticity in the hippocampus is affected by chronic psychosocial stress and concomitant fluoxetine treatment. Neuropsychopharmacology, 31(8), 1616-1626.

DeFries, J. C., \& Plomin, R. (1978). Behavioral genetics. Annu Rev Psychol, 29, 473-515.

DeFronzo, R. A., Tobin, J. D., \& Andres, R. (1979). Glucose clamp technique: A method for quantifying insulin secretion and resistance. Am J Physiol, 237(3), E214-223.

Drapeau, E., Mayo, W., Aurousseau, C., Le Moal, M., Piazza, P. V., \& Abrous, D. N. (2003). Spatial memory performances of aged rats in the water maze predict 
levels of hippocampal neurogenesis. Proc Natl Acad Sci U S A, 100(24), 1438514390.

Ekdahl, C. T., Claasen, J. H., Bonde, S., Kokaia, Z., \& Lindvall, O. (2003). Inflammation is detrimental for neurogenesis in adult brain. Proc Natl Acad Sci US A, 100(23), 13632-13637.

Fan, L. W., Pang, Y., Lin, S., Tien, L. T., Ma, T., Rhodes, P. G., et al. (2005). Minocycline reduces lipopolysaccharide-induced neurological dysfunction and brain injury in the neonatal rat. $J$ Neurosci Res, 82(1), 71-82.

Fernyhough, P., Gallagher, A., Averill, S. A., Priestley, J. V., Hounsom, L., Patel, J., et al. (1999). Aberrant neurofilament phosphorylation in sensory neurons of rats with diabetic neuropathy. Diabetes, 48(4), 881-889.

Gazzara, R. A., \& Altman, J. (1981). Early postnatal x-irradiation of the hippocampus and discrimination learning in adult rats. J Comp Physiol Psychol, 95(3), 484-495.

Gould, E., Beylin, A., Tanapat, P., Reeves, A., \& Shors, T. J. (1999). Learning enhances adult neurogenesis in the hippocampal formation. Nat Neurosci, 2(3), 260-265.

Gould, E., Tanapat, P., McEwen, B. S., Flugge, G., \& Fuchs, E. (1998). Proliferation of granule cell precursors in the dentate gyrus of adult monkeys is diminished by stress. Proc Natl Acad Sci U S A, 95(6), 3168-3171.

Greenwood, C. E., \& Winocur, G. (1990). Learning and memory impairment in rats fed a high saturated fat diet. Behav Neural Biol, 53(1), 74-87.

Grossman, H. (2003). Does diabetes protect or provoke alzheimer's disease? Insights into the pathobiology and future treatment of alzheimer's disease. CNS Spectr, 8(11), 815-823.

Hartman, M. E., O'Connor, J. C., Godbout, J. P., Minor, K. D., Mazzocco, V. R., \& Freund, G. G. (2004). Insulin receptor substrate-2-dependent interleukin-4 signaling in macrophages is impaired in two models of type 2 diabetes mellitus. $J$ Biol Chem, 279(27), 28045-28050.

Hayley, S., \& Anisman, H. (2005). Multiple mechanisms of cytokine action in neurodegenerative and psychiatric states: Neurochemical and molecular substrates. Curr Pharm Des, 11(8), 947-962.

Herman, J. P., \& Cullinan, W. E. (1997). Neurocircuitry of stress: Central control of the hypothalamo-pituitary-adrenocortical axis. Trends Neurosci, 20(2), 78-84.

Hogg, S. (1996). A review of the validity and variability of the elevated plus-maze as an animal model of anxiety. Pharmacol Biochem Behav, 54(1), 21-30.

Huang, Q., Timofeeva, E., \& Richard, D. (2006). Corticotropin-releasing factor and its receptors in the brain of rats with insulin and corticosterone deficits. $J \mathrm{Mol}$ Endocrinol, 37(2), 213-226.

Jackson-Guilford, J., Leander, J. D., \& Nisenbaum, L. K. (2000). The effect of streptozotocin-induced diabetes on cell proliferation in the rat dentate gyrus. Neurosci Lett, 293(2), 91-94.

Jacobson, L. H., \& Cryan, J. F. (2007). Feeling strained? Influence of genetic background on depression-related behavior in mice: A review. Behav Genet, 37(1), 171-213.

Jagannath, C., Hoffmann, H., Sepulveda, E., Actor, J. K., Wetsel, R. A., \& Hunter, R. L. (2000). Hypersusceptibility of $\mathrm{a} / \mathrm{j}$ mice to tuberculosis is in part due to a deficiency of the fifth complement component (c5). Scand J Immunol, 52(4), 369379. 
Joels, M., Karst, H., Alfarez, D., Heine, V. M., Qin, Y., van Riel, E., et al. (2004). Effects of chronic stress on structure and cell function in rat hippocampus and hypothalamus. Stress, 7(4), 221-231.

Kaneko, N., Kudo, K., Mabuchi, T., Takemoto, K., Fujimaki, K., Wati, H., et al. (2006). Suppression of cell proliferation by interferon-alpha through interleukin-1 production in adult rat dentate gyrus. Neuropsychopharmacology, 31(12), 26192626.

Kang, J. O., Kim, S. K., Hong, S. E., Lee, T. H., \& Kim, C. J. (2006). Low dose radiation overcomes diabetes-induced suppression of hippocampal neuronal cell proliferation in rats. J Korean Med Sci, 2I(3), 500-505.

Kempermann, G. (2002). Why new neurons? Possible functions for adult hippocampal neurogenesis. J Neurosci, 22(3), 635-638.

Kiecolt-Glaser, J. K., Preacher, K. J., MacCallum, R. C., Atkinson, C., Malarkey, W. B., \& Glaser, R. (2003). Chronic stress and age-related increases in the proinflammatory cytokine il-6. Proc Natl Acad Sci U S A, 100(15), 9090-9095.

Leuner, B., Gould, E., \& Shors, T. J. (2006). Is there a link between adult neurogenesis and learning? Hippocampus, 16(3), 216-224.

Levin, B. E., Dunn-Meynell, A. A., \& Routh, V. H. (1999). Brain glucose sensing and body energy homeostasis: Role in obesity and diabetes. Am J Physiol, 276(5 Pt 2), R1223-1231.

Li, Z. G., Zhang, W., \& Sima, A. A. (2005). The role of impaired insulin/igf action in primary diabetic encephalopathy. Brain Res, 1037(1-2), 12-24.

Liberto, C. M., Albrecht, P. J., Herx, L. M., Yong, V. W., \& Levison, S. W. (2004). Proregenerative properties of cytokine-activated astrocytes. J Neurochem, 89(5), 1092-1100.

Lindqvist, A., Mohapel, P., Bouter, B., Frielingsdorf, H., Pizzo, D., Brundin, P., et al. (2006). High-fat diet impairs hippocampal neurogenesis in male rats. Eur $J$ Neurol, 13(12), 1385-1388.

Liu, Q., Xie, F., Siedlak, S. L., Nunomura, A., Honda, K., Moreira, P. I., et al. (2004). Neurofilament proteins in neurodegenerative diseases. Cell Mol Life Sci, 61(24), 3057-3075.

Liu, X., Wang, Q., Haydar, T. F., \& Bordey, A. (2005). Nonsynaptic gaba signaling in postnatal subventricular zone controls proliferation of gfap-expressing progenitors. Nat Neurosci, 8(9), 1179-1187.

Lobnig, B. M., Kromeke, O., Optenhostert-Porst, C., \& Wolf, O. T. (2006). Hippocampal volume and cognitive performance in long-standing type 1 diabetic patients without macrovascular complications. Diabet Med, 23(1), 32-39.

Luine, V., Villegas, M., Martinez, C., \& McEwen, B. S. (1994). Repeated stress causes reversible impairments of spatial memory performance. Brain Res, 639(1), 167170.

Lynch, A. M., Moore, M., Craig, S., Lonergan, P. E., Martin, D. S., \& Lynch, M. A. (2003). Analysis of interleukin-1 beta-induced cell signaling activation in rat hippocampus following exposure to gamma irradiation. Protective effect of eicosapentaenoic acid. J Biol Chem, 278(51), 51075-51084.

Maes, M., Song, C., Lin, A., De Jongh, R., Van Gastel, A., Kenis, G., et al. (1998). The effects of psychological stress on humans: Increased production of pro- 
inflammatory cytokines and a th1-like response in stress-induced anxiety. Cytokine, 10(4), 313-318.

Maher, F. O., Clarke, R. M., Kelly, A., Nally, R. E., \& Lynch, M. A. (2006). Interaction between interferon gamma and insulin-like growth factor-1 in hippocampus impacts on the ability of rats to sustain long-term potentiation. $J$ Neurochem, 96(6), 1560-1571.

Maier, S. F., \& Watkins, L. R. (1998). Cytokines for psychologists: Implications of bidirectional immune-to-brain communication for understanding behavior, mood, and cognition. Psychol Rev, 105(1), 83-107.

Mastrocola, R., Restivo, F., Vercellinatto, I., Danni, O., Brignardello, E., Aragno, M., et al. (2005). Oxidative and nitrosative stress in brain mitochondria of diabetic rats. $J$ Endocrinol, 187(1), 37-44.

Mathis, C., Paul, S. M., \& Crawley, J. N. (1994). Characterization of benzodiazepinesensitive behaviors in the $\mathrm{a} / \mathrm{j}$ and $\mathrm{c} 57 \mathrm{~b} / / 6 \mathrm{j}$ inbred strains of mice. Behav Genet, 24(2), 171-180.

Meagher, C., Sharif, S., Hussain, S., Cameron, M. J., Arreaza, G. A., \& Delovitch, T. L. (2003). Cytokines and chemokines in the pathogenesis of murine type 1 diabetes. Adv Exp Med Biol, 520, 133-158.

Mellado-Gil, J. M., \& Aguilar-Diosdado, M. (2005). Assay for high glucose-mediated islet cell sensitization to apoptosis induced by streptozotocin and cytokines. Biol Proced Online, 7, 162-171.

Miller, D. B., \& O'Callaghan, J. P. (2005). Aging, stress and the hippocampus. Ageing Res Rev, 4(2), 123-140.

Molteni, R., Wu, A., Vaynman, S., Ying, Z., Barnard, R. J., \& Gomez-Pinilla, F. (2004). Exercise reverses the harmful effects of consumption of a high-fat diet on synaptic and behavioral plasticity associated to the action of brain-derived neurotrophic factor. Neuroscience, 123(2), 429-440.

Monje, M. L., Toda, H., \& Palmer, T. D. (2003). Inflammatory blockade restores adult hippocampal neurogenesis. Science, 302(5651), 1760-1765.

Moosavi, M., Naghdi, N., Maghsoudi, N., \& Zahedi Asl, S. (2006). The effect of intrahippocampal insulin microinjection on spatial learning and memory. Horm Behav, 50(5), 748-752.

Moosavi, M., Naghdi, N., Maghsoudi, N., \& Zahedi Asl, S. (2007). Insulin protects against stress-induced impairments in water maze performance. Behav Brain Res, 176(2), 230-236.

Musselman, D. L., Betan, E., Larsen, H., \& Phillips, L. S. (2003). Relationship of depression to diabetes types 1 and 2: Epidemiology, biology, and treatment. Biol Psychiatry, 54(3), 317-329.

Narayan, K. M., Boyle, J. P., Thompson, T. J., Sorensen, S. W., \& Williamson, D. F. (2003). Lifetime risk for diabetes mellitus in the united states. Jama, 290(14), 1884-1890.

Northam, E. A., Anderson, P. J., Jacobs, R., Hughes, M., Warne, G. L., \& Werther, G. A. (2001). Neuropsychological profiles of children with type 1 diabetes 6 years after disease onset. Diabetes Care, 24(9), 1541-1546. 
Pelleymounter, M. A., Cullen, M. J., Baker, M. B., Hecht, R., Winters, D., Boone, T., et al. (1995). Effects of the obese gene product on body weight regulation in ob/ob mice. Science, 269(5223), 540-543.

Perry, V. H., Newman, T. A., \& Cunningham, C. (2003). The impact of systemic infection on the progression of neurodegenerative disease. Nat Rev Neurosci, 4(2), 103-112.

Pickup, J. C., \& Crook, M. A. (1998). Is type ii diabetes mellitus a disease of the innate immune system? Diabetologia, 41(10), 1241-1248.

Plumpe, T., Ehninger, D., Steiner, B., Klempin, F., Jessberger, S., Brandt, M., et al. (2006). Variability of doublecortin-associated dendrite maturation in adult hippocampal neurogenesis is independent of the regulation of precursor cell proliferation. BMC Neurosci, 7, 77.

Prickaerts, J., Koopmans, G., Blokland, A., \& Scheepens, A. (2004). Learning and adult neurogenesis: Survival with or without proliferation? Neurobiol Learn Mem, 81(1), 1-11.

Rabinovitch, A., Suarez-Pinzon, W., El-Sheikh, A., Sorensen, O., \& Power, R. F. (1996). Cytokine gene expression in pancreatic islet-infiltrating leukocytes of bb rats: Expression of th1 cytokines correlates with beta-cell destructive insulitis and iddm. Diabetes, 45(6), 749-754.

Reaven, G. M., Thompson, L. W., Nahum, D., \& Haskins, E. (1990). Relationship between hyperglycemia and cognitive function in older niddm patients. Diabetes Care, 13(1), 16-21.

Rees, D. A., \& Alcolado, J. C. (2005). Animal models of diabetes mellitus. Diabet Med, 22(4), 359-370.

Renold, A. E., Burr, I. M., \& Stauffacher, W. (1971). Experimental and spontaneous diabetes in animals: What is their relevance to human diabetes mellitus? Proc $R$ Soc Med, 64(6), 613-617.

Revsin, Y., Saravia, F., Roig, P., Lima, A., de Kloet, E. R., Homo-Delarche, F., et al. (2005). Neuronal and astroglial alterations in the hippocampus of a mouse model for type 1 diabetes. Brain Res, 1038(1), 22-31.

Ristow, M. (2004). Neurodegenerative disorders associated with diabetes mellitus. $J$ Mol Med, 82(8), 510-529.

Ryu, J. K., Franciosi, S., Sattayaprasert, P., Kim, S. U., \& McLarnon, J. G. (2004). Minocycline inhibits neuronal death and glial activation induced by beta-amyloid peptide in rat hippocampus. Glia, 48(1), 85-90.

Saravia, F. E., Beauquis, J., Revsin, Y., Homo-Delarche, F., de Kloet, E. R., \& De Nicola, A. F. (2006). Hippocampal neuropathology of diabetes mellitus is relieved by estrogen treatment. Cell Mol Neurobiol, 26(4-6), 941-955.

Saravia, F., Revsin, Y., Lux-Lantos, V., Beauquis, J., Homo-Delarche, F., \& De Nicola, A. F. (2004). Oestradiol restores cell proliferation in dentate gyrus and subventricular zone of streptozotocin-diabetic mice. J Neuroendocrinol, 16(8), 704-710.

Schulze, M. B., \& Hu, F. B. (2002). Dietary patterns and risk of hypertension, type 2 diabetes mellitus, and coronary heart disease. Curr Atheroscler Rep, 4(6), 462467. 
Shanks, N., \& Anisman, H. (1988). Stressor-provoked behavioral changes in six strains of mice. Behav Neurosci, 102(6), 894-905.

Shors, T. J., Miesegaes, G., Beylin, A., Zhao, M., Rydel, T., \& Gould, E. (2001). Neurogenesis in the adult is involved in the formation of trace memories. Nature, 410(6826), 372-376.

Strachan, M. W., Deary, I. J., Ewing, F. M., \& Frier, B. M. (1997). Is type ii diabetes associated with an increased risk of cognitive dysfunction? A critical review of published studies. Diabetes Care, 20(3), 438-445.

Strachan, M. W., Frier, B. M., \& Deary, I. J. (2003). Type 2 diabetes and cognitive impairment. Diabet Med, 20(1), 1-2.

Surwit, R. S., Feinglos, M. N., Rodin, J., Sutherland, A., Petro, A. E., Opara, E. C., et al. (1995). Differential effects of fat and sucrose on the development of obesity and diabetes in c57bl/6j and a/j mice. Metabolism, 44(5), 645-651.

Surwit, R. S., Kuhn, C. M., Cochrane, C., McCubbin, J. A., \& Feinglos, M. N. (1988). Diet-induced type ii diabetes in c57bl/6j mice. Diabetes, 37(9), 1163-1167.

Taishi, P., Chen, Z., Obal, F., Jr., Hansen, M. K., Zhang, J., Fang, J., et al. (1998). Sleepassociated changes in interleukin-1beta mrna in the brain. $J$ Interferon Cytokine Res, 18(9), 793-798.

Tanapat, P., Hastings, N. B., Rydel, T. A., Galea, L. A., \& Gould, E. (2001). Exposure to fox odor inhibits cell proliferation in the hippocampus of adult rats via an adrenal hormone-dependent mechanism. J Comp Neurol, 437(4), 496-504.

Tannenbaum, B. M., Tannenbaum, G. S., \& Anisman, H. (2003). Impact of life-long macronutrient choice on neuroendocrine and cognitive functioning in aged mice: Differential effects in stressor-reactive and stressor-resilient mouse strains. Brain Res, 985(2), 187-197.

Tannenbaum, B., \& Anisman, H. (2003). Impact of chronic intermittent challenges in stressor-susceptible and resilient strains of mice. Biol Psychiatry, 53(4), 292-303. Thomas, H. E., \& Kay, T. W. (2000). Beta cell destruction in the development of autoimmune diabetes in the non-obese diabetic (nod) mouse. Diabetes Metab Res Rev, 16(4), 251-261.

Trullas, R., \& Skolnick, P. (1993). Differences in fear motivated behaviors among inbred mouse strains. Psychopharmacology (Berl), 111(3), 323-331.

Turk, J., Corbett, J. A., Ramanadham, S., Bohrer, A., \& McDaniel, M. L. (1993). Biochemical evidence for nitric oxide formation from streptozotocin in isolated pancreatic islets. Biochem Biophys Res Commun, 197(3), 1458-1464.

Vallieres, L., Campbell, I. L., Gage, F. H., \& Sawchenko, P. E. (2002). Reduced hippocampal neurogenesis in adult transgenic mice with chronic astrocytic production of interleukin-6. J Neurosci, 22(2), 486-492.

Van der Borght, K., Meerlo, P., Luiten, P. G., Eggen, B. J., \& Van der Zee, E. A. (2005). Effects of active shock avoidance learning on hippocampal neurogenesis and plasma levels of corticosterone. Behav Brain Res, 157(1), 23-30.

van Exel, E., Gussekloo, J., de Craen, A. J., Frolich, M., Bootsma-Van Der Wiel, A., \& Westendorp, R. G. (2002). Low production capacity of interleukin-10 associates with the metabolic syndrome and type 2 diabetes: The leiden 85 -plus study. Diabetes, 51(4), 1088-1092. 
Warner-Schmidt, J. L., \& Duman, R. S. (2006). Hippocampal neurogenesis: Opposing effects of stress and antidepressant treatment. Hippocampus, 16(3), 239-249.

Watson, G. S., \& Craft, S. (2006). Insulin resistance, inflammation, and cognition in alzheimer's disease: Lessons for multiple sclerosis. J Neurol Sci, 245(1-2), 21-33.

Watson, P. M., Commins, S. P., Beiler, R. J., Hatcher, H. C., \& Gettys, T. W. (2000). Differential regulation of leptin expression and function in $\mathrm{a} / \mathrm{j}$ vs. $\mathrm{C} 57 \mathrm{bl} / 6 \mathrm{j}$ mice during diet-induced obesity. Am J Physiol Endocrinol Metab, 279(2), E356-365.

Wietrzych, M., Meziane, H., Sutter, A., Ghyselinck, N., Chapman, P. F., Chambon, P., et al. (2005). Working memory deficits in retinoid $\mathrm{x}$ receptor gamma-deficient mice. Learn Mem, 12(3), 318-326.

Wilson, C. J., Finch, C. E., \& Cohen, H. J. (2002). Cytokines and cognition--the case for a head-to-toe inflammatory paradigm. J Am Geriatr Soc, 50(12), 2041-2056.

Winocur, G., \& Greenwood, C. E. (2005). Studies of the effects of high fat diets on cognitive function in a rat model. Neurobiol Aging, 26 Suppl 1, 46-49.

Winzell, M. S., \& Ahren, B. (2004). The high-fat diet-fed mouse: A model for studying mechanisms and treatment of impaired glucose tolerance and type 2 diabetes. Diabetes, 53 Suppl 3, S215-219.

Wolff, M., Savova, M., Malleret, G., Segu, L., \& Buhot, M. C. (2002). Differential learning abilities of $129 \mathrm{t} 2 / \mathrm{sv}$ and $\mathrm{c} 57 \mathrm{bl} / 6 \mathrm{j}$ mice as assessed in three water maze protocols. Behav Brain Res, 136(2), 463-474. 